Y/DSRD-3117

OOTW FORCE DESIGN TOOLS

Dean S. Hartley III

Richard E. Bell

Stephen L. Packard 


\section{DISCLAIMER}

This report was prepared as an account of work sponsored by an agency of the United States Government. Neither the United States Government nor any agency thereof, nor any of their employees, makes any warranty, express or implied, or assumes any legal liability or responsibility for the accuracy, completeness, or usefulness of any information, apparatus, product, or process disclosed, or represents that its use would not infringe privately owned rights. Reference herein to any specific commercial product, process, or service by trade name, trademark, manufacturer, or otherwise, does not necessarily constitute or imply its endorsement, recommendation, or favoring by the United States Government or any agency thereof. The views and opinions of authors expressed herein do not necessarily state or reflect those of the United States Government or any agency thereof. 


\title{
OOTW FORCE DESIGN TOOLS
}

Dean S. Hartley III

Richard E. Bell

Stephen L. Packard

May 1999

\author{
Prepared for \\ OASD (SO/LIC) \\ The Pentagon \\ Washington, DC
}

Interagency Agreement DOE No. 2223-K040-A1

\author{
Prepared by \\ Data Systems Research and Development Program \\ Advanced Technologies \\ Oak Ridge Y-12 Site \\ Oak Ridge, Tennessee 37831-7620 \\ Managed by \\ LOCKHEED MARTIN ENERGY SYSTEMS, INC. \\ for the \\ U.S. DEPARTMENT OF ENERGY \\ under contract DE-AC05-84OR21400
}




\section{CONTENTS}

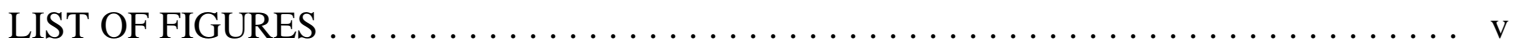

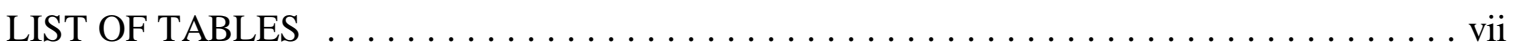

ACKNOWLEDGEMENT $\ldots \ldots \ldots \ldots \ldots \ldots \ldots \ldots \ldots \ldots \ldots \ldots \ldots \ldots \ldots \ldots \ldots \ldots \ldots$

EXECUTIVE SUMMARY $\ldots \ldots \ldots \ldots \ldots \ldots \ldots \ldots \ldots \ldots \ldots \ldots \ldots \ldots \ldots$

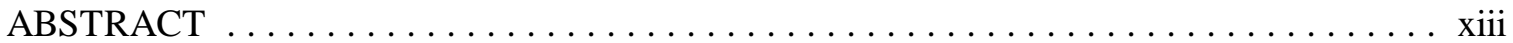

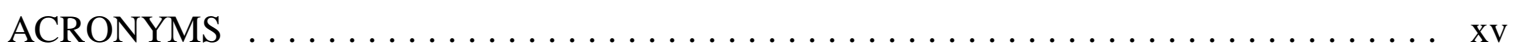

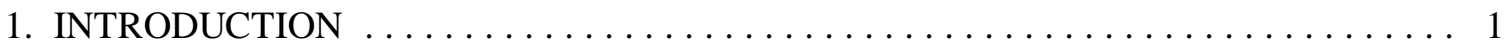

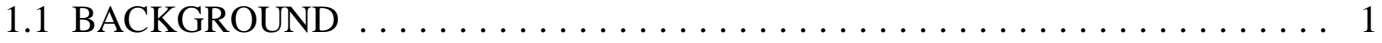

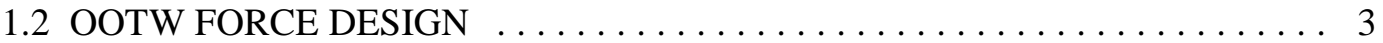

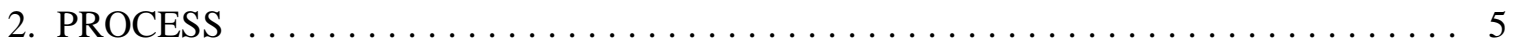

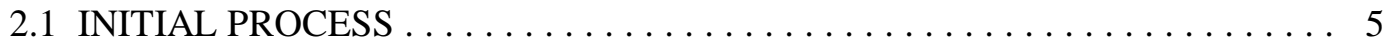

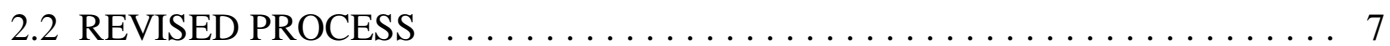

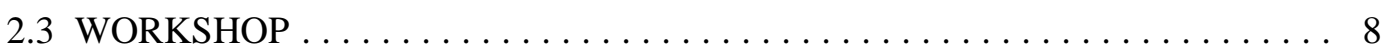

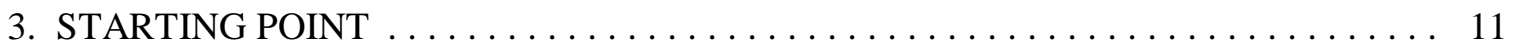

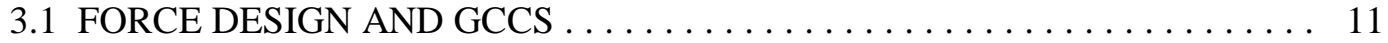

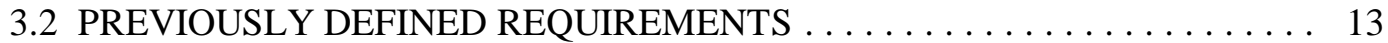

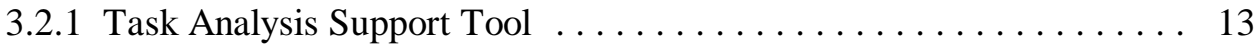

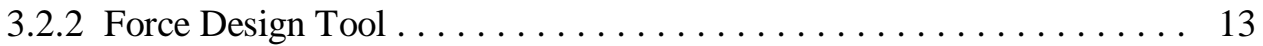

3.2.3 Logistics Analysis Tool . . . . . . . . . . . . . . . . . . . . . 14

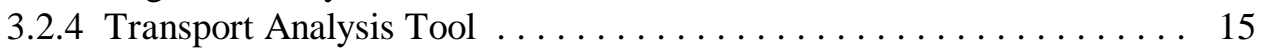

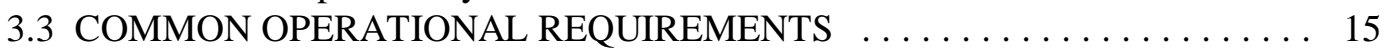

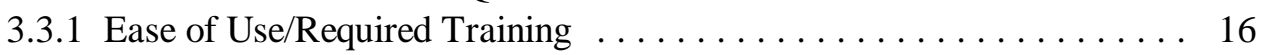

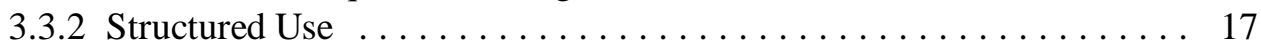

3.4 AVAILABLE TOOL SET $\ldots \ldots \ldots \ldots \ldots \ldots \ldots \ldots \ldots \ldots \ldots \ldots \ldots \ldots \ldots \ldots \ldots \ldots$

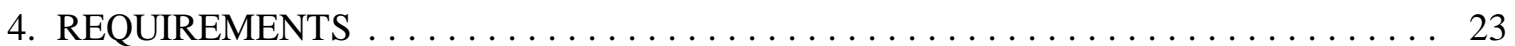

4.1 NATIONAL-LEVEL REQUIREMENTS $\ldots \ldots \ldots \ldots \ldots \ldots \ldots \ldots \ldots \ldots$

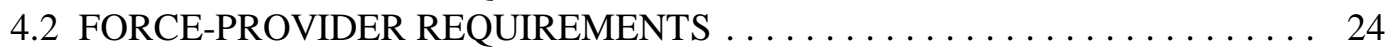

4.3 GEOGRAPHIC CINC-LEVEL REQUIREMENTS $\ldots \ldots \ldots \ldots \ldots \ldots \ldots \ldots . . \ldots 25$

4.4 ALTERNATIVE REQUIREMENTS $\ldots \ldots \ldots \ldots \ldots \ldots \ldots \ldots \ldots \ldots \ldots \ldots$

5. FORCE DESIGN TOOL SPECIFICATIONS $\ldots \ldots \ldots \ldots \ldots \ldots \ldots \ldots \ldots \ldots \ldots$

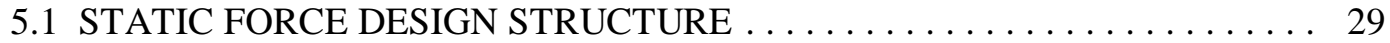

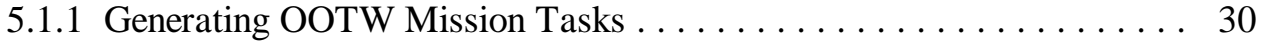




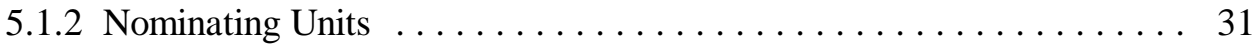

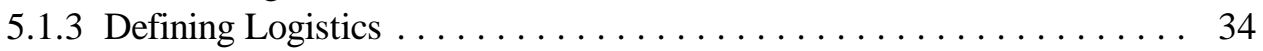

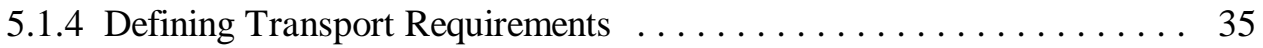

5.1.5 Performing Trade-Off Analysis and Generating Reports . . . . . . 36

5.2 DYNAMIC FORCE DESIGN STRUCTURE . . . . . . . . . . . . . 36

5.3 DATABASE REQUIREMENTS $\ldots \ldots \ldots \ldots \ldots \ldots \ldots \ldots \ldots \ldots \ldots \ldots \ldots$

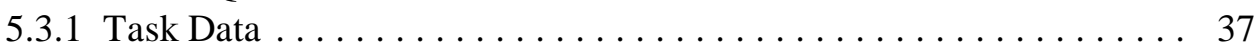

5.3 .2 Unit List Data . . . . . . . . . . . . . . . . . . . . 37

5.3 .3 Unit and Resource Data $\ldots \ldots \ldots \ldots \ldots \ldots \ldots \ldots \ldots \ldots$

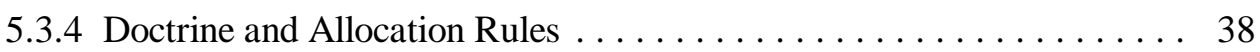

5.4 OPERATIONAL CONSIDERATIONS $\ldots \ldots \ldots \ldots \ldots \ldots \ldots \ldots \ldots \ldots$

5.5 FORCE DESIGN CONCLUSION AND ROADMAP $\ldots \ldots \ldots \ldots \ldots \ldots \ldots 42$

6. VIRTUAL INFORMATION \& ANALYSIS CENTERS $\ldots \ldots \ldots \ldots \ldots \ldots \ldots \ldots$

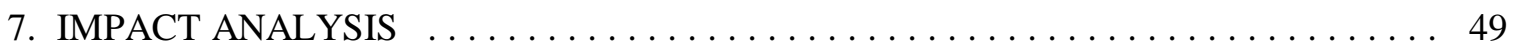

7.1 NEED FOR IMPACT ANALYSIS $\ldots \ldots \ldots \ldots \ldots \ldots \ldots \ldots \ldots \ldots \ldots$

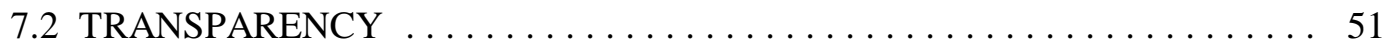

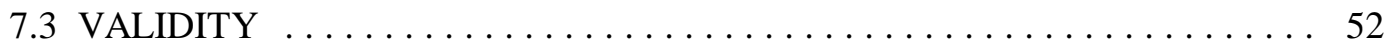

7.4 IMPACT MODELING SPECIFICATIONS $\ldots \ldots \ldots \ldots \ldots \ldots \ldots \ldots \ldots \ldots$

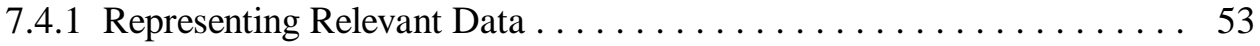

7.4.2 Representing Relevant Influences $\ldots \ldots \ldots \ldots \ldots \ldots \ldots \ldots$

7.4.3 Representing Relevant Actions . . . . . . . . . . . . . . . . 57

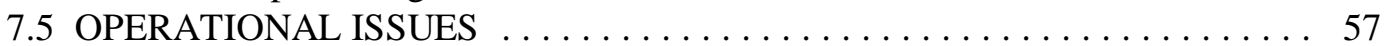

7.6 IMPACT MODELING: TRAINING VERSUS ANALYSIS $\ldots \ldots \ldots \ldots \ldots 58$

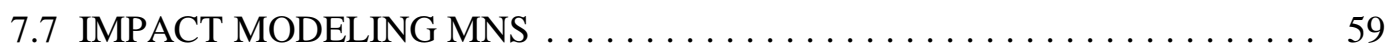

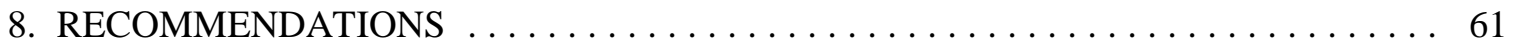

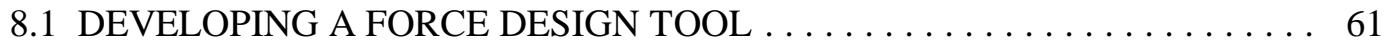

8.2 EXPERIMENTING WITH THE VIC/VAC CONCEPT . . . . . . . . . . . . . 61

8.3 RESEARCH AND DEVELOPMENT OF IMPACT ANALYSIS MODELS . . 62

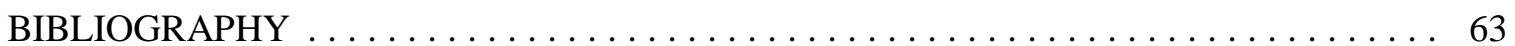




\section{LIST OF FIGURES}

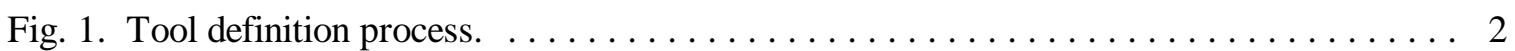

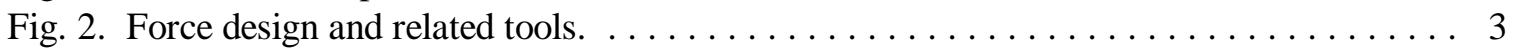

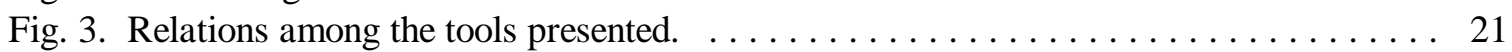

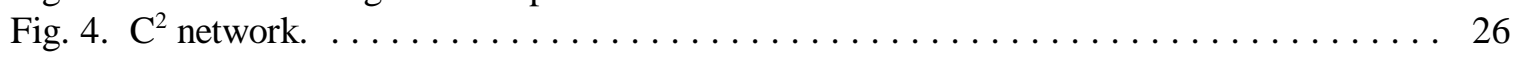

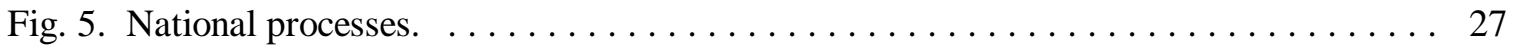

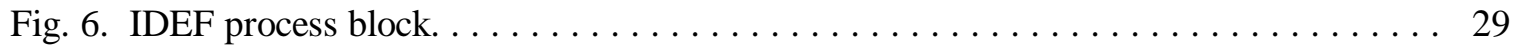

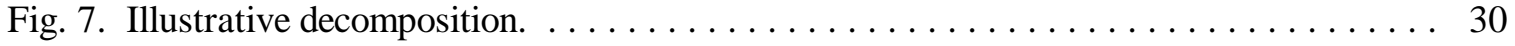

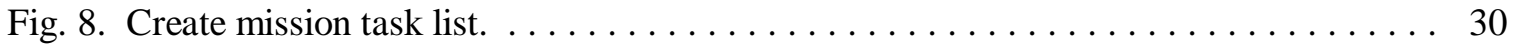

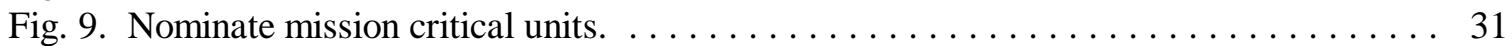

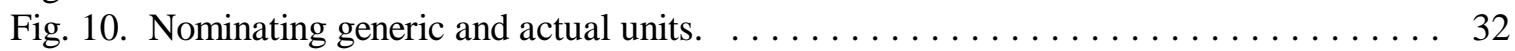

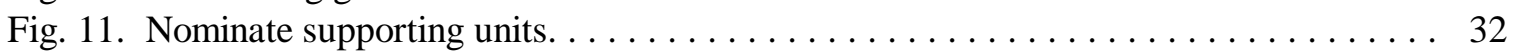

Fig. 12. Nominating generic and actual units and completing unit organization. . . . . . 32

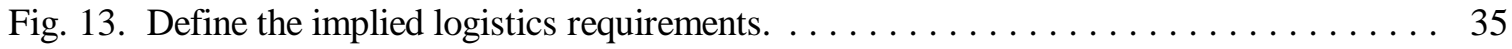

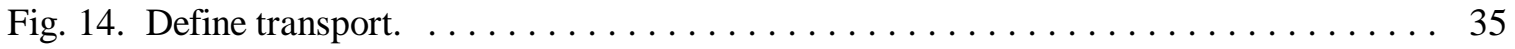

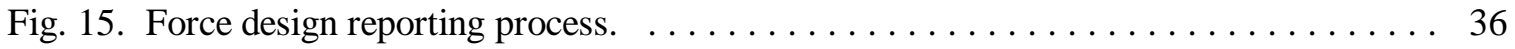

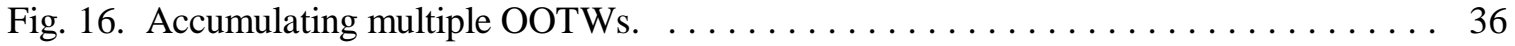

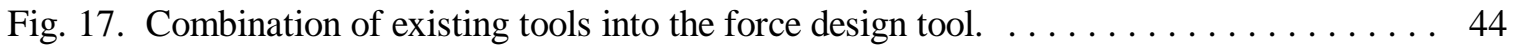

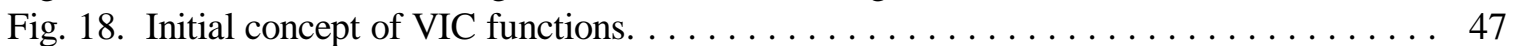

Fig. 19. Geographical sites of VICs and VAC. $\ldots \ldots \ldots \ldots \ldots \ldots \ldots \ldots \ldots \ldots \ldots \ldots$

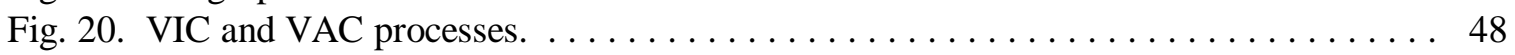

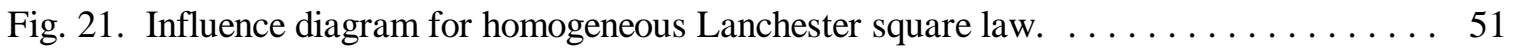

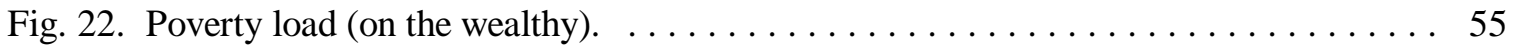

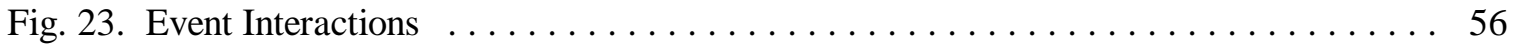




\section{LIST OF TABLES}

Table 1. Workshop Planning Meeting Agenda $\ldots \ldots \ldots \ldots \ldots \ldots \ldots \ldots \ldots \ldots \ldots \ldots \ldots \ldots \ldots$

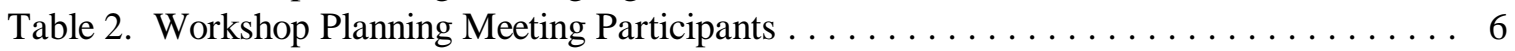

Table 3. Workshop Schedule, Day 1, Tuesday, January 12, $1999 \ldots \ldots \ldots \ldots \ldots \ldots \ldots$. . . . 8

Table 4. Workshop Schedule, Day 2, Wednesday, January 13, $1999 \ldots \ldots \ldots \ldots \ldots \ldots$

Table 5. Workshop Schedule, Day 3, Thursday, January 14, $1999 \ldots \ldots \ldots \ldots \ldots \ldots \ldots . . \ldots$

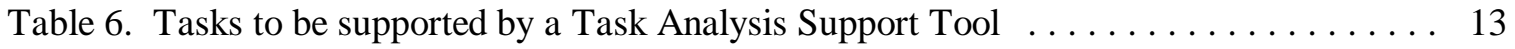

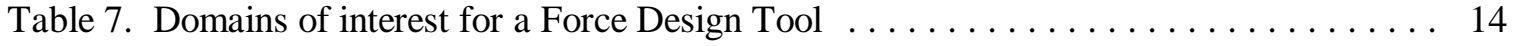

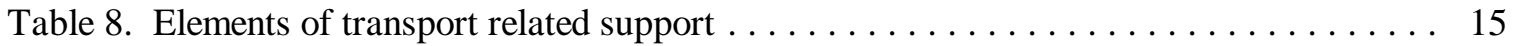

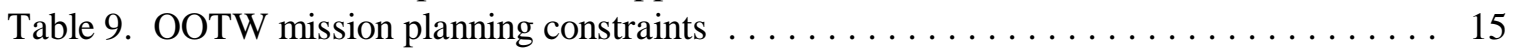

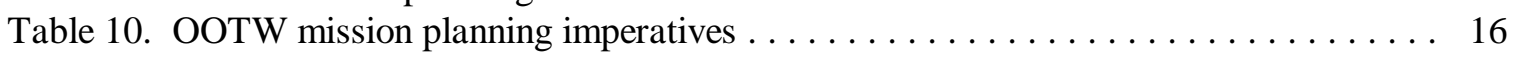

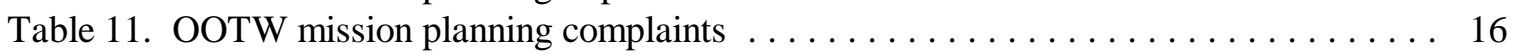

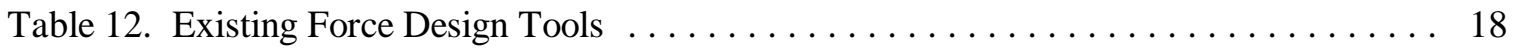

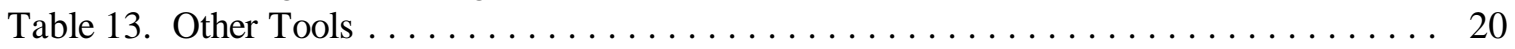

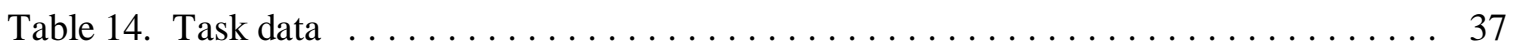

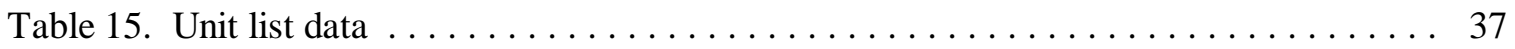

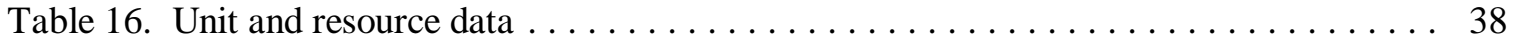

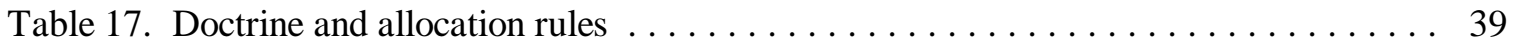

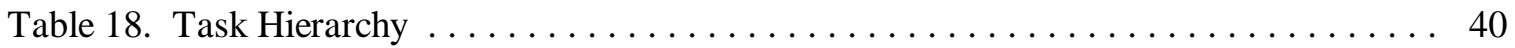

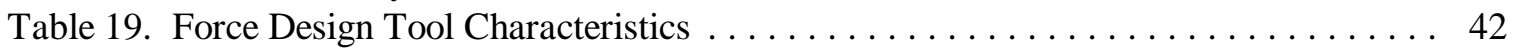

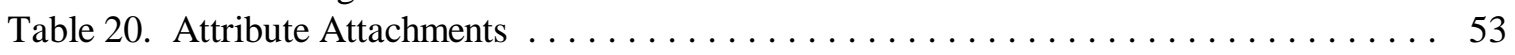

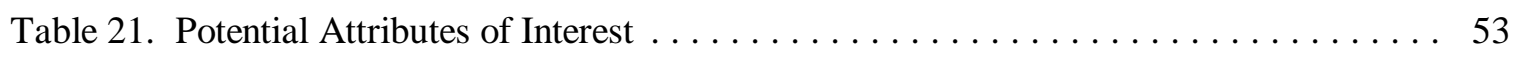




\section{ACKNOWLEDGEMENT}

The authors of this document wish to thank Mr. Martin Lidy and the Institute for Defense Analyses (IDA) for the generous support they provided in hosting the Operations Other Than War (OOTW)

Force Design Workshop. We also wish to thank the participants in the workshop who provided the input that is analyzed in this document. 


\section{EXECUTIVE SUMMARY}

This report documents refined requirements for tools to aid the process of force design in Operations Other Than War (OOTWs). It recommends actions for the creation of one tool and work on other tools relating to mission planning. It also identifies the governmental agencies and commands with interests in each tool, from whom should come the user advisory groups overseeing the respective tool development activities. The understanding of OOTWs and their analytical support requirements has matured to the point where action can be taken in three areas: force design, collaborative analysis, and impact analysis. While the nature of the action and the length of time before complete results can be expected depends on the area, in each case the action should begin immediately.

Force design for OOTWs is not a technically difficult process. Like force design for combat operations, it is a process of matching the capabilities of forces against the specified and implied tasks of the operation, considering the constraints of logistics, transport and force availabilities. However, there is a critical difference that restricts the usefulness of combat force design tools for OOTWs: the combat tools are built to infer non-combat capability requirements from combat capability requirements and cannot reverse the direction of the inference, as is required for OOTWs.

Recently, OOTWs have played a larger role in force assessment, system effectiveness and tradeoff analysis, and concept and doctrine development and analysis. In the first Quadrennial Defense Review (QDR), each of the Services created its own OOTW force design tool. Unfortunately, the tools address different parts of the problem and do not coordinate the use of competing capabilities. These tools satisfied the immediate requirements of the QDR, but do not provide a long-term cost-effective solution.

We recommend that a project be initiated to connect the US Atlantic Command (USACOM) Mission $\underline{\text { Requirements Module (MRM), the Joint Staff/J-8 Contingency Analysis Planning System (CAPS), }}$ the USACOM Joint Electronic Battlebook (JEB), and the US Transportation Command (USTRANSCOM) Model for Intertheater Deployment by Air and Sea (MIDAS) / Joint Flow and Analysis System for Transportation (JFAST) as the basis for a force design tool. The resulting combination should be expanded along the lines indicated in Section 5. Actual users must be involved in the process. A users group should be formed to guide the development. The group should be composed of two classes of members, based on expressed immediacy of need: voting members (Joint Staff, OSD, and Service representatives) and advisory members (interested CINC representatives). Concrete results should be expected within a year.

The other two recommendations derive from the need to create OOTW force designs. Crisis action planning for OOTWs suffers from a scarcity of relevant mission and situation information, which is needed to define the function of the force to be designed. Collaborative analysis is required to acquire the information. Once a plausible force has been designed, impact analysis is needed to evaluate alternative force designs. More detailed impact analysis of alternative courses of action requires the simulation of complex economic, political, cultural, and military activities. 
We recommend that the US Pacific Command (USPACOM) initiated Virtual Information Center (VIC) experimentation be continued and expanded to include the Virtual Analysis Center (VAC) concept, as described in Section 6. Participation should be broadened to include non-DoD parties. Partial results are already being experienced. As the completeness of the system is increased, benefits will increase. Full capability will probably require years, in part because new capabilities will be defined as experience is gained. A user group should be formed to guide the development. This group should be composed of Unified and Specified Command representatives, Joint Staff representatives and others involved in VIC/VAC creation and use. We recommend initiating a task to create appropriate requirements documents, supervised by this user group.

We recommend a study of impact analysis, course of action (COA) analysis, and engagement plan analysis requirements, methodologies and models. This study would be similar to the study on force design tools reported here. Earlier work has identified the significance of impact analysis for OOTWs and this work supports that judgment. Clearly, it should also be useful for Information Warfare, Civil Affairs, Special Operations, and Psychological Operations analysis. There are several models and modeling environments that are potentially useful for OOTW impact analysis; however, there is no current system for comparing and contrasting these or any other candidates. The recommended study would develop the system of meta-models (described in Section 7), gather information, hold workshops, and synthesize the results. The study would also produce input to appropriate requirements documents. The study should require about a year. The logical sponsors are J-8, OSD Program Analysis and Evaluation (PA\&E), and the Office of the Assistant Secretary of Defense Special Operations/Low Intensity Conflict (OASD SO/LIC), with supervision by either the Joint Modeling and Simulation Executive Panel (JMSEP) or the Joint Analytic Model Improvement Program (JAMIP) manager, augmented by Service representatives. 


\begin{abstract}
This document reports on the requirements elicited from members of the Department of Defense (DoD) for mission planning and analysis tools for Operations Other Than War (OOTW). It includes specifications for a force design tool and recommended actions in the areas of situation awareness and impact analysis.
\end{abstract}




\section{ACRONYMS}

ACOM

AOR

BOS

$\mathrm{C}^{2}$

$\mathrm{C} 2 \mathrm{~A}$

C4I

CAA

CarePlan

CAPS

CAT

CATS

CBS

CENTCOM

CFDB

CINC

CJTF

CMAC

$\mathrm{CNO}$

COA

CONPLAN

CONUS

COP

COST

CPX

CTP

DARPA

DEXES

DIAS

DoD

DPG

DSB

DSRD

EUCOM

FA\&CT

FALCON

FEMA

FORSAT

GCAM

GCCS

HLA

IDA
US Atlantic Command

Area of Responsibility

Base Operations Support

Command and Control

Coordination and Collaboration Architecture

Command, Control, Communications, Computers, and Intelligence

Center for Army Analyses

not an acronym

Contingency Analysis Planning System

Crisis Action Team

Consequence Assessment Tool Set

Cost Breakdown Structure

US Central Command

Common Forces Database

Commander in Chief

Commander, Joint Task Force

Counternarcotics Modeling and Analysis Capability

Chief of Naval Operations

Course of Action

Concept Plan

Continental United States

Common Operational Picture

Contingency Operations Support Tool

Command Post Exercise

Common Tactical Picture

Defense Advanced Research Projects Agency

Deployable Exercise Support System

Dynamic Information Architecture System

Department of Defense

Defense Planning Guidance

Defense Science Board

Data Systems Research and Development Program

US European Command

Force Allocation \& Capabilities Tool

Force Allocation \& Contingencies tool

Federal Emergency Management Agency

Force Sufficiency Assessment Tool

General Campaign Analysis Model

Global Command and Control System

High Level Architecture

Institute for Defense Analyses 


\begin{tabular}{|c|c|}
\hline IDEF & Integration Definition for Function modeling \\
\hline IGTL & Integrated General Task List \\
\hline $\mathrm{IO}$ & International Organization \\
\hline IOC & Interagency Operations Center \\
\hline IPB & Intelligence Preparation of the Battlefield \\
\hline IPS & Illustrative Planning Scenario \\
\hline ISR & Intelligence, Surveillance and Reconnaissance \\
\hline JAMIP & Joint Analytic Model Improvement Program \\
\hline $\mathrm{JBC}$ & Joint C4I Battle Center \\
\hline JCATS & Joint Conflict and Tactical Simulation \\
\hline JEB & Joint Electronic Battlebook \\
\hline JEMP & Joint Exercise Management Package \\
\hline JDS & Joint Data Support \\
\hline JFAST & Joint Flow and Analysis System for Transportation \\
\hline JMSEP & Joint Modeling and Simulation Executive Panel \\
\hline JROC & Joint Requirements Oversight Council \\
\hline JSCP & Joint Strategic Capabilities Plan \\
\hline JTF & Joint Task Force \\
\hline JTS & Joint Training System \\
\hline JWAC & Joint Warfare Analysis Center \\
\hline JWARS & Joint Warfare System \\
\hline JWCA & Joint Warfighting Capabilities Assessment \\
\hline LIC & Low Intensity Conflict \\
\hline LOC & Lines of Communication \\
\hline METT-T & Mission, Enemy, Troops, Terrain/Weather, and Time Available \\
\hline MIDAS & Model for Intertheater Deployment by Air and Sea \\
\hline MNS & Mission Needs Statement \\
\hline MOOTW & Military Operation Other Than War \\
\hline MOP & Measure of Performance \\
\hline MORS & Military Operations Research Society \\
\hline MOUT & Military Operations in Urban Terrain \\
\hline MRM & Mission Requirements Module \\
\hline MRS & Mobility Requirements Study \\
\hline MTOF & Mission Task Organized Force \\
\hline NationLab & not an acronym \\
\hline $\mathrm{NEO}$ & Noncombatant Evacuation Operation \\
\hline NGO & Non-Governmental Organization \\
\hline OASD & Office of the Assistant Secretary of Defense \\
\hline OEF & Oxford Economic Forecasting: Model of World Economy \\
\hline OFDA & Office of Foreign Disaster Assistance \\
\hline OFP & Objective Force Planner \\
\hline OOTW & Operation Other Than War \\
\hline OPLAN & Operations Plan \\
\hline ORNL & Oak Ridge National Laboratory \\
\hline OSD & Office of the Secretary of Defense \\
\hline OUSD (C) & Office of the Under Secretary of Defense (Comptroller) \\
\hline PA\&E & Program Analysis \& Evaluation \\
\hline
\end{tabular}




\begin{tabular}{|c|c|}
\hline PACOM & US Pacific Command \\
\hline PDD & Presidential Decision Directive \\
\hline PERICLES & $\begin{array}{l}\text { Political and Economic Risk in Countries and Lands Evaluation } \\
\text { Study }\end{array}$ \\
\hline POL & Petroleum, Oil and Lubricants \\
\hline POM & Program Objective Memorandum \\
\hline PPBS & Planning, Programming, and Budgeting System \\
\hline PSYOP & Psychological Operations \\
\hline PVO & Private Volunteer Organization \\
\hline QDR & Quadrennial Defense Review \\
\hline $\mathrm{RCE}$ & Reserve Component Evaluation \\
\hline RDSS & Regional Development Simulation System \\
\hline SADE & Stochastic Analysis for Deployments and Excursions \\
\hline SeaState & not an acronym \\
\hline SENSE & Synthetic Environment for National Security Estimates \\
\hline SFP & State Failure Project \\
\hline SIAM & Situational Influence Assessment Module \\
\hline SME & Subject Matter Expert \\
\hline $\mathrm{SO} / \mathrm{LIC}$ & Special Operations/Low Intensity Conflict \\
\hline SOCOM & US Special Operations Command \\
\hline SOF & Special Operations Forces \\
\hline SOP & Standing Operating Procedure \\
\hline SOUTHCOM & US Southern Command \\
\hline $\mathrm{SRC}$ & Standard Requirements Code \\
\hline SSC & Small Scale Contingency \\
\hline SSO & Stability Support Operation \\
\hline TacAir & Tactical Air \\
\hline TEP & Theater Engagement Planning \\
\hline TO\&E & Table of Organization and Equipment \\
\hline TPFDD & Time Phased Force Deployment Data \\
\hline TTCP & The Technical Cooperation Program \\
\hline TRANSCOM & US Transportation Command \\
\hline UIC & Unit Identification Code \\
\hline UJTL & Universal Joint Task List \\
\hline US & United States \\
\hline USACOM & US Atlantic Command \\
\hline USCENTCOM & US Central Command \\
\hline USEUCOM & US European Command \\
\hline USPACOM & US Pacific Command \\
\hline USSOCOM & US Special Operations Command \\
\hline USSOUTHCOM & US Southern Command \\
\hline USTRANSCOM & US Transportation Command \\
\hline VAC & Virtual Analysis Center \\
\hline VIC & Virtual Information Center \\
\hline WMD & Weapons of Mass Destruction \\
\hline
\end{tabular}




\section{INTRODUCTION}

This report documents refined requirements for tools to aid the process of force design in Operations Other Than War (OOTW). It recommends actions for the creation of one tool and work on other tools relating to mission planning. It also identifies the governmental agencies and commands with interests in each tool, from whom should come the user advisory groups overseeing the respective tool development activities. The understanding of OOTWs and their analytical support requirements has matured to the point where action can be taken in three areas: force design, collaborative analysis, and impact analysis. While the nature of the action and the length of time before complete results can be expected depends on the area, in each case the action should begin immediately.

Section 1 introduces the problem and its background. Section 2 describes the process used to create the solutions. Section 3 describes the knowledge-base underlying the solution creation and Section 4 describes the requirements elicited by the process. Sections 5, 6 and 7 are technical descriptions of the tools that are required. Section 8 presents the recommended actions to produce the tools.

\subsection{BACKGROUND}

Operations Other Than War suffer from an identity crisis. Sometimes called Military Operations Other Than War (MOOTW), sometimes known as Low Intensity Conflict (LIC), sometimes called Stability Support Operations (SSO), and sometimes designated as Small Scale Contingencies (SSC), these operations have caused both theoretical and practical problems to the military. Whatever they are called, these operations range in size from the airlifting of several fire trucks from Tennessee to Florida to fight the 1998 Summer fires to the Bosnia Peacekeeping operation involving tens of thousands of US military personnel and tens of thousands of other nations' military personnel, hardly a "small scale contingency." They include operations to provide stability to foreign countries, such as Haiti; however, they also include support to insurgencies (e.g., Afghanistan), a "destability support operation." They include Non-combatant Evacuation Operations (NEOs) in which armed force may be needed to support the evacuation; they include operations such as fire-fighting that can be defined as conflict only by stretching the definition; and they include operations such as Somalia that result in a number of US military deaths in combat, with the accompanying media and public attention indicating that any conflict with US combat deaths can no longer be regarded as "low intensity conflict." These operations cannot even be distinguished from other operations by time frame or geographic impact: their time span ranges from the one day cruise missile strike against Iraq to the 17 year peacekeeping operation in the Sinai (or the 45 year peacekeeping operation in Korea) and their geographic impact ranges from the purely local issues of disaster relief in Hawaii for Typhoon Iniki to the global geopolitical concerns stirred by peacekeeping in Bosnia. Clumsy as the OOTW designation may be, it is accurate: operations (as opposed to training activities) that are not war are included and operations that are part of a war are not included. Strictly speaking the people who are using the designation are Department of Defense people and the operations so designated are military

operations, leading to the term MOOTW; however, the shorter term, OOTW, is preferable because most of these operations are not led by the military, but by the State Department or some other agency. 
Labeling these operations "military operations other than war" leads into the more comfortable, but fallacious, assumption that the military is in charge.

OOTWs suffer from an identity crisis that goes beyond just a pleasant exercise in rhetoric. The underlying diversity of activities subsumed in the category creates a problem in defining standing operating procedures (SOPs) for dealing with them. The subordinate role of the military creates problems in planning, budgeting, developing resources for and executing them. Their ad hoc nature means that they are not included in the military's budget; the accounting systems are not designed to capture the costs (until very recently); and recovering the resulting costs is problematic. Moreover, the analytic tools that support policy decisions are incapable of determining what force structures support superior outcomes in OOTWs, e.g., what is the impact of training a four man land mine removal team on the entire operation. These problems would be less troublesome if OOTWs were infrequent; however, since

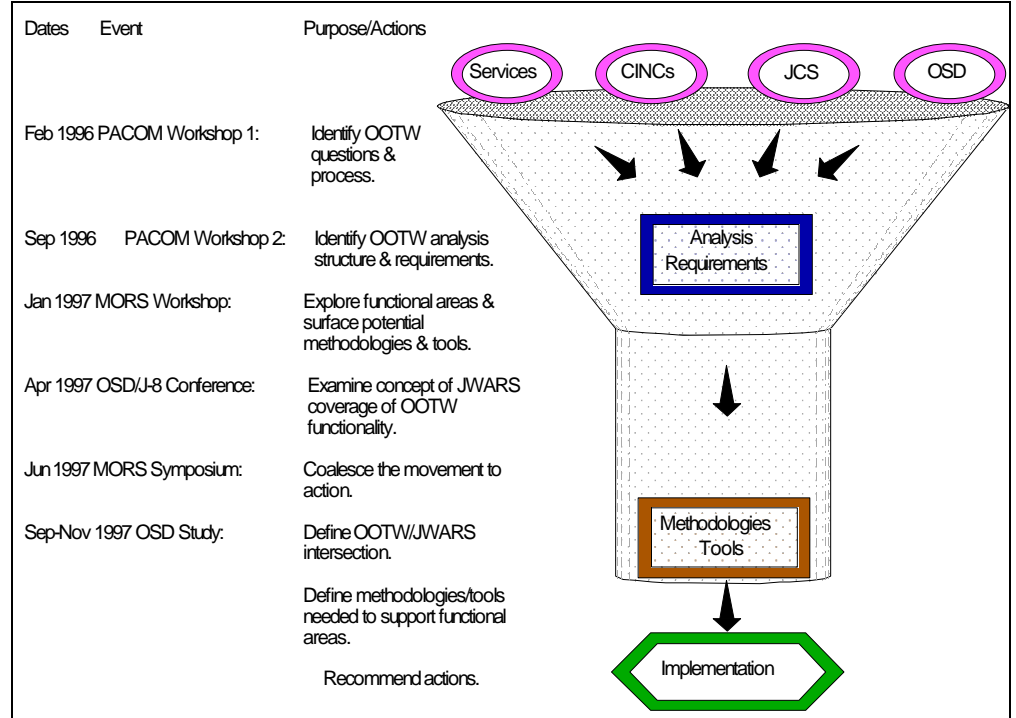

Fig. 1. Tool definition process. 1990 we have been undertaking them at a rate of 20-35 per year! The realization that current tools are inadequate to support these operations effectively has been growing.

Starting in 1995, elements within the Department of Defense (DoD), aided by others in the defense community, began a concerted effort to define OOTW analysis tool requirements and to start their construction (Fig. 1). In February and September of 1996, the United States (US) Pacific Command (USPACOM) sponsored workshops to identify OOTW analytical processes and tool requirements. Oak Ridge was tasked by USPACOM to analyze and document the results [Hartley, 1996]. A third workshop was sponsored by the Military Operations Research Society (MORS) in January of 1997 to explore the functional areas in more depth [Staniec, 1998]. The Joint Staff/J-8 and the Office of the Secretary of Defense, Program Analysis \& Evaluation (OSD (PA\&E)) jointly conducted a conference to examine the concept of OOTW functionality in the Joint Warfare System (JWARS) in April of 1997. Subsequently, Oak Ridge was tasked by OSD (PA\&E) to define the OOTW/JWARS intersection and propose the actions to be taken on OOTW requirements not addressed by JWARS [Hartley and Packard, 1998a]. During this same time, the Office of the Under Secretary of Defense (Comptroller) (OUSD (C)) had tasked the Institute for Defense Analyses (IDA) to create a cost tool for OOTWs, one of the OOTW requirement areas that had been defined in the earlier workshops. Oak Ridge was tasked by the Office of the Assistant Secretary of Defense (Special Operations/Low Intensity Conflict) (OASD (SO/LIC)) to compare the tool that IDA was developing against the requirements that had been developed and report on the results [Hartley and Packard, 1998b]. 
Following the completion of the cost tool task, SO/LIC tasked Oak Ridge to refine the requirements for force design tools to support OOTWs. The earlier Oak Ridge work had defined general requirements for a number of analytical support tools. (See Fig. 2 for an illustration of the relationship of the force design tool to several other tools needed for OOTW analysis.) However, the set of requirements were not sufficiently well defined to specify the details of the tools. The OOTW Force Design Workshop represents one of the sources of data used in completing the requirements definition

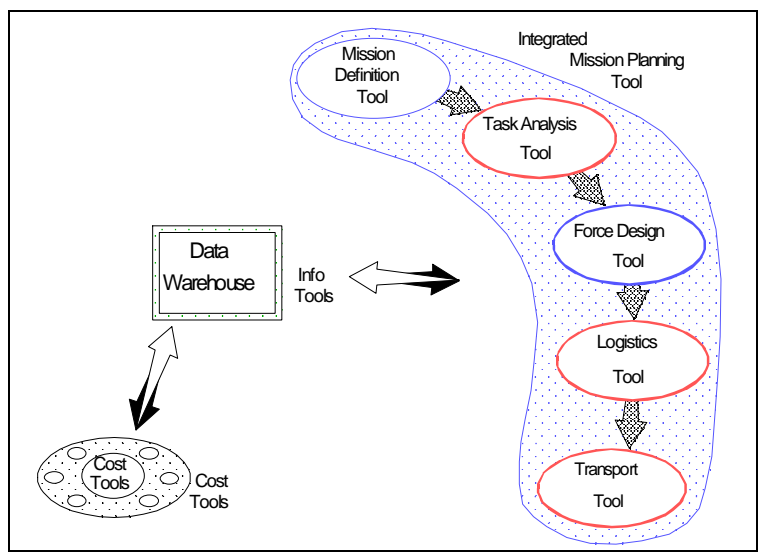

Fig. 2. Force design and related tools. for the force design tools. That workshop is described in its proceedings [Hartley and Bell, 1999], which includes copies of the presentations. As with all successful workshops, the information gained spread beyond the defined focus, yielding results in several areas. The workshop results and other research have been analyzed and the analysis is reported here.

\subsection{OOTW FORCE DESIGN}

Military force design (whether for OOTW or for war) is performed to support four functions, as described below:

- $\quad$ Planning and execution analysis is performed principally by the Geographical Commanders in Chief (CINCs), with participation by the Joint Staff and OSD and the other military communities, and supports the creation of plans for potential and actual use of U.S. military forces. This category is divided into crisis action planning and deliberate planning.

- $\quad$ Force assessment is led principally by the Joint Staff and the Services, using potential crisis situations and associated Operations Plans (OPLANs), Concept Plans (CONPLANs), functional plans, or notional plans. The activities of the force are simulated under various conditions and the results are used in judging the adequacy of the force to meet U.S. needs.

- $\quad$ System effectiveness and trade-off analysis is led principally by OSD, with strong participation by the Services and the Joint Staff, using potential crisis situations and associated OPLANs, CONPLANs, functional plans, or notional plans. Alternative systems are included in the forces and their activities are simulated under various conditions. The results are used in deciding whether to acquire systems or which combinations of systems best meet U.S. needs.

- $\quad$ Concept and doctrine development and analysis is performed principally by the Services, with participation by the Joint Staff in the Joint arena (and perhaps the US Atlantic Command (USACOM) in the future), using potential crisis situations and associated OPLANs, CONPLANs, functional plans, or notional plans. Alternative concepts of employment and employment doctrines are simulated and the results are used in making changes to doctrine. 
The problem of planning for non-military "forces" in OOTWs is unresolved. In an actual operation, the other parties, whether US agency, other nation, United Nations agency, Non-Governmental Organization (NGO), or Host Nation, are responsible for planning their own forces. However, the plans of all are interrelated and should be coordinated. Historically, the quality of the coordination has varied from excellent to non-existent. However, in the other (prospective) functions described above, these organizations are not generally involved and the DoD organization must plan without their help. Accounting for the participation of these other organizations adds another layer of complexity to the military force design planning problem. 


\section{PROCESS}

This section describes the process used in this project to collect the data for analysis. The changes in the process over time reflect the need for the analysis: many of the things people thought they knew about planning for OOTWs were either not true or incomplete.

The basic approach contains three parts. It starts with the force planning requirements developed in earlier work. To this would be added the results of a workshop having the objective of gathering more detailed information on force planning requirements. Finally, everything would be analyzed to produce actionable descriptions of the needed tools and recommendations on their implementation.

\subsection{INITIAL PROCESS}

On August 24, 1998, OASD(SO/LIC) and USPACOM hosted an initial planning meeting in Washington, D.C. for a collaborative effort to advance the development of analytic methodologies to satisfy the varying DoD requirements to analyze OOTWs. The primary purpose of this planning meeting was to design a collaborative project that focused the analytical community on understanding how current and emerging analytical methodologies and technologies can be used to overcome challenges associated with OOTWs. The objectives were to gain broader understanding of OOTW missions, assess current analytic support methodologies, determine value and shortcoming of current analytic tools for OOTWs, and explore issues related to data and process. The agenda for the meeting is given in Table 1. The emphasis of the meeting was on creating the proper framework around the right problem. Organizations and representatives were invited based on their influence and expertise. Table 2 shows the participants and the organizations that they represented.

Table 1. Workshop Planning Meeting Agenda

\begin{tabular}{ll}
\hline \hline Time & Item \\
\hline $0800-0815$ & Welcome and Introduction \\
$0815-0845$ & Presentation of Purpose and Concept of Project \\
$0845-0915$ & Briefing of History of OOTW Projects \\
$0915-0930$ & Break \\
$0930-1000$ & Briefing of Failed State Project \\
$1000-1100$ & Discussion of Participant Goals \\
$1115-1130$ & Discussion of Scenario Issues \\
$1130-1230$ & Working Lunch (Review Possible Scenarios) \\
$1230-1400$ & Definition of Scenario/Excursions \\
$1400-1415$ & Break \\
$1415-1530$ & Definition of 1st Workshop Structure \\
$1530-1545$ & Discussion of Action Items and Milestones \\
$1545-1630$ & Conclusion \\
\hline \hline
\end{tabular}


Table 2. Workshop Planning Meeting Participants

\begin{tabular}{ll}
\hline \hline Participant & Organization \\
\hline Dr. Lynda Jaques & USPACOM \\
Mr. Kevin Baugh & OSD SO/LIC \\
Colonel Noland Bivens & US Special Operations Command (USSOCOM) \\
Colonel Gabe Rouquie & USACOM \\
Colonel Bruce Simpson & US Central Command (USCENTCOM) \\
Ms. Rachele Alvirez & US Southern Command (USSOUTHCOM) \\
LCDR Aasgeir Gangsaas & Joint Staff/J-8 \\
Mr. Donald Owen & Joint C4I Battle Center \\
Ms. Julia Sharkey & Center for Army Analysis \\
Dr. Gordon Schacher & Naval Post Graduate School \\
Dr. Mike Sovereign & Naval Post Graduate School \\
Mr. Martin Lidy & IDA \\
Mr. William Brundage & GRCI (OSD/PA\&E) \\
Dr. Dean Hartley & ORNL \\
Mr. Steve Packard & ORNL \\
\hline \hline
\end{tabular}

There was considerable discussion about what problems should be addressed. Clearly there were different goals, even within this group. The purpose of the meeting was to plan a feasible and productive process. The initial approach was as follows:

- $\quad$ Plan process

- $\quad$ Perform "homework"

- $\quad$ Attend workshop

- $\quad$ Analyze results
$8 / 24 / 98$

September-November 1998

December 1998

January-February 1999

The "homework" would consist of each participant selecting at least one scenario or operation for analysis. Both deliberate planning and crisis action planning would be considered. The following OOTW types would be covered:

- Humanitarian Assistance/Disaster Relief

- $\quad$ Counter-Drug (USSOUTHCOM)

- Counter-Terrorism

- $\quad$ DESERT THUNDER (USCENTCOM)

- Non-Combatant Evacuation Operation

- $\quad$ Consequence Management (USACOM)

- $\quad$ PeaceKeeping (US European Command (USEUCOM))

Each participant would answer the following questions about the selected scenario:

- What was the mission and who assigned it?

- How did you respond and how did you decide on that response?

- What tools and methodology did you use?

- What questions are you unable to answer or would like to answer better (timeliness)?

- What shortfalls keep you from doing OOTW analysis, e.g., lack of tools, lack of data? 
The workshop would consist of about 30-70 participants who would hear and analyze the reports of the "homework." The analysis would include the following:

- $\quad$ Lessons learned and tool requirements

- What should have been done?

- What would have made it easier?

- How should it have been done, e.g., roles, methods, procedures?

There was discussion of bringing software vendor/developer presentations or demonstrations to the December workshop; however, no decision was reached at that time.

\subsection{REVISED PROCESS}

Initially, the participants were asked to find one or more OOTWs that they had supported analytically and describe the processes they used and the problems they encountered. Communications with the CINC participants during the "homework" period revealed that the participants were having trouble: analysts had not been asked to help in crisis response situations and the deliberate planning efforts for OOTWs were too general to present any real planning problems requiring analysis. The following set of questions was then sent to the CINC representatives in an attempt to elicit more useful information:

- What are the types of analytical tasks that you are asked to accomplish routinely?

- What types of OOTW analysis are you asked to accomplish? If you are not asked to perform any OOTW analysis can you explain why? Do you see OOTW analysis as a potential problem for your theater? Why? Why not?

- If possible, provide a recent example of the kind of analytical support you provided for an OOTW problem.

- Have you been asked to perform analysis for OOTW that you cannot currently accomplish? What adaptation to current analytical tools/approaches/methodologies might help you perform this analysis? What types of tools/approaches/methodologies are required from your theater's perspective?

- $\quad$ For those whose theater commanders see limited utility for OOTW analysis. What would it take in your theater to change your CINC's mind?

- $\quad$ Are there any other comments you would like to make concerning support for OOTW analysis?

An additional month was added to the schedule, moving the workshop to January and the analysis to February-March. It was decided that software vendor/developer presentations or demonstrations should be included in the workshop. 


\subsection{WORKSHOP}

The purpose of the workshop was to elicit detailed requirements for a force design tool and to define its prospective users. All organizations had previously exhibited requirements for a force design tool; however, it was realized that the use of the same name for the tool might obscure needs for quite different tools.

Tables 3, 4 and 5 show the schedules (with approximate times) for the three days of the workshop. The concept was to intersperse briefings by the prospective users (each CINC, each Service, OSD, and the Joint Staff) with briefings on relevant existing tools. As it turned out, additional tools were briefed by the users and two briefings were added during the course of the workshop. These briefings were designed to ensure that the understanding of the problem(s) and potential solution(s) was maximally shared among all participants, prior to beginning the deliberations in the working groups. The final day was devoted to the presentations of the working group results and the implications of those results.

The process was successful: a large volume of information was presented and the spirited discussions indicated that the participants digested it all. Although there is no guarantee that all relevant issues were raised, nor that all conclusions were correct, the diversity and skills of the participants lead us to believe that the majority of the most important issues were considered and that the conclusions are closely related to the correct ones.

Table 3. Workshop Schedule, Day 1, Tuesday, January 12, 1999

\begin{tabular}{|c|c|c|}
\hline Time & Title & Speaker \\
\hline $0800-0830$ & Registration & \\
\hline 0830-0900 & Welcome \& Introductory Remarks & Baugh/Hartley \\
\hline $0900-0950$ & USPACOM Presentation & Jaques \\
\hline 0950-1020 & Tool Presentation: CAPS & Atwell \\
\hline $1020-1030$ & Break & \\
\hline $1030-1120$ & USEUCOM Presentation & Baugh \\
\hline $1120-1150$ & $\begin{array}{l}\text { Tool Presentation: FA\&CT/OFP } \\
\text { Army Discussion }\end{array}$ & Waters \\
\hline $1150-1240$ & $\begin{array}{l}\text { USSOUTHCOM Presentation } \\
\text { Tool Presentation: CATS } \\
\text { Tool Presentation: JCATS } \\
\text { Tool Presentation: NationLab }\end{array}$ & Alvirez \\
\hline $1240-1340$ & Lunch & \\
\hline $1340-1410$ & Tool Presentation: SENSE & White \\
\hline $1410-1500$ & USCENTCOM Presentation & Hartley \\
\hline $1500-1510$ & Break & \\
\hline $1510-1540$ & $\begin{array}{l}\text { Tool Presentation: SeaState } \\
\text { Tool Presentation: GCAM } \\
\text { Navy Presentation }\end{array}$ & Free \\
\hline $1540-1630$ & $\begin{array}{l}\text { USSOCOM Presentation } \\
\text { Wrap-up and Closing Remarks for Day One }\end{array}$ & Hope \\
\hline $1630-1700$ & & \\
\hline
\end{tabular}


Table 4. Workshop Schedule, Day 2, Wednesday, January 13, 1999

\begin{tabular}{lll}
\hline \hline Time & Title & Speaker \\
\hline $0800-0815$ & Administrative Remarks & Baugh/Hartley \\
$0815-0845$ & Tool Presentation: CarePlan & Campbell \\
$0845-0920$ & USACOM Presentation & Bazemore \\
$0920-0950$ & Tool Presentation: COST & Goree \\
$0950-1000$ & Break & \\
$1000-1030$ & Tool Presentation: VIC & Owen \\
$1030-1100$ & Tool Presentation: FALCON & Tao \\
& Air Force Discussion & \\
$1100-1130$ & Tool Presentation: JEB & Hartley \\
$1130-1230$ & Lunch & Gangsaas \\
$1230-1300$ & J-8 Presentation (MRS-05) & \\
$1300-1630$ & Working Groups & \\
$1630-1700$ & Wrap-up and Closing Remarks for Day Two & \\
\hline \hline
\end{tabular}

Table 5. Workshop Schedule, Day 3, Thursday, January 14, 1999

\begin{tabular}{lll}
\hline \hline Time & Title & Speaker \\
\hline $0800-0815$ & Administrative Remarks & Baugh/Hartley \\
$0815-0845$ & Working Group Presentation: War Fighters/ Geographical & Bell \\
$0845-0915$ & CINCs & Baugh \\
$0915-0945$ & Working Group Presentation: Force Providers & Hartley \\
$0945-1015$ & Working Group Presentation: National Level & Lidy \\
$1015-1030$ & Working Group Presentation: Alternative Views & \\
$1030-1100$ & Break & DuBois \\
$1030-1130$ & Tool Presentation: SADE & Baugh \\
$1200-1230$ & Wrap-Up and Potential Future Directions & Hartley \\
& Closing Remarks & \\
\hline \hline
\end{tabular}

Four working groups met to discuss Planning Design Requirements. The working groups considered Warfighting CINCs' requirements, Force Providers' requirements, National-level requirements, and "out-of-the-box" thinking.

- What are the particular group-oriented requirements?

- What are the functional divisions that may be needed?

- $\quad$ For each division what are the requirements?

- If you have time, are the original divisions still needed or can the number be reduced? Of the remaining divisions are connections needed between the tools for some of the divisions? Do you have any thoughts on possible connections with tools from other working groups?

The workshop proceedings [Hartley and Bell, 1999] include copies of all briefings except the single classified briefing. The results are synthesized in Section 4. 


\section{STARTING POINT}

The goal of the workshop was to produce a definition of the desired force design tool. However, the participants did not start from scratch; they had a base of knowledge derived from earlier work [Hartley, 1996 and Hartley \& Packard, 1998a]. The main goal of this project is to assess which pieces in the Integrated Mission Planning Tool of Fig. 2 (see page 3) should be physically combined into a single piece of software. The mission definition decision support tool is omitted, as it is assumed that the personnel who are involved in mission definition are flag-level officers who will not be involved in using force design software. The remaining four tools, a task analysis support tool, a force design tool, a logistics analysis tool, and a transport analysis tool remain as possibilities.

\subsection{FORCE DESIGN AND GCCS}

Section 1.2, on page 3, lists the four functions to which the force design tool under investigation here might apply. The first function, "planning and execution analysis," is an operational function, which is performed using the Global Command and Control System (GCCS). GCCS is a major DoD system and is being created under strict configuration control. Changes to GCCS to improve support for OOTW force design cannot be accomplished rapidly.

The full capabilities of GCCS are not known to the authors; however, certain inferences may be drawn from new requirements listed in unclassified documents [e.g., GCCS COP Working Group, 1998]:

OPERATIONAL PLANNING CAPABILITY ... . The Common Operational Picture (COP) needs to have the ability to support the CINC / Joint Task Force (JTF) planning process, to include: planning, decision, execution, and assessment. In order to attain this enhanced planning capability, the COP / Common Tactical Picture (CTP) must:

- Possess planning tools to facilitate the conduct of offensive action. These tools should allow friendly forces to: (1) take the initiative and gain freedom of action to allow swift transition from one action to another putting the enemy at risk throughout the depth and space of the battlefield; and (2) defeat, destroy, or neutralize the enemy force by taking the fight to the enemy in such a way as to achieve victory at least cost.

Possess planning tools to facilitate the conduct of defensive action. These tools should allow friendly forces to: (1) take action to defeat an enemy attack; (2) buy time and hold a piece of terrain in order to facilitate other operations; (3) preoccupy the enemy in one area so that friendly forces can attack him in another; and (4) erode enemy resources at a rapid rate while reinforcing friendly operations.

- Support the operational planning, coordination, and conduct of type operations such as relief in place, passage of lines, linkup, and Military Operations in Urban Terrain (MOUT).

- $\quad$ Provide functional planning capability at the CINC level for course of action (COA), logistics, and communications intent.

- $\quad$ Provide the ability to conduct COA analysis through wargaming. This will require friendly and threat icons to be linked to friendly and threat Order of Battle databases. 
- Be the mechanism by which the JTF commander communicates with and between components. The commander should not have to exit the CTP to do collaborative planning.

MODELING AND SIMULATION ... . The COP requires the following enhancements in the modeling and simulation area:

- $\quad$ Ensure that automation supporting modeling and simulation for COA development and exercise play, as well as for managing current operations can coexist on the same physical platform. We must get away from using different systems for current operations and exercise, and COA modeling and simulation.

These excerpts from the document support the following inferences:

1. The planning system is not complete or the COP is not completely integrated. Explicit "new" requirements for planning offensive and defensive activities imply problems with their current status.

2. The current emphasis is on planning combat activities. The referenced activities closest to OOTW are those listed in the requirement containing planning for MOUT.

3. COA analysis is an important part of planning. COA planning is to be available at the CINC level and COA analysis is to be supported through wargaming and linked to live databases.

4. Modeling and simulation are seen as important for COA analysis. Not only are modeling and simulation for COA development to be supported, but they should coexist on the same physical platform as GCCS COP / CTP.

5. The GCCS COP / CTP is envisioned as the operational planning environment. The JTF Commander should not have to exit CTP to do collaborative planning.

After considering the above inferences, we can conclude the following:

6. If planning for OOTWs requires different methods than planning for combat, GCCS will not support it well in the near future. Changes to support force design for OOTWs will follow current changes to support combat planning and modeling and simulation to support OOTW COA analysis does not exist yet.

7. A stand-alone tool to support OOTW force design will not be an acceptable long-term solution. The JTF Commander is not going to want to exit CTP and use a stand-alone system once CTP is satisfactory for combat planning.

At the outset of this project, the need for any changes to GCCS (for OOTW force design) was undetermined; however, it appears that changes will be needed. The strategy for implementing any such changes must be based on an understanding of the entire system surrounding GCCS. Accordingly, the strategy would consist of creating a stand-alone tool to serve as a prototype for testing changes that might eventually be introduced into GCCS. 


\subsection{PREVIOUSLY DEFINED REQUIREMENTS}

Earlier work had produced general descriptions of the parts of a mission planning tool, which are repeated here. These descriptions are not complete, but do suggest the basic concepts.

\subsubsection{Task Analysis Support Tool}

The object of the tool is to support an accurate and complete analysis of the mission tasks. The first goal is to identify tasks in the task categories shown in Table 6.

\section{Table 6. Tasks to be supported by a Task Analysis Support Tool}

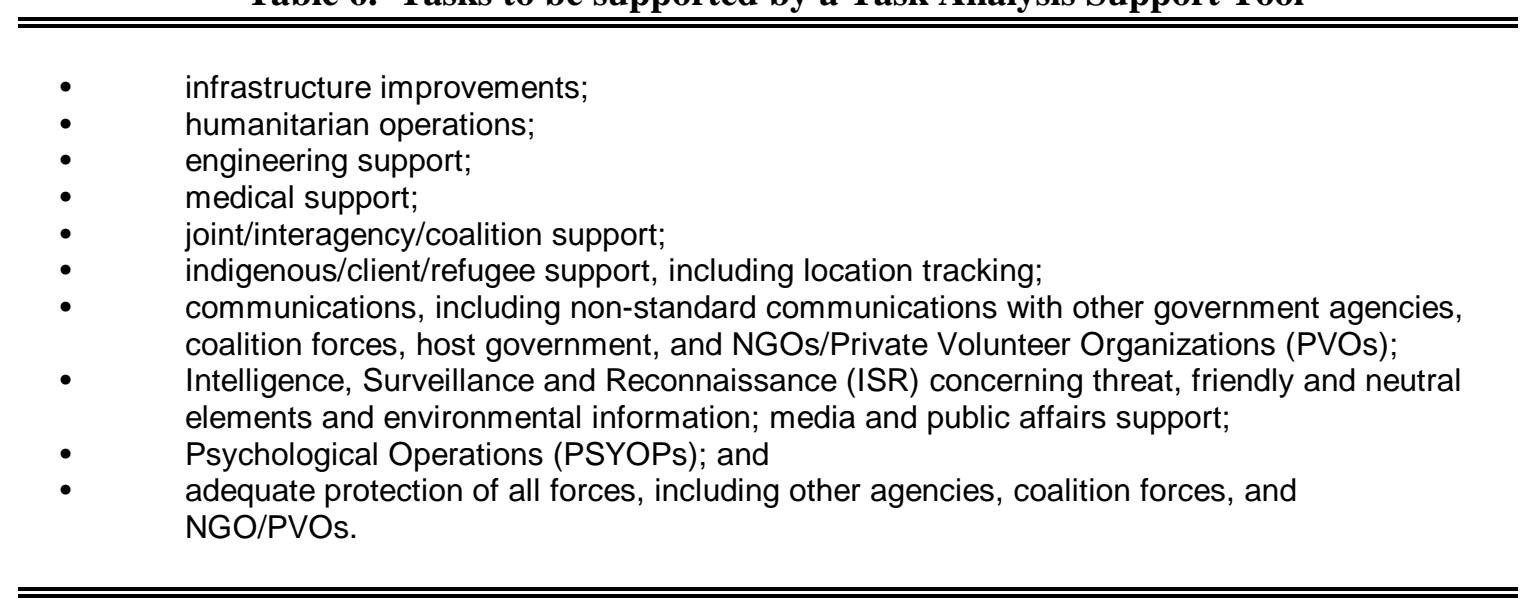

The second goal is to identify whether tasks involved in the use of force, whether lethal or non-lethal, are required.

The tool needed is a decision support tool that connects missions to strategies to tasks, both explicit and implied, in the OOTW domain. It should identify both those tasks that are central to the mission and any contingent tasks that might be implied by reasonable shifts in mission definition. It should also support replanning as the situation changes.

\subsubsection{Force Design Tool}

The object of the tool is to support the designation of U.S. forces required for an operation in an OOTW context. The first goal is to identify human resources, materiel and procedures supporting the domains of interest shown in Table 7. 


\begin{tabular}{|c|c|}
\hline • & heavy vs light forces and weapons mix plus forces needed to open and maintain Lines of \\
\hline$\bullet$ & $\begin{array}{l}\text { active vs reserve forces, service mix (including Coast Guard), and coalition force mix } \\
\text { (conditioned on the range of expected contributions by civilian organizations, including } \\
\text { NGO/PVOs); }\end{array}$ \\
\hline • & $\begin{array}{l}\text { readiness and availability of U.S. military forces, U.S. agency elements, and coalition } \\
\text { elements; }\end{array}$ \\
\hline • & requirements to support media and public affairs; \\
\hline • & forces to support military contingency operations; \\
\hline • & balancing tooth to tail ratio; \\
\hline • & balancing effectiveness vs availability/feasibility; \\
\hline • & $\begin{array}{l}\text { reserve call-up (requires maintenance of information on immediate availability of reserves } \\
\text { and availability of active service time); }\end{array}$ \\
\hline & $\begin{array}{l}\text { communications, including non-standard communications with other government agencies, } \\
\text { coalition forces, host government, and NGOs/PVOs; }\end{array}$ \\
\hline & $\begin{array}{l}\text { determining redeployment priorities, comparing effectiveness in current and future tasks } \\
\text { against the availability or feasibility of alternative options (including consideration for } \\
\text { rotation of troops); }\end{array}$ \\
\hline & determining what retraining, etc., is needed to reconstitute the forces; and \\
\hline & $\begin{array}{l}\text { gathering and codifying the cultural issues and to identify proper procedures with respect to } \\
\text { cultural issues. }\end{array}$ \\
\hline
\end{tabular}

The second goal is to provide a framework for the Mission, Enemy, Troops, Terrain/Weather, and Time Available (METT-T) analysis, answer "what-if" questions, and identify necessary materiel, human resources and procedures.

The tool needed is a decision support tool that connects the tasks to generic resources and connects generic resources to actual available resources, including U.S. military, U.S. non-military, foreign government, NGO/Private Volunteer Organization (PVO), and contractor resources. Data requirements include task capability for all resources (or the facility for user input for unique resources) and availability data (based on reserve commitments, etc.). It should provide for restrictions on choices based on cultural issues (such as female doctors in Muslim countries). Processing should include selection of military resources and substitution of other resources. The tool should also support replanning as the situation changes.

\subsubsection{Logistics Analysis Tool}

The object of the tool is to support the logistics analysis of the mission in an OOTW context. The goal is to plan for adequate logistics and supply for all mission forces (well understood process) and to support humanitarian mission needs (new process).

The tool needed is a decision support tool that derives the logistics requirements from the total force structure. It should allow for supply from outside sources and provide for supply of non-military personnel. It should support replanning as the situation changes. Because such a tool will also be critically dependent on keeping the data current, the design for the tool must include data maintenance considerations. 


\subsubsection{Transport Analysis Tool}

The object of the tool is to support the transportation analysis for mission arrival, sustainment, and departure in an OOTW context. The goal is to plan for all transportation related support, as shown in Table 8. New elements for OOTWs involve deconfliction of non-military transport and military transport of non-military items and for non-military groups.

Table 8. Elements of transport related support

\begin{tabular}{l}
\hline \hline$\quad$ determine the sequence of arrival by units required to accomplish the mission and provide \\
- $\quad$ decurity; \\
determine deployment priorities to resolve bottlenecks; \\
mission, including any transport needed for or supplied by other agencies, coalition \\
partners, and NGOs/PVOs; \\
establish LOCs; \\
plan for transportation support for mission forces, including appropriate NGOs/PVOs and \\
media personnel; \\
determine the sequence of departure of units required to accomplish the mission and \\
provide security; and \\
determine availabilities and capabilities of the transport resources needed for departure, \\
including any transport needed for other agencies, coalition partners, and NGOs/PVOs.
\end{tabular}

The tool needed is a decision support tool that plans the transport requirements, based on all appropriate constraints. It must support replanning as the situation changes over time (e.g., as supplies are moved within the theater).

\subsection{COMMON OPERATIONAL REQUIREMENTS}

Certain operational requirements may be inferred from the known environment. Ideally, the military would like to create plans for an OOTW in concert with all interested parties, at the very earliest time; however, there are constraints, as described in Table 9.

Table 9. OOTW mission planning constraints

- $\quad$ the military is brought in as a last resort;
military objectives are most definitely subordinate to other objectives, including political
objectives;
other organizational interests do not coincide with the military objectives and may be not
just irrelevant to military objectives, but in part contrary to military objectives;
while the planning capacities of other organizations are significantly less than the military's,
they are started earlier and cannot be rationalized within the military's planning system; and
the situations which necessitate the OOTW, by their very nature, change with time,
requiring replanning.


Thus military planning for OOTWs must make a virtue of the necessity of reactive planning rather than proactive planning. Analysis of the realities yields insights on the nature of a good military system for planning OOTWs, as shown in Table 10.

Table 10. OOTW mission planning imperatives

\begin{tabular}{lll}
\hline \hline - $\quad$ time is short & $\begin{array}{l}\text { some preplanning for generic operations is } \\
\text { required; } \\
\text { robust plans have higher value than optimized } \\
\text { plans; } \\
\text { extensive communications plans with allies } \\
\text { must admit some compartmentalization; } \\
\text { plans should be modular, allowing for changes } \\
\text { in received and provided support; and } \\
\text { continuous replanning ability will be required. }\end{array}$ \\
- coordination of plans is hard & \\
\hline
\end{tabular}

Some of the frustration is illustrated by the statement, "We did five NEOs in the past six months. Since we already do these, why don't we already know the shortfalls in planning?" Other complaints are given in Table 11.

Table 11. OOTW mission planning complaints

- In looking at all past operations, we do not know what forces we really used. We have no clue on the required force size or duration of OOTWs for new operations. We often start with a gross plan then tweak the shortfalls (speed and data), all pluses and minuses from standard TO\&E units.

- Many military tasks for OOTWs correspond to the UJTL and service lists, but many tasks require modification and many are entirely new; mission support definition is a problem. However, the military is not the only player. The OOTW Sectors include diplomacy, military, humanitarian assistance, internal politics, civil law, public diplomacy and education, infrastructure, and human rights. Interagency checklists would be valuable tools. There exists a Federal Response Plan. The framework for Presidential Decision Directive (PDD) 56 establishes lead and support roles.

- We can do all the tasks with military resources, but if we knew about the NGO/PVO resources, we could avoid some DoD cost. We need to know, up front, what other agencies are providing and requiring.

\subsubsection{Ease of Use/Required Training}

Military rotation policies, the undersupply of personnel likely to need to use a force design tool, and the variety of tasks such personnel must perform implies that a force design tool should be easy to use. The user is unlikely to have had dedicated training on the tool and is unlikely to be tolerant of obscure functions or non-intuitive procedures. 
1. A novice user should be able to construct the entire force design.

2. A sophisticated user should be able to bypass parts of the system.

3. No additional infrastructure should be added (the tools should run on a mid-level PC, as the very latest $\mathrm{PC}$ is unlikely to be available).

\subsubsection{Structured Use}

The sequence of creating a force design is often iterative: the CINC staff is given a mission; it replies with the forces required to perform that mission with confidence; then it is told how large a force it can assign; and finally it negotiates the mission down to something that the available force can handle with an acceptable degree of risk. Later, the mission is changed. Details on the force design process are sparse. One expert said: NEOs seem to be the crisis de jour, but little or no documentation exists describing their planning process.

1. Changes will occur frequently that require fast and accurate integration and recalculation.

2. Although a structured input sequence should be available to ensure that a novice user considers all necessary factors and to enable post-entry error detection, the structured sequence should not prohibit alternate sequences.

3. Differing levels of resolution should be achievable.

\subsection{AVAILABLE TOOL SET}

Before designing a force design tool, data on what tools were already available was required. Knowledge of the functionality of available tools served the purpose of reminding the workshop participants of what is possible, as well as allowing them to determine what is missing. Previous research has identified a large number of tools that might be useful in OOTW analysis and planning. We selected those tools that promised some use in the force design process and requested more detailed information from their proponents.

Presentations were made (both to the authors and to the workshop) on the Contingency Analysis Planning System (CAPS), the Force Allocation \& Capabilities Tool (FA\&CT)/Objective Force Planner (OFP), the Force Allocation \& Contingencies tool (FALCON), the Force Analysis Spreadsheet Tool Operations Other than War Requirements (FAST-OR), the Joint Electronic Battlebook (JEB), and SeaState. The Joint Training System (JTS) Mission Requirements Module (MRM) of the Joint Exercise Management Package (JEMP III) was not discussed at the workshop; however, its excellent documentation indicates extensive capabilities as a task analysis tool, perhaps with some generic OOTW task analysis supplied as starting data. The Force Facilitator For Operations Other Than War (FFFOOTW) was also not discussed at the workshop, but is reputed to be force design tool for OOTW. Table 12 summarizes some pertinent observations concerning these tools that were gleaned from the presentations. The column labeled "Positives" represents features that satisfy some part of an "ideal" force design tool, a joint/combined, complete, easy to use, and OOTW oriented tool (more fully described in Section 5). The column labeled "Negatives" represents areas in which the tool falls 
short of the ideal. The "Mitigation" column indicates the effort required to improve a "negative" area. Shaded cells indicate especially significant comments.

Table 12. Existing Force Design Tools

\begin{tabular}{|c|c|c|c|}
\hline TOOL & POSITIVES & NEGATIVES & MITIGATION \\
\hline \multirow[t]{8}{*}{ CAPS } & $\begin{array}{l}\text { has structure to aid in deciding which units } \\
\text { to use }\end{array}$ & $\begin{array}{l}\text { does not have actual forces in } \\
\text { structure }\end{array}$ & requires programming \& data \\
\hline & has internal help facility & $\begin{array}{l}\text { does not allow for coalition or } \\
\text { NGO/PVO contribution to effort }\end{array}$ & requires minor programming \\
\hline & host nation support can offset US support & does not allow for time phasing & requires programming \\
\hline & workloads by UJTL & $\begin{array}{l}\text { does not have data on } \\
\text { transportation or logistics } \\
\text { requirements for units }\end{array}$ & $\begin{array}{l}\text { requires minor programming } \\
\text { and data collection }\end{array}$ \\
\hline & units have capacity to do work & limited task set & $\begin{array}{l}\text { requires data collection and } \\
\text { cross referencing }\end{array}$ \\
\hline & security forces can be planned & no data maintenance utilities & requires major programming \\
\hline & allows modification of previous plans & limited mission types & requires data collection \\
\hline & good base to build force design tool & limited user input to design & \\
\hline \multirow[t]{3}{*}{ FA\&CT } & $\begin{array}{l}\text { relates tasks to actual Army units (converts } \\
\text { SRC to Unit Identification Code (UIC)) }\end{array}$ & current data Army only & requires major programming \\
\hline & can allocate future forces & & \\
\hline & accumulates for multiple OOTWs & & \\
\hline \multirow[t]{3}{*}{ FALCON } & $\begin{array}{l}\text { computes tempo \& resource stress analysis, } \\
\text { support requirements, force allocations \& } \\
\text { mix/sizing }\end{array}$ & Air Force orientation & requires major programming \\
\hline & has rules for reconstitution requirements & Tactical Air (TacAir) orientation & requires data \\
\hline & accumulates for multiple OOTWs & scheduling orientation & \\
\hline \multirow[t]{6}{*}{ FAST-OR } & $\begin{array}{l}\text { has extensive data about Standard } \\
\text { Requirements Code (SRC) units }\end{array}$ & $\begin{array}{l}\text { has only partial structure to aid in } \\
\text { deciding which units to use (built- } \\
\text { in Army assumptions) }\end{array}$ & $\begin{array}{l}\text { requires major programming } \\
\text { to go beyond assumptions }\end{array}$ \\
\hline & has documentation & data are basically Army only & $\begin{array}{l}\text { requires data collection and } \\
\text { analysis }\end{array}$ \\
\hline & host nation support can offset US support & $\begin{array}{l}\text { enforces Army doctrine } \\
\text { Army allocation rules are no } \\
\text { longer current }\end{array}$ & requires major programming \\
\hline & $\begin{array}{l}\text { permits support to other Services, refugees } \\
\& \text { allied forces }\end{array}$ & $\begin{array}{l}\text { doesn't deal with Active vs } \\
\text { Reserve unit availability or } \\
\text { readiness (equipment or } \\
\text { personnel) }\end{array}$ & requires major programming \\
\hline & $\begin{array}{l}\text { extensive allocation rules for units implied } \\
\text { by workloads, including HQ units \& tailored } \\
\text { sizes }\end{array}$ & $\begin{array}{l}\text { no connection to non-military } \\
\text { command and control }\left(\mathrm{C}^{2}\right)\end{array}$ & \\
\hline & contains Army doctrine & & \\
\hline FAST-OR & $\begin{array}{l}\text { allows manual creation of time phases for } \\
\text { when units are needed }\end{array}$ & $\begin{array}{l}\text { not a good base from which to } \\
\text { build operational tool }\end{array}$ & \\
\hline FFFOOTW & $\begin{array}{l}\text { automated tool to determine force structure } \\
\text { requirements for OOTW }\end{array}$ & no personal knowledge of tool & \\
\hline JEB & $\begin{array}{l}\text { generates needs assessment using } \\
\text { included planning factors }\end{array}$ & $\begin{array}{l}\text { does not have structure to aid in } \\
\text { deciding which units to use }\end{array}$ & requires major programming \\
\hline
\end{tabular}


Table 12. Existing Force Design Tools

\begin{tabular}{|c|c|c|c|}
\hline TOOL & POSITIVES & NEGATIVES & MITIGATION \\
\hline & $\begin{array}{l}\text { has information on unit capabilities, } \\
\text { characteristics and on-hand status of } \\
\text { consummables and equipment }\end{array}$ & does not address security & requires major programming \\
\hline & $\begin{array}{l}\text { permits conversion of notional units to } \\
\text { actual units }\end{array}$ & & \\
\hline & direct access to joint data & & \\
\hline & $\begin{array}{l}\text { permits collaborative planning by supporting } \\
\text { connected multiple workstations }\end{array}$ & & \\
\hline MRM & joint mission-to-task (UJTL) support tool & built as training tool & minimal to zero conversion \\
\hline \multirow[t]{4}{*}{ OFP } & $\begin{array}{l}\text { started as aid to group decisions on } \\
\text { mission-to-task-to-forces planning }\end{array}$ & $\begin{array}{l}\text { not designed as an active } \\
\text { planning tool }\end{array}$ & none \\
\hline & thorough attempt to span OOTW scenarios & contains only Army data & \\
\hline & $\begin{array}{l}\text { excellent source of data on Army resources } \\
\text { to apply to OOTW missions }\end{array}$ & $\begin{array}{l}\text { determines primary forces } \\
\text { required, not support to those } \\
\text { forces }\end{array}$ & \\
\hline & & $\begin{array}{l}\text { not a good base from which to } \\
\text { build operational tool }\end{array}$ & \\
\hline \multirow[t]{5}{*}{ SeaState } & has data on Navy unit capabilities & Navy orientation & \\
\hline & uses data from SORTS on unit readiness & $\begin{array}{l}\text { units are assigned in rank order, } \\
\text { but tasks are not sized }\end{array}$ & requires major programming \\
\hline & $\begin{array}{l}\text { understands "whole ship" assignment } \\
\text { problem }\end{array}$ & & \\
\hline & accumulates for multiple OOTWs & & \\
\hline & $\begin{array}{l}\text { general OOTW mission types defined by } \\
\text { UJTL tasks }\end{array}$ & & \\
\hline
\end{tabular}

Because any force design tool must be used in a larger context, knowledge of that context may help produce a more comprehensive discussion of the requirements for the force design tool. Several tools that do not directly relate to force design were discussed in the formal presentations (both to the authors and to the workshop), while other tools were discussed informally, as participants brought them up. The Virtual Information Center (VIC) tool could be used to gather information about the operation. The Consequence Assessment Tool Set (CATS) tool is useful in defining the problems to be solved by a force design. CarePlan, the General Campaign Analysis Model (GCAM), the Joint Conflict and Tactical Simulation (JCATS), NationLab, and the Synthetic Environment for National Security Estimates (SENSE), tools that might be useful in evaluating the effectiveness of a planned force, were also discussed. The Contingency Operations Support Tool (COST) was discussed, as it will be used in evaluating the incremental cost of a force design. Table 13 summarizes data on these tools.

Because the workshop participants identified actual needs beyond that of force design tools, several tools have been added to Table 13, reflecting this expanded scope. These are the Counternarcotics Modeling and Analysis Capability (CMAC), CyCAM III, the Deployable Exercise System (DEXES), the Joint Warfare Analysis Center (JWAC) model, the Oxford Economic Forecasting: Model of World 
Economy (OEF), the Political and Economic Risk in Countries and Lands Evaluation Study (PERICLES), the Regional Development Simulation System (RDSS), the State Failure Project (SFP), the Situational Influence Assessment Module (SIAM), SimCity ${ }^{\mathrm{TM}}$ a commercial computer game, and Spectrum. Each of these might be useful in evaluating the effectiveness of a planned force.

Table 13. Other Tools

\begin{tabular}{|c|c|}
\hline TOOL & DESCRIPTION \\
\hline VIC & $\begin{array}{l}\text { Pulled data from open sources on a semi-real time basis with later development to include firm links } \\
\text { to experts and info services. }\end{array}$ \\
\hline CATS & $\begin{array}{l}\text { May be used to develop requirements for a mission to be planned. The model predicts and displays } \\
\text { the damages, casualties and effects of several types of natural and man-made disasters. }\end{array}$ \\
\hline CarePlan & $\begin{array}{l}\text { Simulation system using object oriented simulation (Smalltalk) that models persons and } \\
\text { organizations. Persons have demographics, perceptions, cultural, health, membership, specialty, } \\
\text { agenda, and cognitive behavior attributes. Organizations have resources, staff, agenda, behavior } \\
\text { attributes. It runs on Unix or Windows NT platforms. Human physiology models and a geo- } \\
\text { referenced development tool have been developed. The Dynamic Information Architecture System } \\
\text { (DIAS) underlying CarePlan is High Level Architecture (HLA) compliant. }\end{array}$ \\
\hline CMAC & Counternarcotics simulation that has been used to support at least one exercise. \\
\hline CyCAM III & $\begin{array}{l}\text { Simulation system that can be used to analyze conflict trends, including sociological, economic and } \\
\text { political factors. }\end{array}$ \\
\hline DEXES & Training simulation used drive exercises. \\
\hline GCAM & $\begin{array}{l}\text { Simulation environment. The Force Sufficiency Assessment Tool (FORSAT) is a model built using } \\
\text { GCAM and is used to evaluate the utility of a given force structure; however, the model for the given } \\
\text { OOTW may need to be created first. }\end{array}$ \\
\hline JCATS & $\begin{array}{l}\text { High-resolution (down to individual systems) simulation used for training, analysis, planning, and } \\
\text { mission rehearsal. }\end{array}$ \\
\hline JWAC & Combination game theory, social network analysis, general systems theory predictor of instability. \\
\hline NationLab & $\begin{array}{l}\text { Influence diagram of narcotrafficing in Bolivia, with relationships and data supplied by Bolivia. It } \\
\text { permits the analysis of causes and effects of attempts to counter the narcotics trade. }\end{array}$ \\
\hline OEF & Economic forecasting model of the world economy, used as a seminar driver. \\
\hline PERICLES & Model of risk indicators for long range cultural and ethnic strife for over 200 countries. \\
\hline RDSS & Socio-political, economic and military factors simulation for training and analysis. \\
\hline SENSE & $\begin{array}{l}\text { Training simulation for multiple participants, using linked workstations, to exercise the interactions of } \\
\text { socio-economic policy decisions. }\end{array}$ \\
\hline SFP & Classified analysis of multiple indicators for state failures. \\
\hline SIAM & Collaborative analytic tool for examining influences of multiple factors involved in OOTWs. \\
\hline SimCity $^{\mathrm{TM}}$ & Commercial game that could be extended to simulate multiple OOTW factors. \\
\hline Spectrum & Training simulation used to drive exercises. \\
\hline COST & $\begin{array}{l}\text { Produces planning and detailed estimates of the incremental costs of OOTWs. It has a Cost } \\
\text { Breakdown Structure (CBS) that the Services are now required to use to report actual costs. }\end{array}$ \\
\hline
\end{tabular}

The relationships among the tools are illustrated in Fig. 3. CAPS, FA\&CT/OFP, FALCON, FASTOR, FFFOOTW, JEB, and SeaState would be placed in the "Integrated Mission Plan" category. VIC would be placed in the "Situation Display" category. CATS belongs in the "Disaster and other 
specialized impact models" category. CarePlan, CMAC, CyCAM III, DEXES, GCAM, JCATS, NationLab, OEF, RDSS, SENSE, SIAM, SimCity ${ }^{\mathrm{TM}}$, and Spectrum would be placed in the "Impact Simulation" category. JWAC, PERICLES and SFP belong in the "Real-Time Indicators \& Warnings" category. COST belongs in the "Cost tools" category.

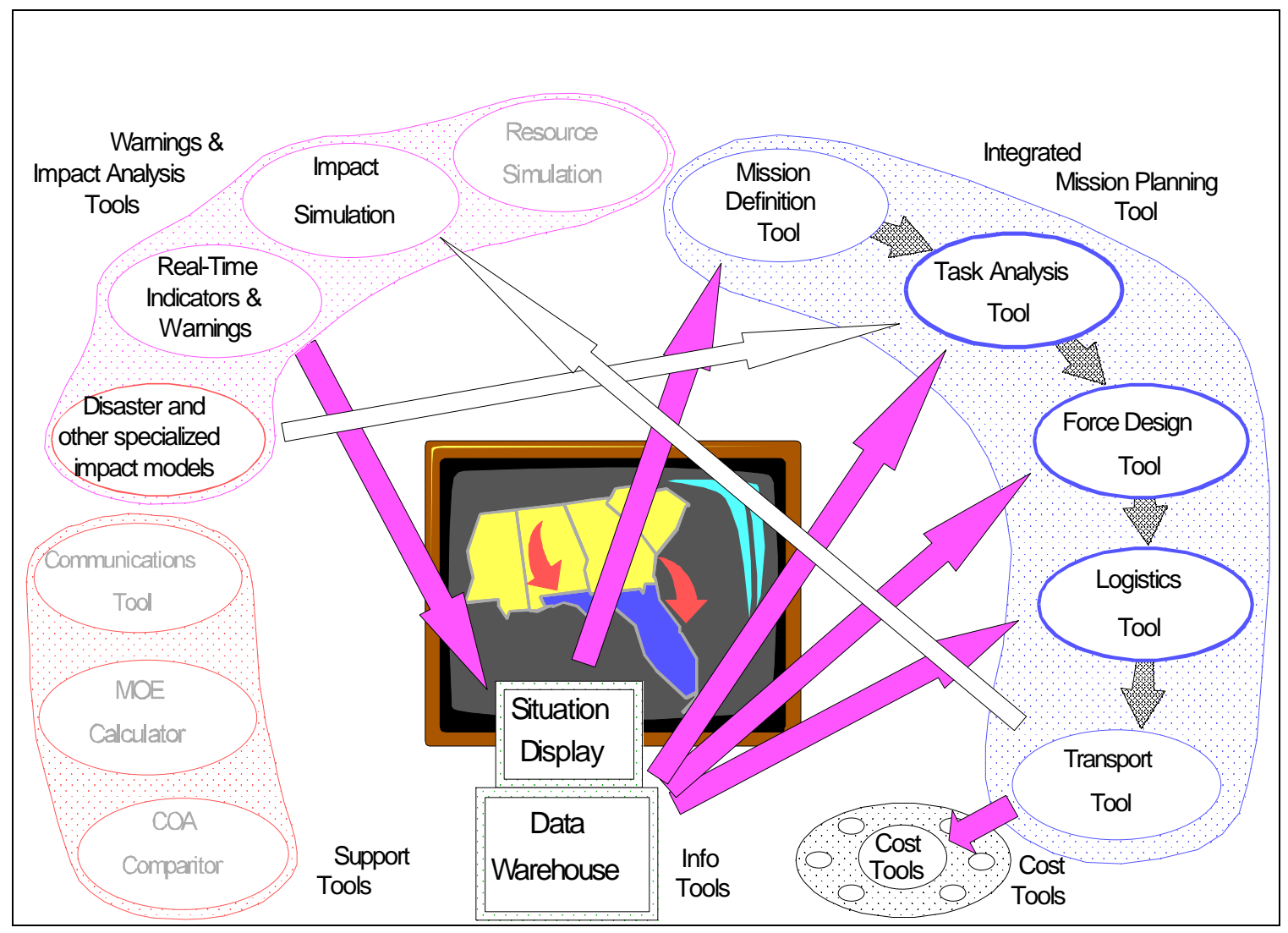

Fig. 3. Relations among the tools presented. 


\section{REQUIREMENTS}

The requirements are divided into four areas, based on three $\mathrm{DoD}$ user groups and one other area. The DoD user groups are National-Level, Force Provider, and Geographic CINC-Level. The other area is described as alternative requirements.

\subsection{NATIONAL-LEVEL REQUIREMENTS}

The national level analysis functions that might require a force design tool, include: the Quadrennial Defense Review (QDR) in forecasting resource needs, Defense Planning Guidance (DPG) and Joint Strategic Capabilities Plan (JSCP) issues, the Planning, Programming, and Budgeting System (PPBS) / Program Objective Memorandum (POM) process, analyses of overseas posture (forces and basing), analyses of the reserve vs active duty mix (Reserve Component Evaluation (RCE)), CINC OPLAN review, acquisition, prospective operations (Joint Staff, OSD, interagency), studies that involve OOTW analysis as part, e.g., the Mobility Requirements Study 2005 (MRS-05), wargaming, Defense Science Board (DSB), and Joint Requirements Oversight Council (JROC). The group decided all these analyses used a common technique: a large problem is decomposed into scenarios or vignettes; the scenario or vignette is analyzed; and the set of scenarios or vignettes is used to infer an overall result. In the case of vignette analysis of OOTWs, it is important to remember that the military is generally a late arrival, departs early, and plays a supporting role.

The conceptual force design tool starts with the assumption that the user already knows what DoD needs to do and what all other parties are going to be doing. Deployment planning is separated from force design; however, the force design tool should supply certain data that a deployment planning tool would use. None of the tools that were demonstrated could perform all of the functions needed for force design at the national level; however, there were features in all that would be useful. The group described the ideal tool as combining the desirable features of several tools:

- $\quad$ Pre-planned packages (such as developed for the Mission Task Organized Forces (MTOFs) and the task analysis of MRM) were considered valuable starting points for designing the force for a particular OOTW.

- $\quad$ The logistic needs assessment provided in JEB provides valuable information.

- The computation of workloads and the assessment of which units can perform the workloads, provided in CAPS, is required.

- The assessment of security force requirements performed by CAPS is also required, although there are questions about CAPS' methodology.

- The computation of cubic feet, square feet and short ton requirements of the force, provided by FA\&CT, should be part of the tool. 
- The tool should also compute the effects of tempo, readiness, training, depreciation, and recovery time in the manner of FALCON.

- $\quad$ The rules on ship allocation in SeaState are required for addressing naval units.

- The data should be drawn from common sources such as the Common Forces Database (CFDB).

- $\quad$ Additionally, the tool should produce outputs such as the percent of each task that can be performed, the amount of excess capacity allocated, the security risk, a time phased force and equipment list, data to support mobility and logistics calculations, degradation values. It should calculate results for individual vignettes and the cumulative results for a set of vignettes.

The force design tool, as defined, would not be all-encompassing. Impact and value analysis (the evaluation of whether the resulting force would do a good job for the defined OOTW) would not be part of this tool. Currently, such an evaluation must be based on the experience of the Commander. Further, as a practical matter, there would be a problem with assuming that the user would be sufficiently knowledgeable on non-DoD capabilities. This problem could be mitigated by having periodic outside consultations, supported by localized within-DoD expertise (such as at IDA). Additionally, the users would need education in the process of picking the right units from among the possibilities offered in the tool.

The group concluded that there is a requirement at the national level for this force design tool. The question was the level of priority (especially for funding) to be given to this requirement.

\subsection{FORCE-PROVIDER REQUIREMENTS}

The issues for the force providers center on providing forces for the long-term (e.g., what is needed, how do systems or doctrines contribute to the needs) and can be divided by the various involved parties.

The theater Service Component Commands and Continental US (CONUS) commands, are involved in both crisis action and deliberate planning; POM development; training; combat development; Base Operations Support (BOS) and Installation Support; and combat analysis. The Component Commands have both reachback and deployable analytical cells to support Component Command "combat" needs.

The Service Staffs have a programmatic (future) focus, going seven to ten years out. They do prioritization and tradeoff analyses; requirements, shortfalls and surpluses, and modernization analyses; comparative (force mix and structure) analyses; life cycle cost analyses; and capability assessment and capability maintenance (readiness) analyses. Unfortunately, there has been no "joint" analytical support community for the force-providers.

The CINC staffs, the Joint Staff and OSD are also concerned with force provision. They do Joint Warfighting Capabilities Assessment (JWCA) analyses; determine the risk associated with force 
alternatives for the DPG, Illustrative Planning Scenarios (IPS), Theater Engagement Planning (TEP), and routine engagement; provide combat analysis support (for Service components); and provide training.

The key analytical functions for all involved are decision support, risk analysis, requirements prioritization, force design/optimization, and subject matter expertise. The qualities of the tools differ from those required for CINC use. While there is an increasing requirement for speed, accuracy is extremely important. There is a need for greater accuracy in budgeting and defending programs - the $80 \%$ solution required by the Geographical CINCs is not good enough. However, the tools also need to be compatible with the force design tools used by others. Tool transparency and realism is required: the tool workings, limitations and assumptions must be understandable to decision-makers, subject matter experts (SMEs), and any other users. The tool must be relevant to operational issues and cover the desired mission areas; it must be validated, verified and have current data available; and it must be close to the decision maker.

\subsection{GEOGRAPHIC CINC-LEVEL REQUIREMENTS}

Each CINC has unique features and expertise:

- $\quad$ based on the nature of Area of Responsibility (AOR),

- $\quad$ USCENTCOM has experienced bulk of combat operations;

- USSOUTHCOM has major counterdrug operations;

- $\quad$ USEUCOM has Bosnia in Europe and multiple NEOs in Africa;

- $\quad$ USPACOM has broad disaster relief experience in an immense ocean area;

- $\quad$ USSOCOM is a force provider and is more like a Service; and

- $\quad$ USACOM also has major support roles, especially in training.

- $\quad$ based on the personality of current CINC ( this appears to be more significant in determining analytical roles than does personality of current Chief of Staff/Chief of Naval Operations (CNO)/Commandant of a Service).

However, the CINCs have some things in common:

- their analysis people are not in position to provide analysis support for crisis action planning;

- their analysis people are more likely to be involved in engagement planning, that is, shaping the environment, and impact analysis tools are needed;

- COA tools are needed; and

- data, information and links to information resources are needed.

The group reported that the most productive project to address geographical CINC needs is an extension of the VIC concept, providing data to use existing tools better. In addition to CINC VICs, a central Virtual Analysis Center (VAC) is needed to collect data and links to data, tools and people. 
The VAC would provide a resource to convert data into useful information. The VAC could also link to other agencies.

The geographical CINCs did define a need for an impact analysis tool (or tools). EUCOM, PACOM and SOUTHCOM all declared intensive engagement efforts within their AORs. These efforts involve attempts to shape the environment in ways more favorable to US interests; however, tools to gauge the impact of proposed efforts are either unavailable, unsatisfactory, or limited in use. A separate, although related, need for COA tools was expressed. The COA tool would be used at the operational level and would need to be simpler. (A definition of success would appear to be required for either tool.)

If GCCS has problems with force design for OOTWs, they were not identified in the workshop. The geographical CINCs did not identify a need for new tools for deliberate planning, but stated a need for data to use existing tools better For the Crisis Action Team (CAT), there is a resolution issue, similar data are needed, but there is no time to gather it. The CAT ought to use the same tools as used in deliberate planning. An $80 \%$ solution provided immediately is adequate. The engagement planning process needs an automated checklist. This group also reported a problem in defining success for OOTWs.

\subsection{ALTERNATIVE REQUIREMENTS}

In addition to the user group divisions of Sections 4.1 - 4.3, there is a need for coordination with non-DoD organizations. In war, military operations comprise the bulk of the content; however, in OOTWs, the military part is the small part. The military plays a part because it can provide security; it can provide logistics at the wholesale level; and it has a few unique capabilities that it can provide. A proper understanding of the military force design issues requires putting the military activities in the context of all activities.

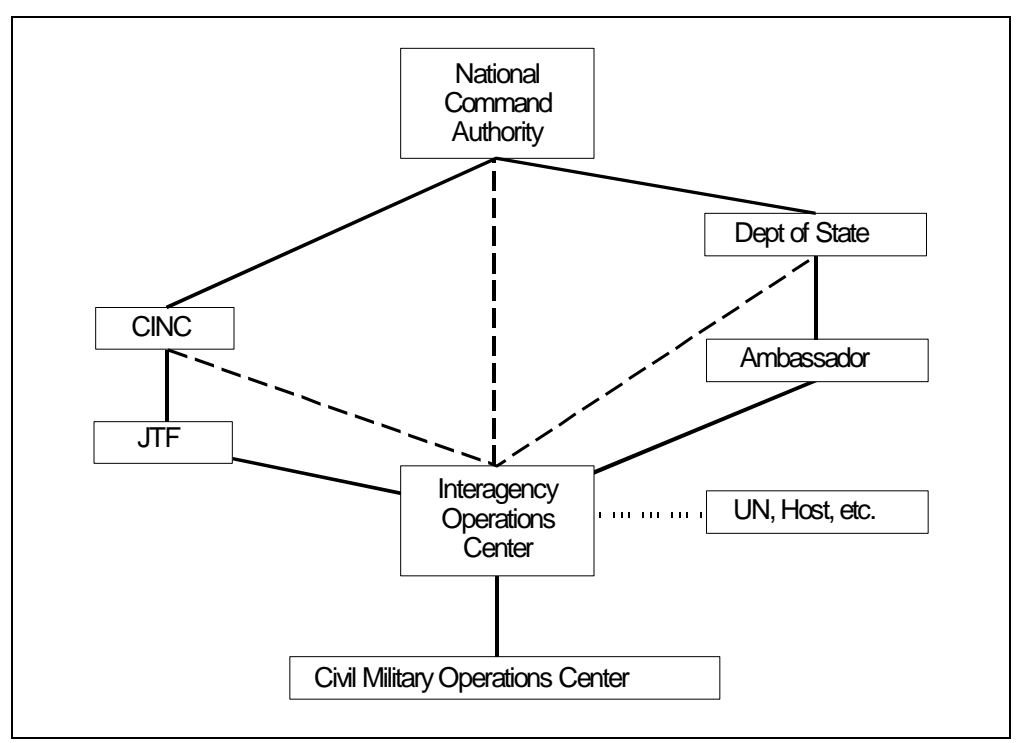

Fig. 4. $C^{2}$ network.

This understanding helps explain the weird (from a military perspective) chain of command in a many OOTWs. The command and control $\left(\mathrm{C}^{2}\right)$ structure for US forces operating in a foreign country is more properly understood as a network of command and control or as a coordination and collaboration architecture (C2A), as shown in Fig. 4, produced by the Alternatives Working Group. The ambassador controls all personnel not assigned to a CINC, including military and civilians. The Interagency Operations Center (IOC) also extends back to the other US government departments. It may be inclusive or exclusive regarding other participants, including the host nation, the UN, IOs, 
NGOs, other donor nations, contract groups, etc. The connections may be on an issue to issue basis (not just varying from one OOTW to the next), particularly on policy issues. Thus, the IOC exchanges information with several sources, in some cases including non-US authorities. The existence of this network structure helps explain the outsize military headquarters (for comparable combat force size) required for an OOTW: extensive liaison activities are an integral part of the mission. Another reason for extreme size is to exercise control over resources often found in other organizations, e.g., a division headquarters controlling national technical means of intelligence, civil affairs, PSYOP, special forces, a joint information bureau, and constabulary forces.

Analytical support tools (shown as ellipses in Fig. 5) might be useful at several points in the interagency process. First, a checklist type tool is needed to help in assigning tasks to agencies from the sector/task matrix (under development by IDA). The cells of the matrix contain the names of the US government lead agency and supporting agencies for that combination of sector and task. The checklist is used to formulate the mandate for the operation and to establish the coordination and collaboration architecture for the operation so that the appropriate participants can establish connectivity and exchange relevant information by task within sector. This checklist and its supporting details

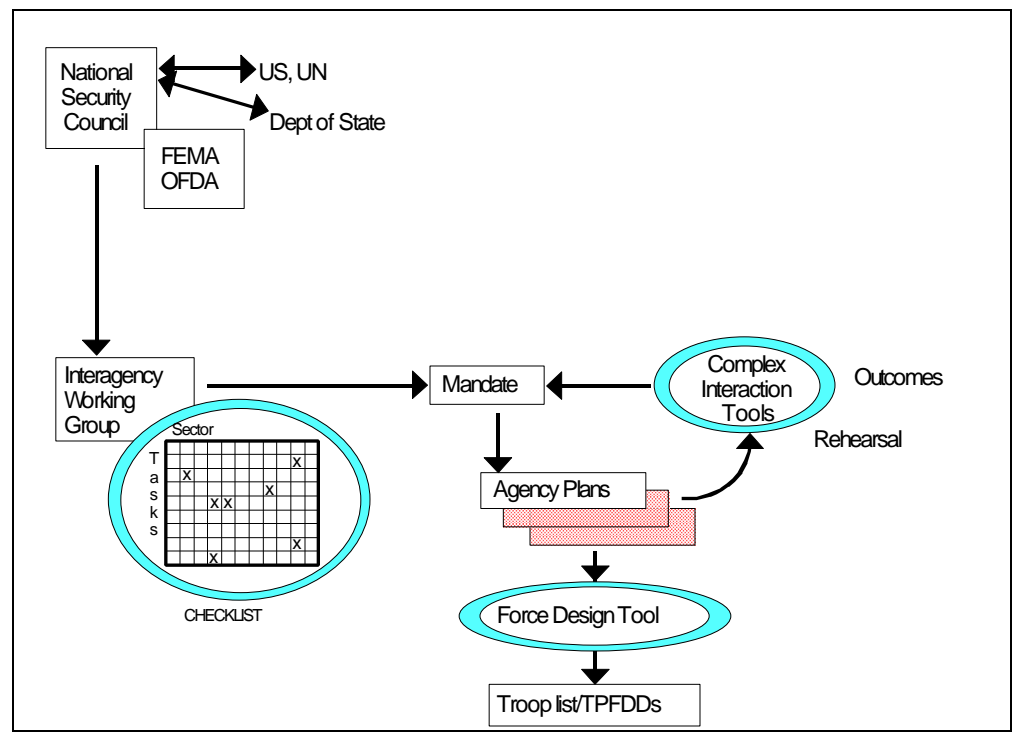

Fig. 5. National processes. should form the basis for the Integrated General Task List (IGTL) needed by the force design tool (specified in Section 5). Second, a force design tool is needed to support creating a troop and equipment list from multi-agency/interagency plans (including military assigned tasks and military support for civilian agencies when required). And, third, complex interaction tools are needed to help evaluate outcomes (impact analysis) and provide a rehearsal capability. The results from the impact analysis and rehearsals may require modifications to the mandate.

As a practical matter, DoD might recognize the need for these tools and go so far as to create them; however, if no other agency knew about them or were interested in using them, their value would be practically nil. While there is no guarantee that their value will be realized, there is an interagency task force concerned with interagency mechanisms, under the leadership of Ambassador Oakley at the National Defense University, and this task force is involved with these concepts and may effect their acceptance. 


\section{FORCE DESIGN TOOL SPECIFICATIONS}

The national level working group validated a requirement for a force design tool. The force providers working group also identified requirements for an operational force design tool at the CINC Service Component level and for a common cumulative force design tool to support total force definition questions, e.g., for QDR analyses. The CINC working group asserted that the CINCs have no current need for a force design tool; however, that may change at some time in the future.

Figure 6 shows a variation of a useful software design concept, the "Integration Definition for Function modeling" (IDEF) process block. Each process within a piece of software has its required inputs and outputs. In addition, the process has required resources (the standard is mechanisms). Here we will confine resources to data that is drawn from databases, as opposed to user input. The fourth component of the IDEF process block is the controls for the process, which consist of such things as doctrine and rules. A piece of software is (theoretically) defined by decomposing each process block into

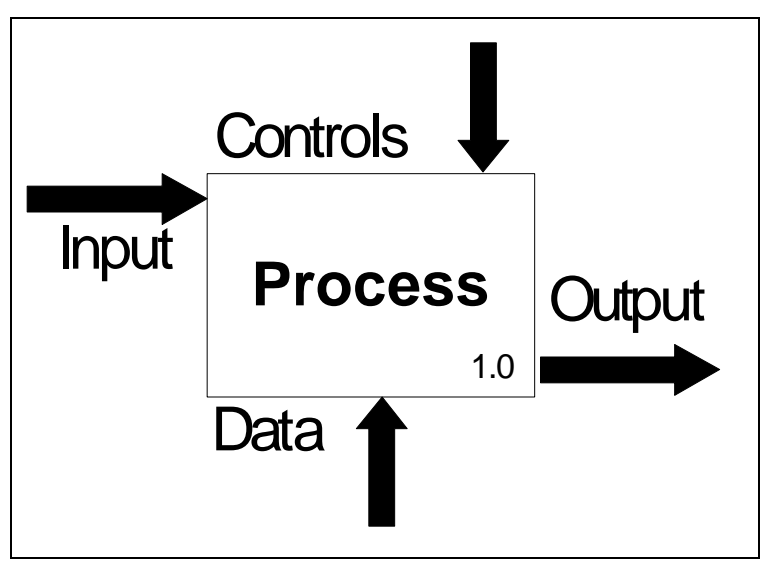

Fig. 6. IDEF process block.

smaller blocks until the smallest blocks are simple pieces of code, each with its four readily defined components. Note that this process block is numbered 1.0, indicating a top level process. In our case, we define the top level by replacing the label "Process" with "Force Design Tool," and leaving the four components to be defined as the block is decomposed.

The force design tool may be used to design forces for a particular mission, a static structure, or to investigate the impact of multiple missions, a dynamic structure. In this section, the static structure will be discussed first, developing most of the details of the force design tool, followed by a brief discussion of the dynamic structure. General constraints on the force design tool will be discussed, followed by a list of the data requirements for the tool.

\subsection{STATIC FORCE DESIGN STRUCTURE}

Figure 5 shows an illustrative decomposition of our top level process into six processes. Your descriptions of how you actually do mission planning will drive the actual decomposition. Note that some inputs are labeled "Choices" to indicate user input and some inputs "Externals" to indicate user input of coalition, NGO/PVO, etc., data to supplement the indicated process data, which may contain only US forces' data. Note also that no processing sequence is implied, as long as the sub-processes can operate on null or partial input. This means that iterative processing is not explicitly shown. 


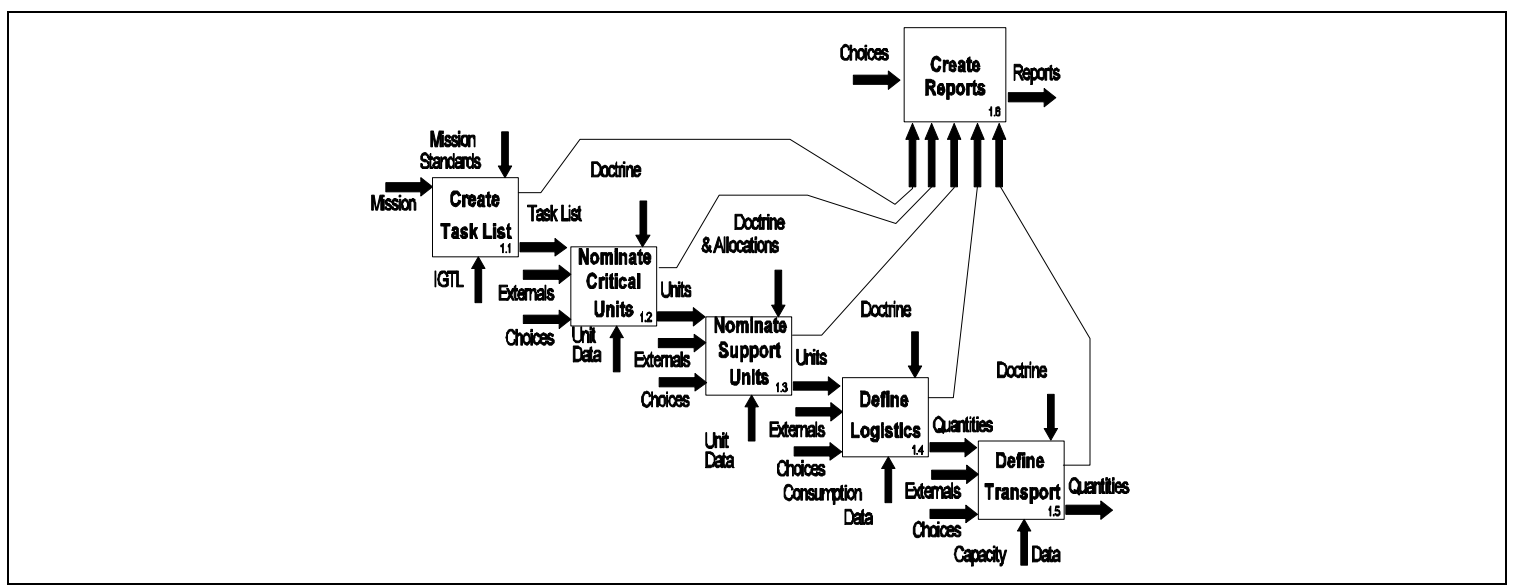

Fig. 7. Illustrative decomposition.

\subsubsection{Generating OOTW Mission Tasks}

The function of process 1.1 is to create a list of tasks (with associated schedules) for this particular mission from a generic task list. The data item in Fig. 8 is the (proposed) IGTL, which combines non-DoD tasks with a version of the UJTL that is tailored to OOTWs. Other options are generic mission-type task lists, such as have been created by the Army Center for Army Analyses (CAA) OFP process, or task lists for previous actual operations. The inputs are derived from the mission under consideration and include in information to permit mission sizing (e.g., food for 5000 people/day). The

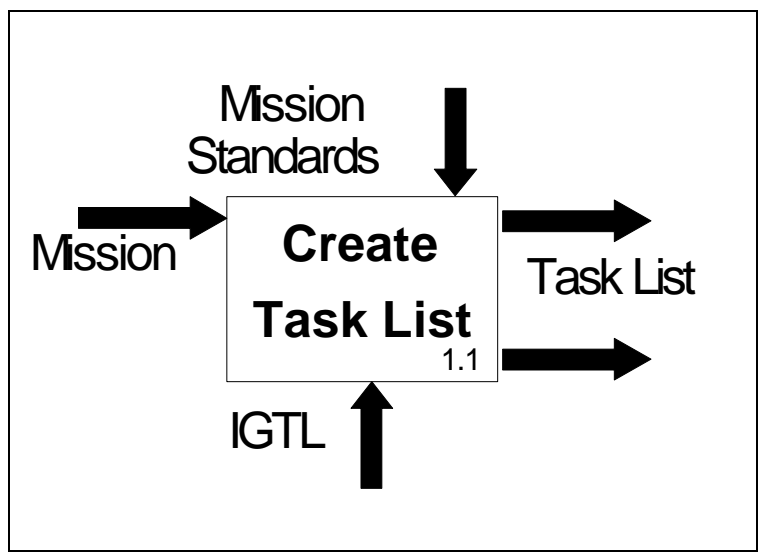

Fig. 8. Create mission task list. output task list is shown as being used for two purposes (shown in Fig. 7 as input to the next process and data for the report process). The controls are derived from Mission Standards (DoD standards, general U.S. standards, or international standards, as appropriate). This description is a perfect fit for the MRM and need not be duplicated.

The object of process 1.1 is to support an accurate and complete analysis of the mission tasks. It should identify both those tasks that are central to the mission and any contingent tasks that might be implied by reasonable shifts in mission definition. It should also support replanning as the situation changes. The first goal is to identify tasks concerning:

- $\quad$ infrastructure improvements;

- $\quad$ humanitarian operations;

- $\quad$ engineering support;

- $\quad$ medical support; 
- $\quad$ joint/interagency/coalition support;

- $\quad$ indigenous/client/refugee support, including location tracking;

- $\quad$ communications, including non-standard communications with other government agencies, coalition forces, host government, and NGOs/PVOs;

- ISR concerning threat, friendly and neutral elements and environmental information;

- $\quad$ media and public affairs support;

- $\quad$ PSYOPs; and

- $\quad$ adequate protection of all forces, including other agencies, coalition forces, and NGO/PVOs.

The second goal is to identify whether tasks involving in use of force (whether lethal or non-lethal) are required.

The intent of process 1.1 has been specified; however, there are still questions that remain unanswered that impact the methodology for accomplishing it. Some of the questions relate to the flow of using the force design tool, as shown in the two steps below:

1 Break out set of tasks relevant to the type of mission.

(How is this done? Is it a direct process or does it require iterations to discover implied tasks?)

2 Select the tasks relevant to this particular mission.

(How is this done? If the first step involves an iteration process, is this step included in the iteration or is the first step completed first? Does the user separate the tasks by Federal Agency, Coalition partner, Service, NGO/PVO at this point or sometime later or never?)

\subsubsection{Nominating Units}

The function of process 1.2 is to create a list of units (with time schedules) that will satisfy the mission critical tasks (Fig. 9). The task list comes from process 1.1. Process 1.2 can be split into two sub-processes, 1.2.1 and 1.2.2, to allow nomination of generic units and actual units (Fig. 10). The externals input refers to host nation "units," other countries' military units, other U.S. agencies' "units," and NGO/PVO "units" that have been defined as participating. The presence of these "units" will reduce the critical tasks required for U.S.

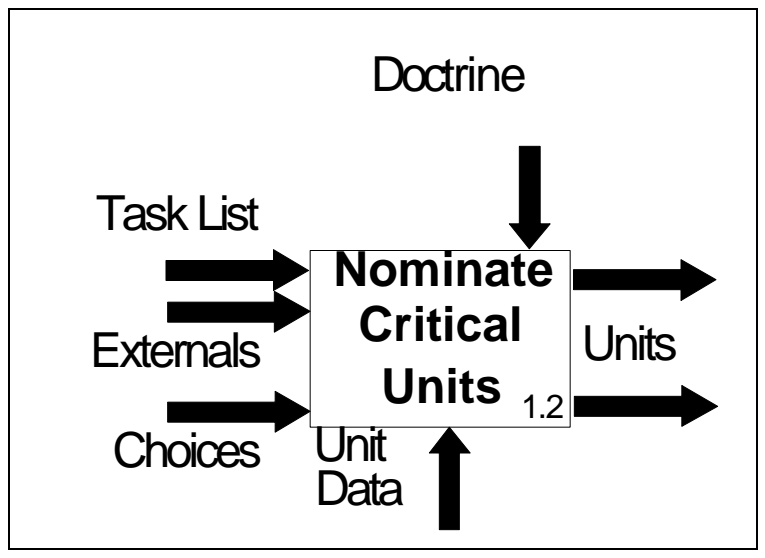

Fig. 9. Nominate mission critical units. 
military units and (perhaps) increase the support tasks required in process 1.3. The unit data that are required here include the capacity of units to perform tasks in the task list; the effects of tempo (and the performance of the task itself) on readiness, training, and equipment depreciation; and the recovery times required. Ideally, all potential "units" will have these data provided in the automatic database; however, some of the external inputs will be capacity data that are missing or that need to be revised for this mission. The other input category consists of the user's choices among "units" that can

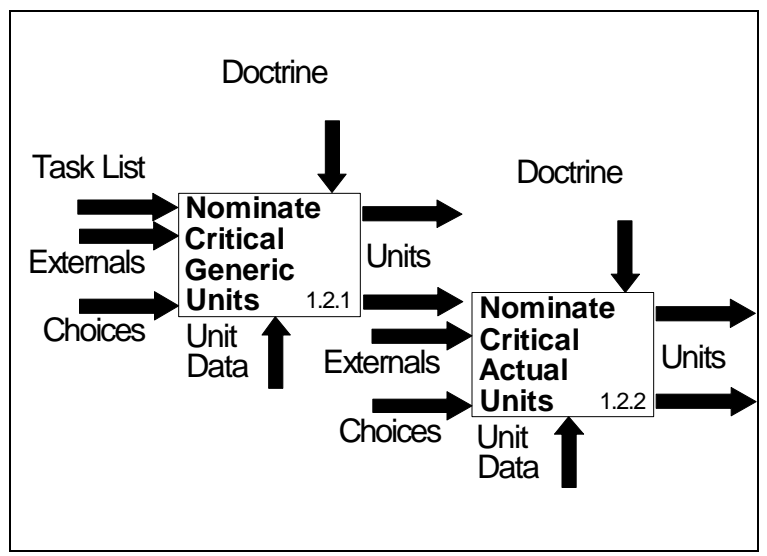

Fig. 10. Nominating generic and actual units. perform the critical tasks. The output unit list will be used both in process 1.3 and in the report process.

The function of process 1.3 is to create the complete list of units to satisfy all mission tasks (Fig. 11). Additional units are added in this process to provide the necessary support to the units defined in process 1.2. The separation of the unit nomination process into two parts is a matter of convenience, as it provides a natural method of making the nomination process simpler for the user. It also provides a division of doctrinal rules, allowing for a simpler computer calculation process. Process 1.3 includes the nomination for support tasks such as chaplain services and food preparation, the definition of command and control structures to ensure that the overall force is functional, and the definition of inseparable unit and equipment structures (for example, if a required unit implies that a ship must be committed to the operation, that implication is manifested here).

Figure 12 shows the decomposition of process 1.3. In addition to the nomination of generic and actual units, there is process to organize all of the elements into a workable command structure. Process 1.3.3 allows the option of automatically iterating over a

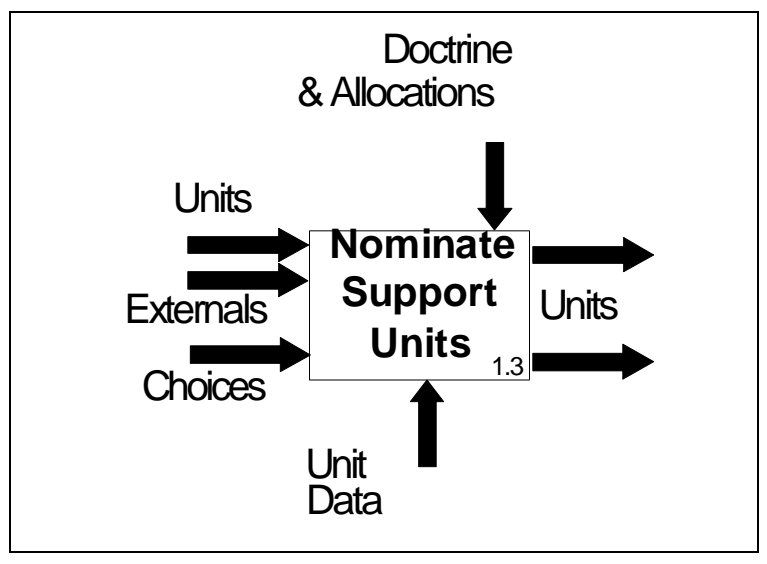

Fig. 11. Nominate supporting units.

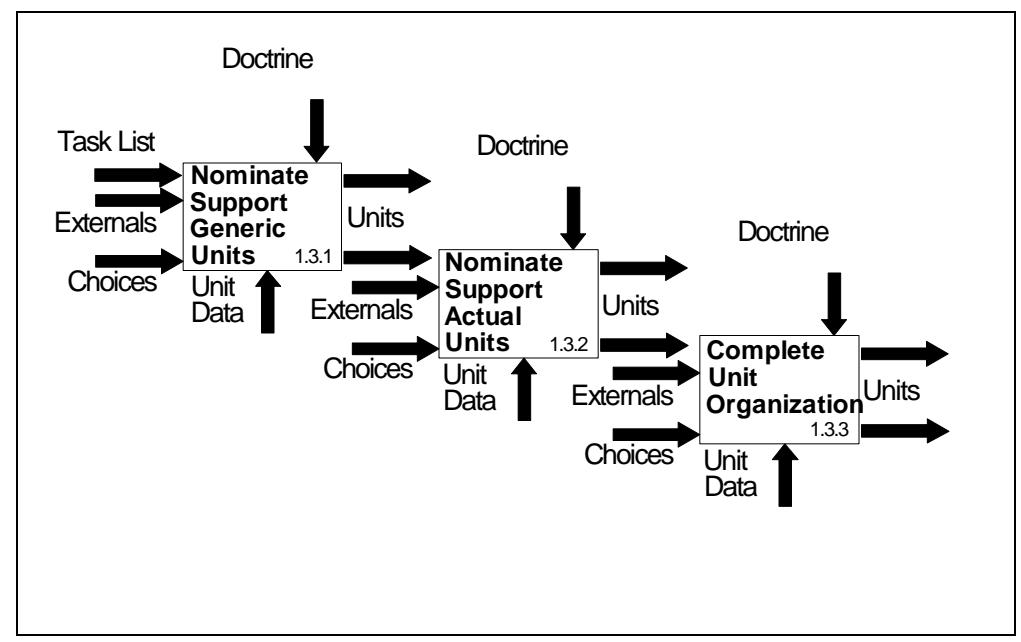

Fig. 12. Nominating generic and actual units and completing unit organization. 
set of allocation rules to size supporting units by integral number or fractional size (depending on the rules), including headquarters units. The processes should have the functionality to reduce total size to an input value and compare performance values (based on capability factors). The process should have defaults that indicate doctrinal choices where they have been defined.

The object of processes 1.2 and 1.3 is to support the designation of U.S. forces required for an operation in an OOTW context. The processes connect the tasks to generic resources and may connect generic resources to actual available resources, including U.S. military, U.S. non-military, foreign government, NGO/PVO, and contractor resources. Data requirements include task capability for all resources (or the facility for user input for unique resources) and availability data (based on reserve commitments, etc.). The data should provide for restrictions on choices based on cultural issues. Processing should include selection of military resources and substitution of other resources. The processes should also support replanning as the situation changes. The first goal is to identify human resources, materiel and procedures. The concerns that must be addressed include:

- $\quad$ heavy vs light forces and weapons mix plus forces needed to open and maintain LOCs;

- $\quad$ active vs reserve forces, service mix (including Coast Guard), and coalition force mix (conditioned on the range of expected contributions by civilian organizations, including NGO/PVOs);

- $\quad$ readiness and availability of U.S. military forces, U.S. agency elements, and coalition elements;

- $\quad$ requirements to support media and public affairs;

- $\quad$ forces to support military contingency operations;

- $\quad$ balancing tooth to tail ratio;

- $\quad$ balancing effectiveness vs availability/feasibility;

- $\quad$ reserve call-up (requires maintenance of information on immediate availability of reserves and availability of active service time);

- communications, including non-standard communications with other government agencies, coalition forces, host government, and NGOs/PVOs;

- determining redeployment priorities, comparing effectiveness in current and future tasks against the availability or feasibility of alternative options (including consideration for rotation of troops);

- $\quad$ determining what retraining, etc., is needed to reconstitute the forces; and

- $\quad$ gathering and codifying the cultural issues and to identify proper procedures with respect to cultural issues.

The second goal is to provide a framework for the METT-T analysis, answer "what-if" questions, and identify necessary materiel, human resources and procedures.

The intent of processes 1.2 and 1.3 have been specified; however, there are still questions that remain unanswered that impact the methodology for accomplishing it. Some of the questions relate to the flow of using the force design tool (including the possibility of alternative flows), as shown in the two steps and their sub-steps below:

$1 \quad$ Make (generic) type selections. 
(Does the user start with a size restriction or leave that until last, etc.? Does the user make one pass for the central mission task all the way through and then determine what support units are required? Will the user want to skip the generic step because he or she has the information on what forces can be nominated and selecting a generic unit that isn't available is a waste of time?)

1.1 Input all tasks then select by logical groups of tasks.

(Does the user start with tasks that require special units to get that out of the way or start with the central mission task, etc.?)

1.2 Select all (or at least more than one) possible type units for each task or group of tasks.

(Does the user try to maintain Service contributions at a given level or percentage? Is this something one might have to do occasionally but not usually?)

Refine selections to actual forces/resources.

(Is this really easy because there are limited choices in most instances? Are units time-phased at this point?)

$2.1 \quad$ Pick one:

Alternative 1: first, eliminate all non-available forces/resources.

Alternative 2: first, rank preferences.

Alternative 3: first, apply external constraints (total force size, etc.).

Alternative 4: first, allocate all forces/resources to be supplied externally (coalition, NGO/PVO, etc.).

2.2 Second, do one of the alternatives not picked as first action.

2.3 Third, do one of the alternatives not already picked.

2.4 Do the last alternative.

2.5 Decide what to do about short-falls in task accomplishment.

\subsubsection{Defining Logistics}

The function of process 1.4 is to define the logistics requirements for the force (Fig. 13). The "units" that have been defined will require food, water, and other classes of supply, based on unit factors, time, environment, etc. Some of the logistics will be supplied by external (nonDoD) sources. In addition, some items may be "forced" into the solution that were not implied by previous inputs. The output quantities will include bulk measurements (tons, gallons, etc.),

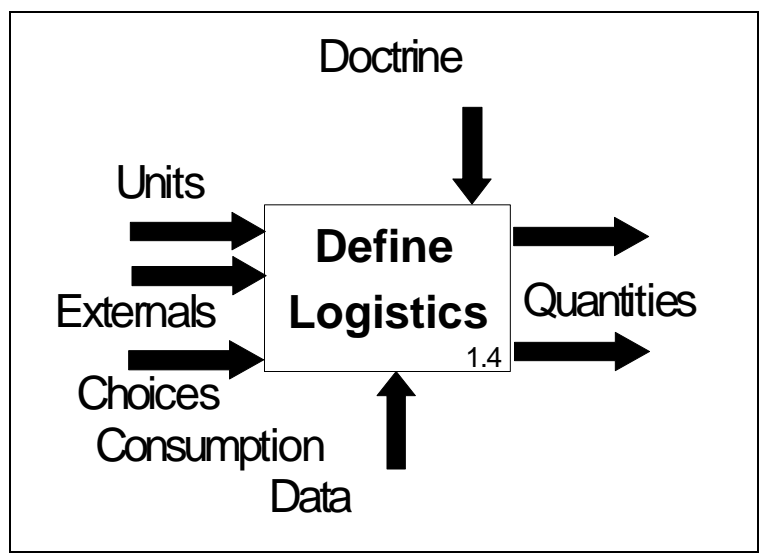

Fig. 13. Define the implied logistics requirements.

size measurements, and item quantities, as appropriate. The quantities will also be tied to a time schedule. 
The object of process 1.4 is to support the logistics analysis of the mission in an OOTW context. It should derive the logistics requirements from the total force structure. It should allow for supply from outside sources and provide for supply of non-military personnel. It should support replanning as the situation changes. The goal is to plan for adequate logistics and supply for all mission forces and to support humanitarian mission needs.

\subsubsection{Defining Transport Requirements}

The function of process 1.5 is to define the transportation requirements for the force (Fig. 14). Two tools already exist that are adequate for this purpose, the Model for Intertheater Deployment by Air and Sea (MIDAS) and the Joint Flow and Analysis System for Transportation (JFAST). The appropriate choice depends on the level of detail required in the transportation planning. The force design tool being defined here should not replicate this function: it should be designed to format and pass information to both MIDAS and JFAST (or other selected tools). This process should also accept data from these tools to support comprehensive analysis of the force design.

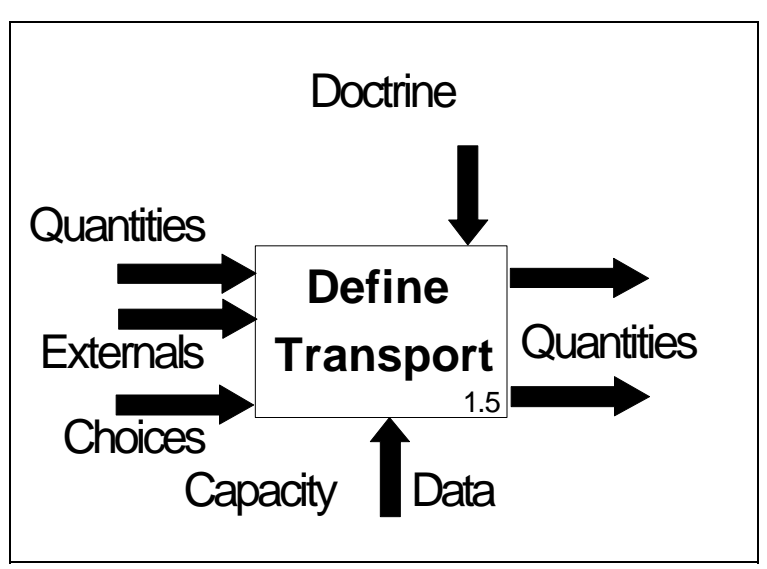

Fig. 14. Define transport.

The object of process 1.5 is to support the transportation analysis for mission arrival, sustainment, and departure in an OOTW context. It must support replanning when the situation changes after some transport has been accomplished. The goal of process 1.5 (when combined with the transportation planning tool) is to plan for all transportation related support:

- $\quad$ determine the sequence of arrival by units required to accomplish the mission and provide security;

- determine deployment priorities to resolve bottlenecks;

- determine availabilities and capabilities of the transport resources needed to accomplish the mission, including any transport needed for other agencies, coalition partners, and NGOs/PVOs;

- $\quad$ establish LOCs;

- $\quad$ plan for transportation support for mission forces, including appropriate NGOs/PVOs and media personnel;

- $\quad$ determine the sequence of departure of units required to accomplish the mission and provide security; and

determine availabilities and capabilities of the transport resources needed for departure, including any transport needed for other agencies, coalition partners, and NGOs/PVOs. 


\subsubsection{Performing Trade-Off Analysis and Generating Reports}

The function of process 1.6 is to produce reports about the force being designed (Fig. 15). The process should be capable of producing reports to aid in the design process and to aid in the analysis of the finished force. The process should produce various totals and breakdowns, such as time phased troop and equipment lists, rotation schedules, degradation values, breakdowns of forces by function (extended tooth-to-tail analysis), breakdowns by active vs reserves, and breakdowns by Service. It should also report on the capability of the selected force to perform various parts of mission (percentage of tasks completed, security risk) and the amount of excess capability allocated. The process should also produce outputs that can be fed into COST (to compute incremental costs of the mission).

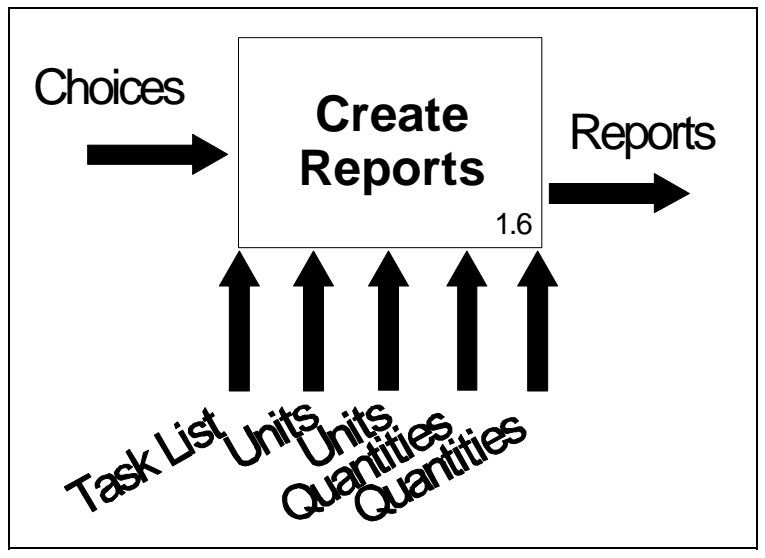

Fig. 15. Force design reporting process.

\subsection{DYNAMIC FORCE DESIGN STRUCTURE}

Part of the need for a force design tool consists of a requirement to analyze the resource drain on U.S. capabilities created by multiple simultaneous and sequential OOTWs. The ability to accumulate a set of OOTWs over a span of time is referred to here as dynamic structure. For this purpose, the report process must be expanded to cover the cumulative results over the time frame, such as call-up of reserves, depreciation of equipment, on-going reconstitution of forces, and rotation schedules, as illustrated in Fig. 16.

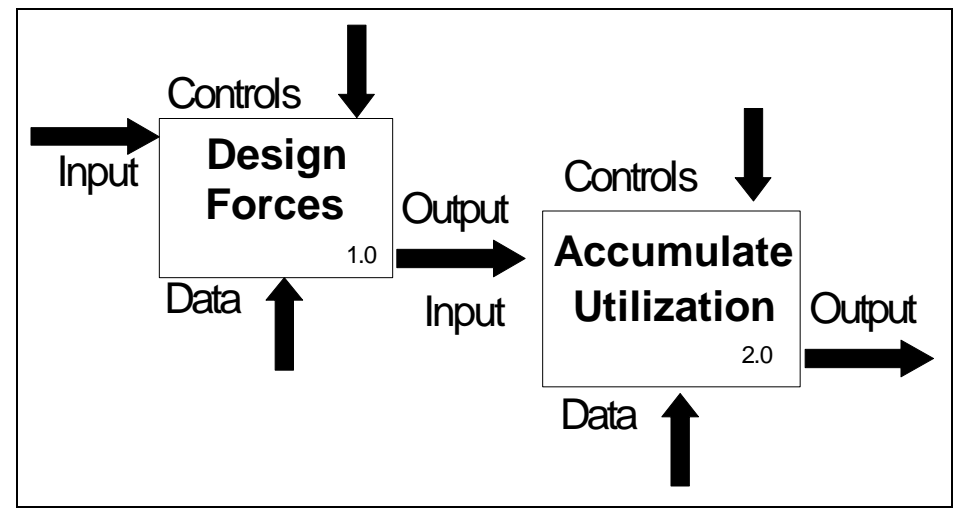

Fig. 16. Accumulating multiple OOTWs. 


\subsection{DATABASE REQUIREMENTS}

The data requirements to support force design planning are surprisingly large. Four categories of data are defined: task data, unit list data, unit and resource data, and doctrine and allocation rules.

\subsubsection{Task Data}

Table 14 begins the description of the task data requirement by identifying two categories of task data: a complete list of possible tasks and various subsets. The table also presents initial data sources.

\section{Table 14. Task data}

\begin{tabular}{ll|l}
\hline \hline Data & Source \\
\hline - & $\begin{array}{l}\text { The IGTL, a general task list for all } \\
\text { concerned organizations }\end{array}$ & $\begin{array}{l}\text { Initially from IDA project (Martin Lidy) or from the } \\
\text { UJTL, augmented by the user. Ultimately a Joint } \\
\text { responsibility } \\
\text { Joint conferences }\end{array}$ \\
\hline & $\begin{array}{l}\text { Specialized subsets of the IGTL, } \\
\text { customized for particular OOTW types }\end{array}$ & \\
\hline \hline
\end{tabular}

\subsubsection{Unit List Data}

Table 15 identifies categories of unit list data that will be needed. The table also presents initial data sources.

Table 15. Unit list data

\begin{tabular}{ll|l}
\hline \hline Data & & Source \\
\hline - & Unit lists from previous missions & Users \\
Earlier versions of the unit list for the & Users \\
& $\begin{array}{l}\text { current mission } \\
\text { MTOF-like unit lists for generic mission } \\
\text { types }\end{array}$ & Start with CAA MTOFs, build joint MTOFs \\
\hline \hline
\end{tabular}

\subsubsection{Unit and Resource Data}

Table 16 identifies categories and subcategories of unit and resource data that will be need table also presents initial data sources. 
Table 16. Unit and resource data

\begin{tabular}{|c|c|c|}
\hline Data & & Source \\
\hline \multirow[t]{6}{*}{ - } & $\begin{array}{l}\text { Generic unit data: database contains force types for all Air Force, } \\
\text { Army, Coast Guard, Marines, Navy, most likely allies and major } \\
\text { NGO/PVO/IOs and is maintained by OSD Joint Data Support (JDS) }\end{array}$ & Services \\
\hline & $\begin{array}{l}\text { Each force type in database is described by its consumption } \\
\text { and transportability factors }\end{array}$ & JEB \\
\hline & $\begin{array}{l}\text { Each force type in database is described by its capabilities } \\
\text { to do work }\end{array}$ & CAPS \\
\hline & Each force type contains unit equipment & \\
\hline & $\begin{array}{l}\text { Each force type in database can be decomposed and its } \\
\text { descriptions are automatically decomposed }\end{array}$ & \\
\hline & Data to support cultural restriction tests & \\
\hline \multirow[t]{5}{*}{ - } & $\begin{array}{l}\text { Actual unit data: database contains real (named) forces and is } \\
\text { maintained by JDS Each real force has a connection to a force type }\end{array}$ & $\begin{array}{l}\text { Services, FA\&CT, } \\
\text { COST, SeaState, } \\
\text { FALCON }\end{array}$ \\
\hline & $\begin{array}{l}\text { Each real force has the same data types as the generic unit } \\
\text { data }\end{array}$ & \\
\hline & $\begin{array}{l}\text { Each real force has availability data (e.g., } x \text { days left of } \\
\text { reserve call-up, y days required to disengage from current } \\
\text { activity) }\end{array}$ & \\
\hline & Each real force has readiness data, by type OOTW & \\
\hline & $\begin{array}{l}\text { Each real force has reconstitution requirements by type } \\
\text { OOTW }\end{array}$ & \\
\hline \multirow[t]{4}{*}{ • } & Resource data: & \\
\hline & Equipment has depreciation data, by type ООTW & FALCON \\
\hline & Communication equipment has interoperability data & \\
\hline & $\begin{array}{l}\text { Resources have size, weight, transportability factors, and } \\
\text { task capability factors }\end{array}$ & FA\&CT \\
\hline
\end{tabular}

\subsubsection{Doctrine and Allocation Rules}

Table 17 identifies categories and subcategories of doctrine and force allocation rules that will be needed as controls. The table also presents initial data sources. 
Table 17. Doctrine and allocation rules

\begin{tabular}{|c|c|c|}
\hline Control I & & Source \\
\hline $\begin{array}{l}\bullet \\
\bullet \\
\bullet\end{array}$ & $\begin{array}{l}\text { Concurrencies vs exclusiveness of tasks } \\
\text { Expected or required tasks, by type OOTW } \\
\text { Normally implied additional tasks for each task }\end{array}$ & Joint conference \\
\hline $\begin{array}{l}\bullet \\
\bullet \\
\bullet\end{array}$ & $\begin{array}{l}\text { ctrine } \\
\text { Preferred unit size } \\
\text { Cultural restriction rules } \\
\text { Preferences for unit/task combinations }\end{array}$ & Services, joint doctrine \\
\hline • & $\begin{array}{l}\text { ce doctrine } \\
\text { Preferences for equipment or resource/task combinations }\end{array}$ & Services, joint doctrine \\
\hline $\begin{array}{l}\bullet \\
\bullet \\
\bullet\end{array}$ & $\begin{array}{l}\text { zational doctrine } \\
\text { Rules on unit separation and tailoring for partial units } \\
\text { Rules on } \mathrm{HQ} \text { tailoring } \\
\text { Rules for mandatory inclusion of additional units (e.g., } \\
\text { whole ship required) }\end{array}$ & $\begin{array}{l}\text { Services, joint doctrine } \\
\text { FAST-OR } \\
\text { FAST-OR } \\
\text { SeaState }\end{array}$ \\
\hline$\bullet$ & cs doctrine & JEB \\
\hline$\bullet$ & ortation doctrine & USTRANSCOM \\
\hline • & $\begin{array}{l}\text { Unit rotation } \\
\text { Reserve usage } \\
\text { Depreciation } \\
\text { Reconstitution }\end{array}$ & $\begin{array}{l}\text { OSD, Services, joint } \\
\text { doctrine } \\
\text { FALCON } \\
\text { FALCON } \\
\text { FALCON } \\
\text { FALCON }\end{array}$ \\
\hline
\end{tabular}

To be useful, these data need to be current, which implies a requirement for data maintenance procedures. Where possible, the data should be drawn from standard sources, rather than compiled manually. The data structures need to be designed both for efficient access by the force design tool and for comprehensible access to a user needing to alter or understand the data. As data to be used by a joint tool, the Joint Data Support (JDS) organization is a natural choice as the organization to maintain the data.

In addition to data to support the use of the force design tool, data are required that describe the methodology for calculating requirements to support software design. Rules on defaults and formulas are required. For example, food provision would be based on number of people to be fed and any unique dietary requirements for that population. Additional data would be required to define the type of food and how to calculate the amount to be provided. 


\subsection{OPERATIONAL CONSIDERATIONS}

Several conditions on the operation of a useful force design tool form a framework for specifying the tool:

1 The operator will make selections, not the computer (although it may produce default suggestions);

1.1 the operator controls the force nomination process by deciding upon alternatives and tailoring forces;

1.2 the operator can create new forces to represent things not in the databases;

1.3 the operator selects the time phases for when units are needed; and

1.4 the operator can override data recommended or provided by the tool.

2 Although a structured input sequence should be available to ensure that a novice user considers all necessary factors and to enable post-entry error detection, the structured sequence should not prohibit alternate sequences;

2.1 a novice user should be able to construct the entire force design; and

2.2 a sophisticated user should be able to bypass parts of the system.

3 Differing levels of resolution should be achievable,

3.1 generic forces,

3.2 tailored generic forces,

3.3 mixed generic and actual forces, and

3.4 actual forces.

4 The process is re-entrant, permitting iterative decision making

4.1 tasks can be added or deleted at any time in the process (allows iterative design),

4.2 changes will be needed that require recalculation.

5. Infrastructure impact should be minimal;

5.1 the tool should run on a mid-level PC; and

5.2 training requirements should be minimal.

A task hierarchy for a humanitarian assistance operation might resemble the one in Table 18.

Table 18. Task Hierarchy

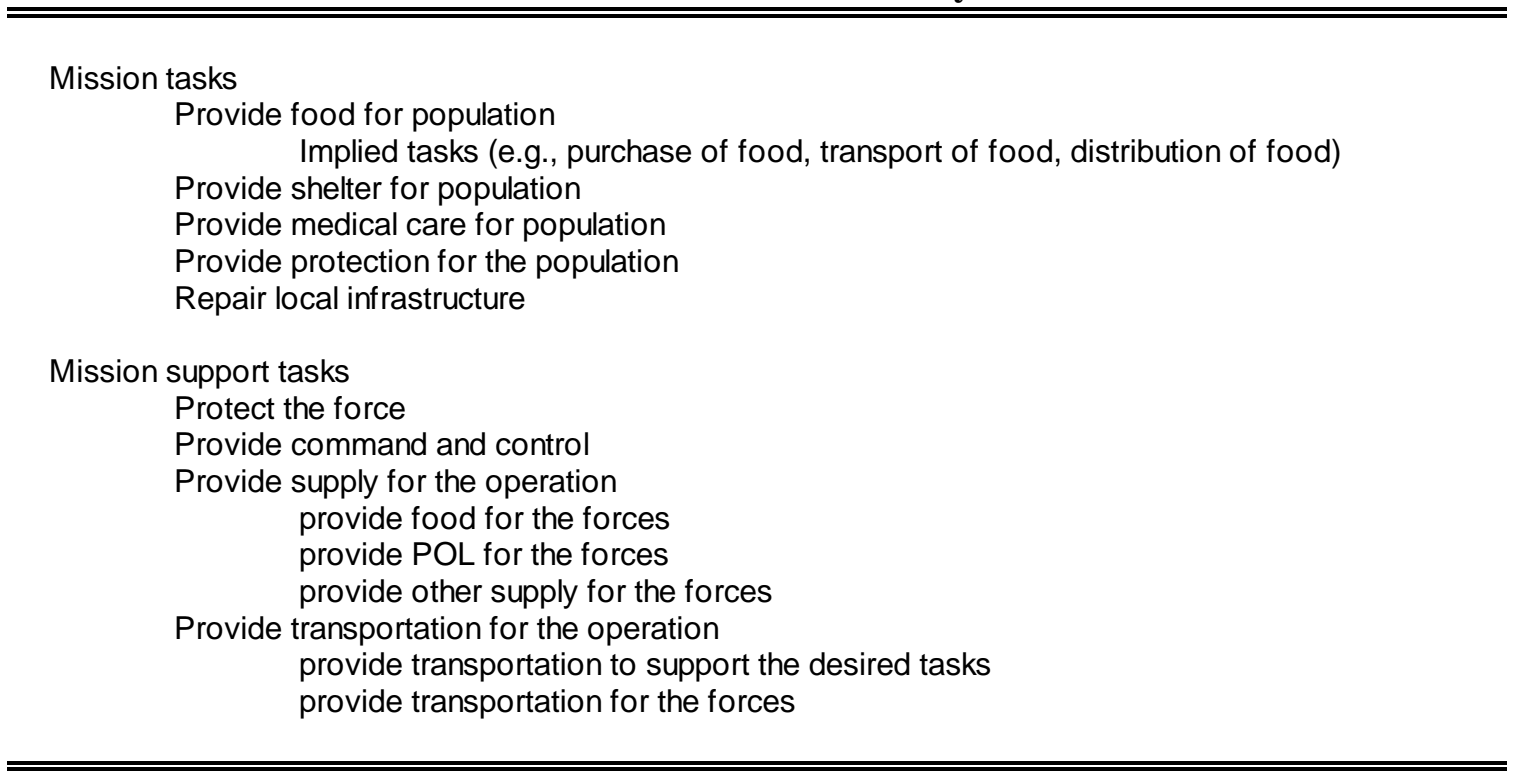

The means of accomplishing each task would be provided by selecting a "unit of force" from among the following providers: host nation, NGO/PVO, allies, US non-DoD Agencies (e.g., Coast Guard and 
Federal Emergency Agency (FEMA)), Special Operations Forces (SOF), Army, Navy, Marine Corps, Air Force, or the task could be omitted. Each task should be filled by the smallest unit of each type with the organic capability to perform the task. It is assumed that subtasks would generally yield smaller units. Higher level tasks will generally be left blank as they will be task organized.

The choices made will generate a bare set of requirements, e.g., 347 cooks needed. From these requirements, task organization decisions are required to define a manageable force. Recalculation of required tasks may necessitate further iterations; however, the user must be able to make decisions contrary to the planning factors. For example, the planning factors may indicate 347 cooks are needed and organizational structure says that a normal structure would yield 346 cooks. Providing the extra cook would mean adding another unit. Obviously, the factors are imprecise enough that 346 cooks are ample or an extra cook could be added to a unit. The user should be able to override the calculation.

The system can be designed so that information can be entered at any level, overriding the calculations of previous levels. For example, the user may start with the force choices and then proceed to the transportation and logistics requirements; however, if the user overrides formulas with firm numbers (as would happen in a standard spreadsheet override), there will be problems when revisions are required later, because the formulas are no longer available.

However, with a different implementation approach, the latter problem can be overcome. The Quicken ${ }^{\mathrm{TM}}$ program provides a simple example. In purchasing stock, the calculation is price per share (Price) times number of shares (Shares) plus purchase costs (Commission) equal total cost (Cost):

$$
\text { Price } * \text { Shares }+ \text { Commission }=\text { Cost. }
$$

A user generally has a broker's statement with these four numbers in hand while entering his purchase into Quicken and enters all four numbers into the program. Occasionally, the numbers on the statement are rounded off so that the calculation from the input does not generate the required equality. Quicken then asks which number to modify, suggesting that Price is the most likely one to change. This philosophy catches errors while allowing for user decisions.

Applying this philosophy to the case at hand would be more complex, but would yield benefits. In the example of the cooks above, the user would be asked whether to change the food production rate (in this instance) for the cooks, or the number of people to be served, suggesting the food production rate as causing the least repercussions elsewhere. In an unlikely, but simple to describe, application of an expert direct entry, the user inputs the unit containing 346 cooks and the other forces, the system calculates that 46 cooks are required for the defined forces and determines that the population to be served is the number that can be supported by 300 cooks. This philosophy permits the direct entry of decisions, while permitting later changes of logically earlier data, because the data and mathematical relationships are created and preserved, rather than being simply overridden.

As defined to this point, the system requires all tasking and unit/resource decisions to be made at the lowest level. One method of permitting rough estimates to be made at a lower level of resolution consists of using default choice sets. Another method consists of choosing fairly large military units and calculating task shortfalls, then adding additional units until the shortfalls either disappear or are 
acceptably small. If possible, both methods (plus combinations) should be implemented because this increases the flexibility of the approach methods available to the user.

\subsection{FORCE DESIGN CONCLUSION AND ROADMAP}

The MRM is the only candidate for the task analysis portion of the specifications; however, it appears to be entirely sufficient for that portion. Similarly, MIDAS and JFAST (depending on the detail required) are the proper tools to handle the transportation portion of the specifications. Of the existing tool set, only CAPS and JEB have a joint orientation and have sufficiently comprehensive structures to support the remaining specifications described here. Even so, either would require substantial modifications. Table 19 contains a detailed comparison of the necessary characteristics, their weights, and the support that each of the active tools (MRM, CAPS, JEB, MIDAS/JFAST, FA\&CT, FALCON, and SEASTATE) provides for each characteristic. The entries in the table for CAPS and JEB indicate support for a characteristic or an estimate for the effort required to support it $\$=$ low, $\$ \$=$ moderate, $\$ \$ \$=$ high). The entries for the Service tools indicate support for a characteristic, Service-specific support, or non-support. Question marks are used where available documentation was insufficient to assess the tool's capability. The total effort in terms of "\$" for each weight level is used to provide an overall expandability rating for CAPS and JEB.

Table 19. Force Design Tool Characteristics

\begin{tabular}{|c|c|c|c|c|c|c|c|c|}
\hline CHARACTERISTICS & $\backslash$ TOOLS & MRM & CAPS & JEB & $\begin{array}{l}\text { MIDAS } \\
\text { JFAST }\end{array}$ & FA\&CT & FALCON & SEASTATE \\
\hline Joint & $* * *$ & yes & yes & yes & yes & no & no & no \\
\hline Mission-to-task & ** & yes & $\$ \$ \$$ & $\$ \$ \$$ & $\mathrm{~N} / \mathrm{A}$ & no & no & no \\
\hline Full mission set & * & yes & $\$$ & $\$$ & transprt & no & no & no \\
\hline Full task set & * & yes & $\$$ & $\$ \$$ & transprt & no & no & no \\
\hline $\begin{array}{l}\text { Permits support to other Services, } \\
\text { refugees, allies }\end{array}$ & * & yes & $\$ \$$ & $\$ \$$ & yes & no & no & no \\
\hline Service doctrine & * & yes & $\$ \$$ & $\$ \$$ & yes & Army & Air Force TacAir & Navy \\
\hline Full range of forces & ** & yes & yes & $\$ \$ \$$ & $\mathrm{~N} / \mathrm{A}$ & no & no & no \\
\hline Time phasing & ** & yes & yes & $?$ & yes & yes & yes & yes \\
\hline Pre-built scenarios & & yes & yes & $?$ & $\mathrm{~N} / \mathrm{A}$ & Army & Air Force TacAir & Navy \\
\hline Modify previous plans & ** & yes & yes & $?$ & yes & yes & yes & $?$ \\
\hline Host nation can offset US efforts & * & yes & yes & $\$$ & yes & ? & $?$ & ? \\
\hline Task structure for deciding on units to use & ** & no & yes & $\$ \$ \$$ & transprt & Army & Air Force TacAir & Navy \\
\hline Workloads by UJTL & ** & no & yes & $\$ \$ \$$ & no & Army & no & Navy \\
\hline Units have capacity to do work & ** & no & yes & $\$ \$ \$$ & transprt & Army & Air Force TacAir & no \\
\hline $\begin{array}{l}\text { Allocation/splitting rules for workload, } \\
\text { including } \mathrm{HQ} \text { units \& tailored sizes }\end{array}$ & ** & no & some & $\$ \$$ & transprt & Army & no & Navy \\
\hline Security forces logic & ** & no & yes & $\$ \$ \$$ & no & Army & no & $?$ \\
\hline Task accomplishment report & ** & no & yes & $\$ \$$ & transprt & & & \\
\hline Excess capacity report & ** & no & yes & $\$ \$$ & transprt & & & no \\
\hline Task shortfalls report & ** & no & yes & $\$ \$$ & transprt & & & \\
\hline Logistic needs assessment & ** & no & $\$ \$ \$$ & yes & $\mathrm{N} / \mathrm{A}$ & & & \\
\hline
\end{tabular}


Table 19. Force Design Tool Characteristics

\begin{tabular}{|c|c|c|c|c|c|c|c|c|}
\hline CHARACTERISTICS & $\backslash$ TOOLS & MRM & CAPS & JEB & $\begin{array}{l}\text { MIDAS } \\
\text { JFAST }\end{array}$ & FA\&CT & FALCON & SEASTATE \\
\hline Actual forces & * & no & $\$ \$$ & yes & transprt & Army & Air Force TacAir & Navy \\
\hline Convert notional to actual units & * & no & $\$ \$$ & yes & yes & Army & Air Force TacAir & $?$ \\
\hline Unit transportation requirements & ** & no & $\$ \$$ & yes & $\mathrm{N} / \mathrm{A}$ & Army & no & $?$ \\
\hline Unit logistics data & ** & no & $\$ \$$ & yes & $\mathrm{N} / \mathrm{A}$ & $?$ & no & $?$ \\
\hline Transport calculations & ** & no & $\$ \$ \$$ & $\$ \$ \$$ & yes & no & no & no \\
\hline Coast Guard, Coalition, NGO/PVO units & * & no & $\$$ & $\$$ & yes & no & no & no \\
\hline $\begin{array}{l}\text { Considers Active vs Reserve unit } \\
\text { availability or readiness }\end{array}$ & * & no & $\$ \$$ & $\$ \$$ & ? & ? & Air Force TacAir & ? \\
\hline Tempo report & * & no & $\$ \$$ & $\$ \$$ & transprt & no & Air Force TacAir & $?$ \\
\hline Resource stress analysis & * & no & $\$ \$$ & $\$ \$$ & $?$ & no & Air Force TacAir & Navy \\
\hline Retraining/reconstitution calculations & * & no & $\$ \$$ & $\$ \$$ & $\mathrm{~N} / \mathrm{A}$ & no & Air Force TacAir & no \\
\hline Force allocation computation & & no & $\$ \$$ & $\$ \$$ & no & $?$ & Air Force TacAir & Navy \\
\hline Mix/sizing computation & & no & $\$ \$$ & $\$ \$$ & $?$ & $?$ & Air Force TacAir & $?$ \\
\hline Non-military $\mathrm{C} 2$ & & & & & yes & & & \\
\hline Allows future forces & & & $\$$ & $\$$ & $?$ & Army & $?$ & $?$ \\
\hline Help facility & & $?$ & yes & $?$ & yes & $?$ & $?$ & $?$ \\
\hline Accumulates for multiple OOTWs & ** & yes & $\$$ & $\$$ & yes & Army & Air Force TacAir & Navy \\
\hline Supported by standard external databases & * & yes & $\$$ & yes & yes & & & \\
\hline Data maintenance utilities & ** & $?$ & $\$ \$$ & some & yes & no & $?$ & $?$ \\
\hline $\begin{array}{l}\text { Collaborative planning on multiple } \\
\text { workstations }\end{array}$ & & yes & & yes & ? & & & \\
\hline Documentation & * & yes & yes & $?$ & yes & ? & $?$ & ? \\
\hline User Friendly & ** & yes & yes & $?$ & yes & yes & yes & yes \\
\hline Total effort (by weight) & $\stackrel{*}{*}$ & & $\begin{array}{l}12 \$ \\
18 \$ \\
16 \$ \\
\end{array}$ & $\begin{array}{l}7 \$ \\
15 \$ \\
30 \$ \\
\end{array}$ & & & & \\
\hline Overall Expandability & $* * *$ & $\mathrm{~N} / \mathrm{A}$ & excellent & OK & $\mathrm{N} / \mathrm{A}$ & poor & poor & poor \\
\hline
\end{tabular}

The specifications of this section, if supervised by a group of active prospective users of the tool, would provide sufficient technical information for a contract to create a force design tool. The creation of a new tool is, however, only one option. A second option is to modify an existing tool. The potential benefits to be gained by the second option are buy-in by the selected tool's proponent and cost savings. The potential risks to this option are resistance from the proponents of tools that were not selected, the possibility that the modification of an existing tool might be more costly than creating a tool from scratch, and the possibility that compromises to the specifications might be required, either because of the chosen tool's structure or because of resistance by the chosen tool's proponent. The choice between the two options rests mainly on the technical issue concerning the current structure of the available tools. Either CAPS or JEB appear to have a structure that would support the required modifications to meet the specifications developed here. However, a better choice is to connect CAPS and JEB because there is little overlap in their functionality. The desired characteristics of FA\&CT, 
FALCON and SEASTATE should be added to the combination of CAPS and JEB. At the same time, the additional characteristics that are missing from all of the tools should be added.

Figure 17 shows the general concept of operations for the recommended force design tool. Ideally, the user would not be aware of any seams between the components; however, in initial versions, the seams will certainly be evident. The user will convert an OOTW mission into its time-phased tasks in the MRM component. He or she will use the CAPS component to nominate notional units to perform the tasks and will use CAPS to evaluate the performance in terms of workload. (Logic added from the Service tools will allow for proper definition of headquarters sizing.) The user will create logistics requirements for the notional forces using the JEB component and transportation requirements using the MIDAS or JFAST component. He will cycle through the components as needed to refine the definitions.

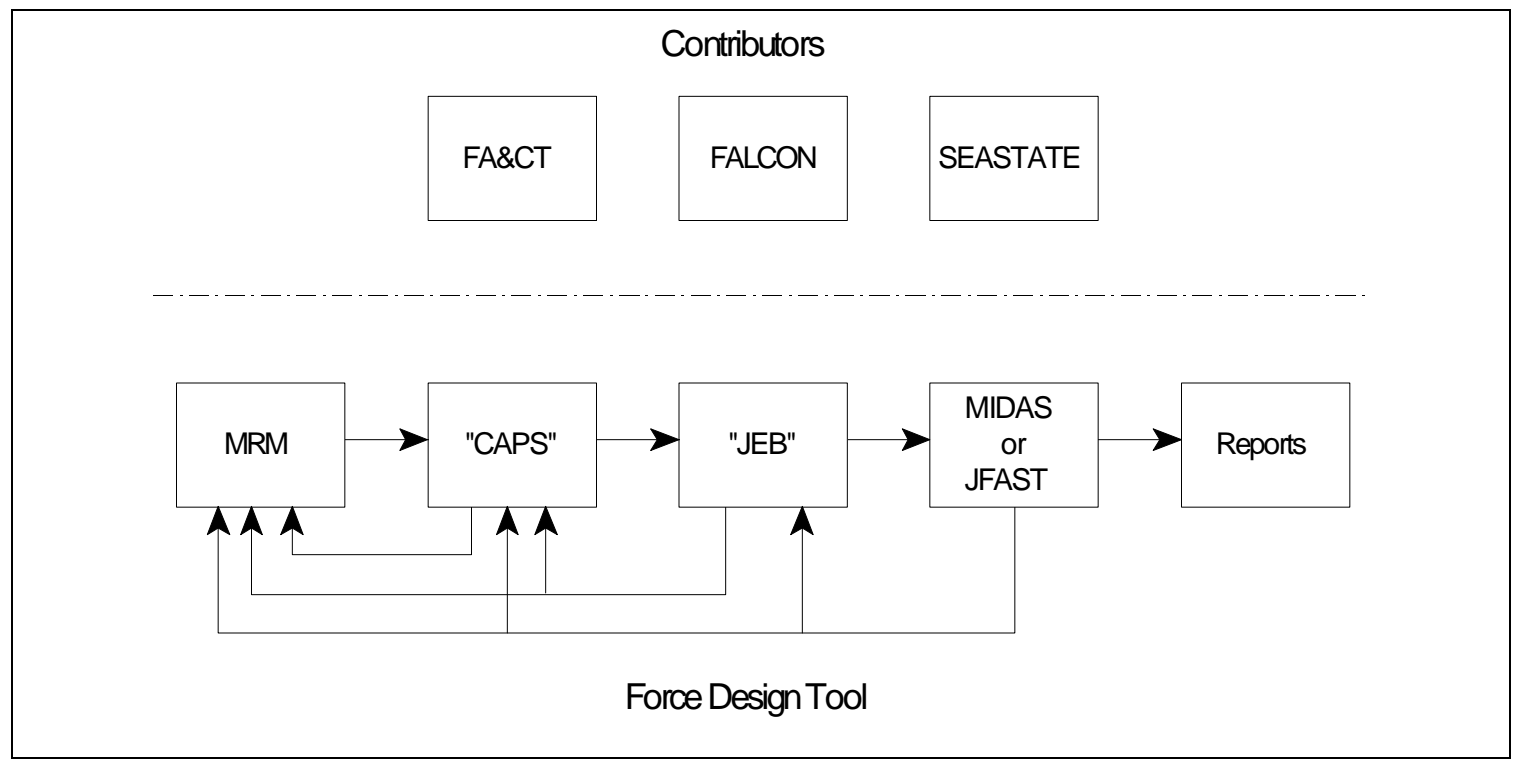

Fig. 17. Combination of existing tools into the force design tool.

If the particular problem requires actual unit nomination, the expanded conversion facility of JEB will be used. For QDR-type problems, added logic from the Service tools in CAPS and JEB will be used to generate tempo and resources stress data. The reporting facilities from CAPS, JEB and MIDAS/JFAST will be augmented to support both reports on single OOTW missions and multiple simultaneous and sequential missions. The joint nature of the tool will permit Joint or OSD study team use, single Service study team use, or submissions from each Service to be combined and deconflicted by a Joint or OSD study team.

Because its proponent, $\mathrm{J}-8$, is sufficiently interested in CAPS to have a current improvement program spending money on CAPS and is one of the major prospective users of the force design tool, there should be no problems from that source. In addition, JEB is actively supported through Defense Advanced Research Projects Agency (DARPA) funding. Using a combination of the two avoids the 
problem of the selection of one Service tool engendering resistance from the other Services. Further, each Service's tool has something to contribute to the final product.

The force design tool under discussion has been specified to meet the expressed needs of the last three functions of Section 1.2, page 3, "force assessment," "system effectiveness and tradeoff analysis," and "concept and doctrine development and analysis." It may also prove useful as a prototype for the operational function, "planning and execution analysis;" however, that need is conjectural at this point. 


\section{VIRTUAL INFORMATION \& ANALYSIS CENTERS}

The initial concept of a VIC placed almost all of the functionality within the VIC, as shown in Fig. 18. Some data were to be gathered within the VIC and both the conversion to information and the analysis leading to the conversion to knowledge were to be performed by the VIC system. The users of the VIC would synthesize the results into an understanding of the situation. Experimentation showed that this concept was over-ambitious. The analytic capabilities available to any

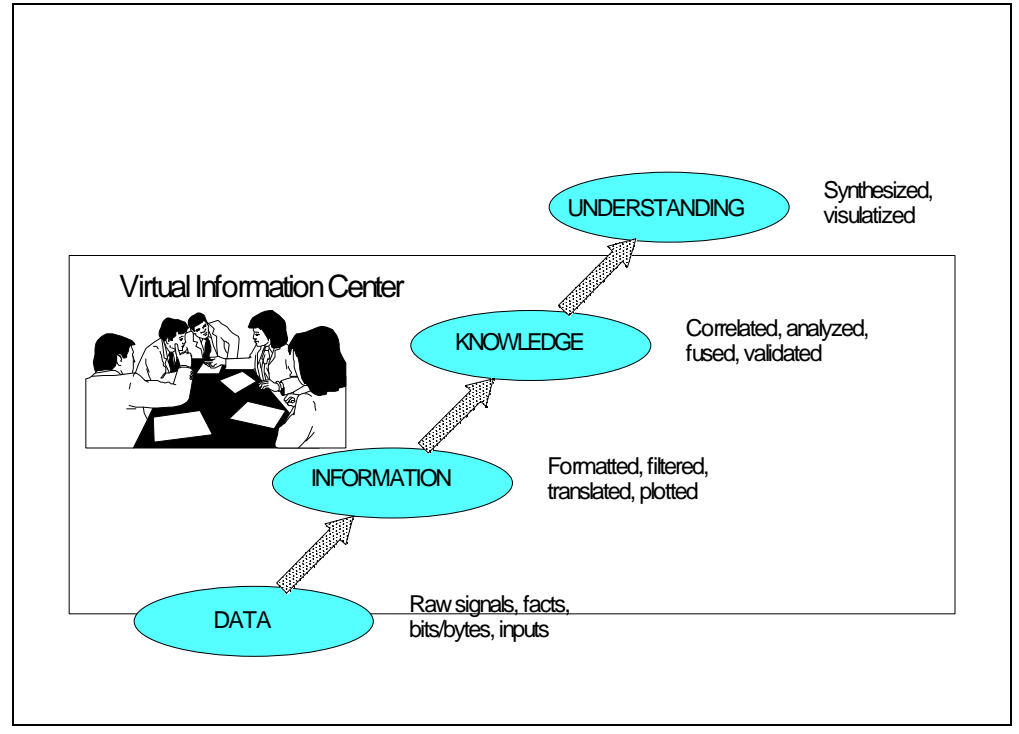

Fig. 18. Initial concept of VIC functions.

given CINC were simply insufficient to process the extremely large amounts of information necessary for OOTWs.

The revised concept, with multiple VICs and a single, centrally located VAC is illustrated by Fig. 19. As shown in Fig. 20, the VICs interact with NGOs, International Organizations (IOs), the UN, the available business community, available local models, remote sensors $(\mathrm{h} \mathrm{u} \mathrm{m} \mathrm{a} \mathrm{n}$ a $\mathrm{n} \mathrm{d}$ mechanical/electronic), the Internet, and other data sources (written and electronic). As shown in the figure, some information is requested, some tasked, and some information flows both into and out of the

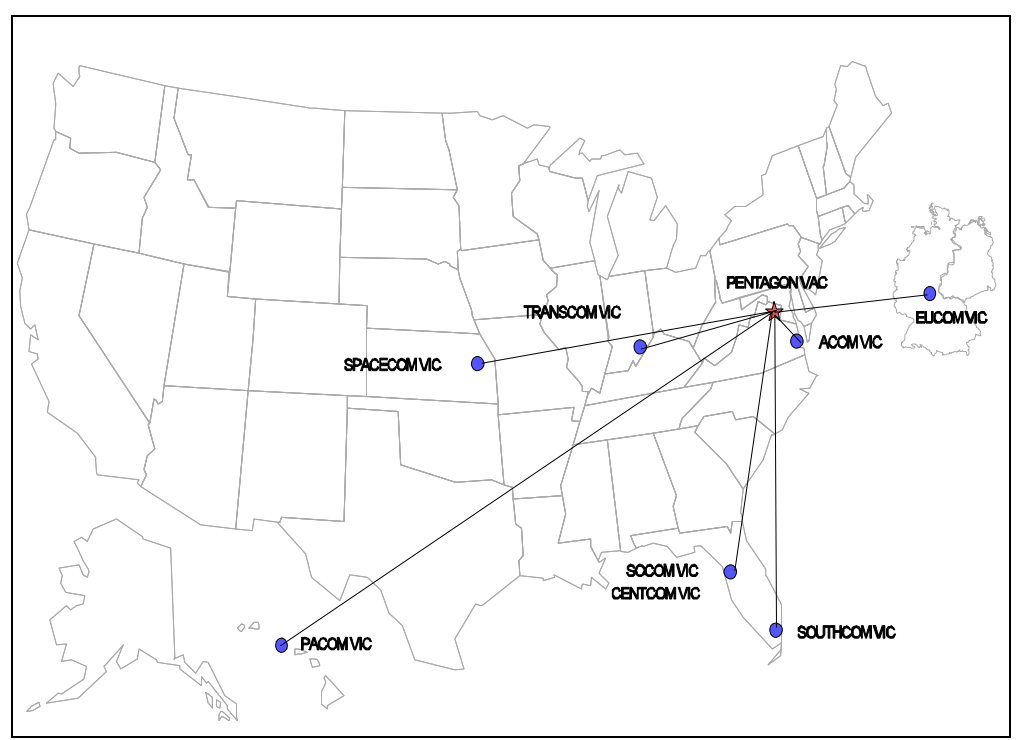

Fig. 19. Geographical sites of VICs and VAC.

VICs. The VAC employs some information gathering and analyzes the results with a more extensive set of tools. The direct users of the output of the VIC/VAC system are the CINCs and the 
Commanders of Joint Task Forces (CJTFs). Information flows from them to non-DoD organizations, as appropriate.

Because the VIC/VAC concept is still in flux, detailed specifications (such as those for a force design tool) are not possible or desirable. The experimentation process initiated by USPACOM and the Joint Command, Control, Communications, Computers, and Intelligence (C4I) Battle Center (JBC) has yielded valuable insights and can be expected to produce more. As experimental VICs are created at additional sites, some parts of the concept will be confirmed, while other parts

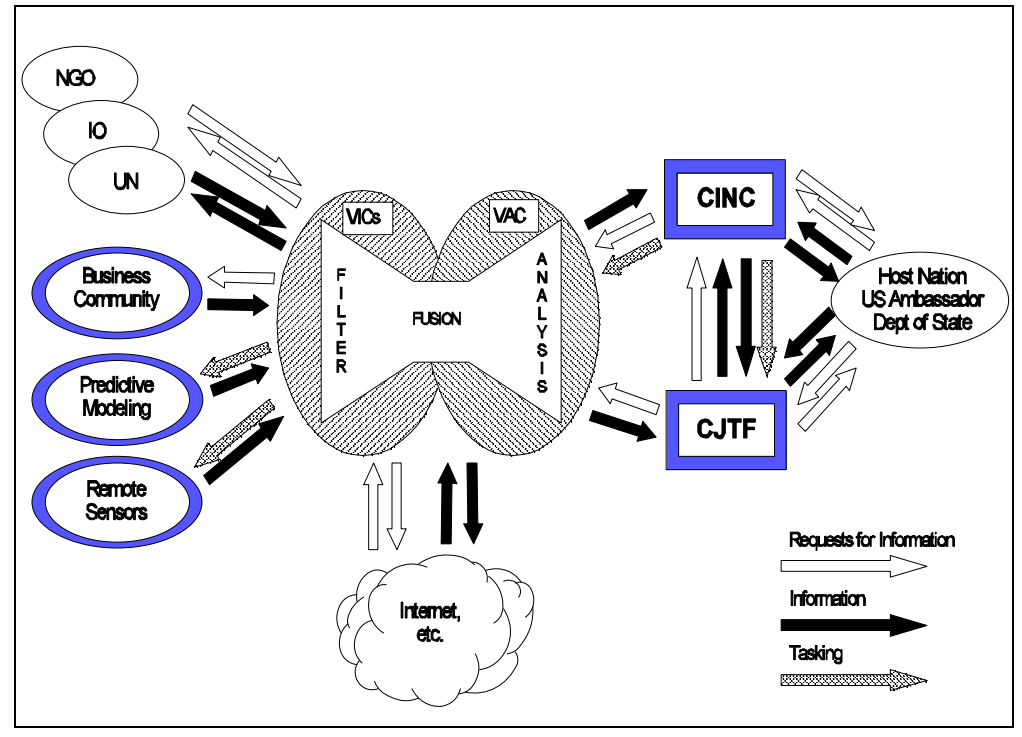

Fig. 20. VIC and VAC processes.

will be shown to require modification or deletion. Also, new users will inject new ideas and new requirements.

The VIC/VAC concept is described from a DoD point of view and all of the sites pictured in Fig. 19 are DoD sites. However, while technically true, the view is actually broader. There is a second VIC site in Hawaii, hosted by the Center of Excellence in Disaster Management \& Humanitarian Assistance, located at Tripler Army Hospital. While USPACOM is a partner in the Center and it is located at a military facility, the Center does not report to USPACOM. The Center's orientation explicitly includes the civilian world and its area of interest covers the full ramifications of complex humanitarian emergencies. There are also other organizations that would be natural candidates for VIC sites. For example, the Department of Energy is currently working on domestic chemical and biological Weapons of Mass Destruction (WMD) and its efforts should be included. Similarly, FEMA and the Office of Foreign Disaster Assistance (OFDA) would benefit from such a connection.

The VIC/VAC concept has the potential for being a unifying force in a world in which interorganizational politics often hinders the efficient and effective performance of OOTW missions. While the concept will undergo revisions as its users perform experiments, the concept would benefit from a preliminary Mission Needs Statement (MNS) and other appropriate documents. A workshop organized around a VIC/VAC MNS would produce the necessary starting point for appropriate requirements documents. 


\section{IMPACT ANALYSIS}

Military personnel, including planners and analysts, are as familiar with combat as we can make them. We educate them about combat; we train them in combat operations; and we provide them tools to help deal with combat. Combat impact analysis permeates military decision making. At the individual and squad level, combat impact analysis is used to create the rules that are taught about weapons placement, air combat engagement tactics, basic loads, and virtually every other aspect of military operational behavior. The rules are created to help the individual survive and perform under extremely severe conditions. At higher levels, we start planning with an Intelligence Preparation of the Battlefield (IPB), which provides the information to create COAs and evaluate them - combat impact analysis. At the highest levels, combat impact analysis is used to decide what forces we need, how they should be structured, what they should do (doctrine), and how to do it under fiscal constraints. In Desert Storm, the Army CAA sent its major combat impact analysis model into the war to aid in real-time planning. Personal Computers have achieved the power to run models that used to require mainframes. It has taken thirty years (since the ATLAS model of the 1960s) to reach our current state of capability to perform combat impact analysis and we are unsatisfied. The Joint Warfare System (JWARS) is to be our latest version of the major combat impact analysis model.

Every day of every year since the close of the Cold War (and before) we have been engaged in an OOTW somewhere in the world. Some of these operations have looked a lot like mini-wars operations in which we dropped bombs and launched cruise missiles; many have been more like police activities - peacekeeping; many have been less combat-like - humanitarian assistance and disaster relief. As this is being written, we are dropping bombs in Yugoslavia; however, the measure of success is not the amount of damage done, but the psychological reaction of one man or the joint psychological reactions of many. The campaign in Yugoslavia is not being conducted as a war, but as a giant psychological operation. We do not have one OOTW impact analysis model to aid us - we do not even have an OOTW impact analysis model for each man, woman and child in the United States. Because we are inconsistent, each of us may entertain a different model each time we consider the matter - and thus reach a different conclusion.

Military commanders and planners may overlook or fail to adequately consider relevant factors in OOTWs. It is not just a lack of experience or knowledge of the specific socio-politico-economic influences in a given situation, although this lack is a factor. The sheer number of potentially important influences make consistent and complete evaluations unlikely.

\subsection{NEED FOR IMPACT ANALYSIS}

Studies at the national level require outcomes predictions to compare to desired outcomes. And, ultimately, the evaluation of doctrinal or force changes at the force providers level requires outcomes predictions. Where the studies or evaluations involve OOTWs, they require the computation of the interaction of social, political, economic, and military factors. The course of events is forcing an increased interest in studies and evaluations of OOTWs. 
The geographical CINCs stated a need for COA analysis. In cases where more than one course of action is possible (the majority of cases), analytical support in selecting the best (or at least in rejecting the worst) COA is needed. In some cases, this need is satisfied by the methodology used in force design: capability to do the required work, availability (several sub-factors), general satisfaction of security requirements, and cost (both in resource use and in dollars). However, in some cases, this methodology is not sufficient. Questions of capability are complex, such as the ability to keep the peace or create a working democracy. The interaction of social, political, economic, and military factors must be computed.

The geographical CINCs also stated a need for engagement impact support. The heart of "engagement" is performing actions that will prevent wars or other geopolitical actions against the interests of the United States. This also requires the computation of the interaction of social, political, economic, and military factors.

In evaluating military COAs (at any level), planners must ensure that all relevant factors are considered in order to determine pros and cons. The intent here is not to develop socio-economicpolitical policy. The impact tool is required to raise those issues that are not in the normal scope of knowledge of traditionally trained military operations planners. This is comparable to the current IPB process; however, factors and issues other than relative combat power ratio, force composition and disposition are identified. These factors might include population density and composition or politicoeconomic indicators of unrest or cultural factors affecting operational choices. The impact tool is also required to predict possible outcomes. It must remind us that factors other than relative combat power ratio, force composition and disposition affect the outcomes and help us understand the situation.

One reason that there is no generally accepted analytical impact model for OOTWs is suspicion. There are several commercial games (such as SimCity ${ }^{\mathrm{TM}}$ ) that model the impact of many of the important activities and factors of OOTWs. There are also several OOTW simulations (some are listed in Table 13 on page 20) that model the impact of OOTW activities; however, most are used for training, not analysis, or have not been used extensively. (Section 7.6 discusses the issues concerning impact modeling for training versus for analysis.) Despite the existence of candidate models, the suspicion is that they are not valid models and their complexity prevents individual users from assessing their validity. (Section 7.2 discusses the transparency issue [whether the rationales of a model are obvious to a user] and Section 7.3 discusses the validity issue.)

The other reason that there is no generally accepted analytical impact model for OOTWs is ignorance. We are ignorant of the relationships among the important factors. We are not even sure which factors are the important ones. Section 7.4 discusses the specifications for impact analysis tools. As this section makes clear, modeling OOTWs for analysis is a hard problem. However, each time we begin a new OOTW, someone has created a model and used it to decide what to do. Usually this is a mental model. The question is whether a computer model can or will yield better results. Will its consistency ensure that significant elements are always addressed? Will it yield a spread of possible results to reduce the likelihood of tunnel vision? Can it be timely? Can it be improved over the years to yield order-of-magnitude predictions? Section 7.5 describes the consequences of such operational issues and Section 7.7 concludes with a discussion of the creation of an MNS for impact analysis tools. 


\subsection{TRANSPARENCY}

The word "transparency" is used to mean that the internal workings of a model are obvious and not hidden from view. More, it means that they are easily understandable (and preferably manifestly correct). This quality is clearly valuable in allaying suspicion; however, it often means that either the model is too simple for use or the complexity of the efforts to make the model transparent makes the model too difficult to use.

The most recent computer coding methodology to claim transparency advantages is object-oriented programming. (A previous methodology making similar claims was structured programming.) It is true that some models that use object-oriented programming are easier to understand than comparable models written using older methodologies for someone reading the computer code. However, once the number of objects grows into the hundreds or for anyone not reading the code, objectoriented programming does not (by itself) produce transparent models.

The most useful (current) technique for increasing the transparency of a model is the creation of a meta-model using influence diagrams. The metamodel has two levels. The first level is graphical, showing which factors influence each other factor and each decision. This makes it clear whether all significant factors have been considered. The second level is

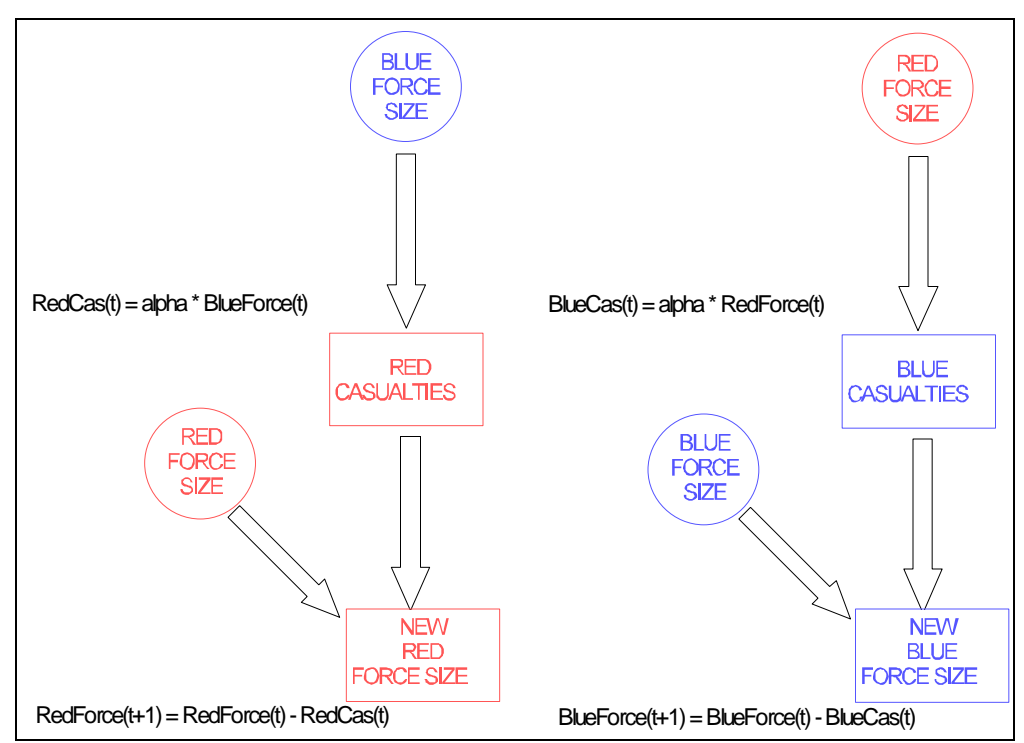

Fig. 21. Influence diagram for homogeneous Lanchester square law.

mathematical (and thus less easily comprehended). This level presents the functions, showing how the factors influence the decision or other factor. This concept is illustrated in Fig. 21, in which the homogeneous Lanchester law is implemented as an influence diagram. The graphics clearly show the influences; however, the equations that form the second level, while complete, do not convey the complexity or the arguments that have revolved around Lanchester Theory. No less should be expected of OOTW Theory. While this meta-modeling technique is insufficient to completely produce the desired transparency, it does focus attention on the issues that need to be argued. 


\subsection{VALIDITY}

Beyond the suspicion that hidden equations can cause, there is the suspicion that the equations may be visible, yet still wrong. Fatigue and fear in combat are generally ignored in computerized combat models, which are designed for predictions (within limits), for generality, and to embody corporate memory. In these models, the questions being answered are restricted to those in which the psychosocial effects may be presumed to be constant over the domain of interest. This has been true, in part, due to a reluctance to defend conjectural human factors models. However, in modeling impact in OOTWs, equations are required to connect military actions to economic, social, and political actions and states. Even the most academically sound equations, those connecting economic events to other economic events, are not uniformly accepted all by economists. However, these events and states do interact and any impact model must contain such interactions. At this point, models must be transparent and the conjectured equations and influence diagrams must be openly debated.

The initial expectations of validity for OOTW models must be low. Early analytical models should introduce consistency of factor consideration into OOTW analysis. The definition of a "good" model would probably be one that identifies all probable repercussions and produces rough sequences of likelihood. Recent investigations of validation of human behavior representations suggest means of improving the definition of "good" [Harmon and Youngblood, 1999]. Part of the technique involves dividing the validation into tests of the models at five levels of representation: domain, physiological, psychological, organizational, and physical. After several years of effort, a "good" model might be expected to generate factor-of-two correctness (a $10 \%$ prediction means not less than $5 \%$ and not more than $20 \%$ ).

\subsection{IMPACT MODELING SPECIFICATIONS}

The purpose of impact modeling is to provide the commander (or the analyst surrogate) with the answer to the question, "What will happen if I do X?" and other similar questions. Measures of performance (MOPs) providing an organizing principle to support this purpose. In the performance of OOTWs, what is attempted is based on what is thought to matter. That is, performance is driven by MOPs, whether external and imposed MOPS or internal and self-adopted MOPs. Example MOPs include the percentage of the population voting, the level of looting, and the percentage of farmers planting traditional crops. In designing a model of OOTWs, as in designing any other model, some elements of reality must be omitted to concentrate on what matters. An understanding of the MOPs used in OOTWs is necessary for the proper design of a model of OOTWs. The Technical Cooperation Program (TTCP) of the five nations (Australia, Canada, New Zealand, the United Kingdom, and the United States) held a workshop on Defining and Measuring Success in the New Strategic Environment [Christopher, Dickson and Pritchard, 1999] to help increase the understanding of just what does matter in OOTWs. The broad result was that the things that matter are particularly dependent on the situation; however, the general areas that matter include political, economic, social, religious, and psychological components. Military factors also matter; however, they may be relegated to lesser status in some OOTWs.

Three stages of specifications are described here: representing the data, representing the influences among the objects, and representing active objects. 


\subsubsection{Representing Relevant Data}

General specifications for impact modeling can be and have been produced [Hartley, 1995]. A key concept is dual level of resolution, illustrated in Table 20 . The most important objects in the model are specifically enumerated, e.g., the heads of state and the key governmental and nongovernmental organizations for each country. The rules for evaluating the impact of each potential factor (and the interactions) are developed specifically for each object, based on their known characteristics. These objects represent the basic level of resolution for the model.
Table 20. Attribute Attachments

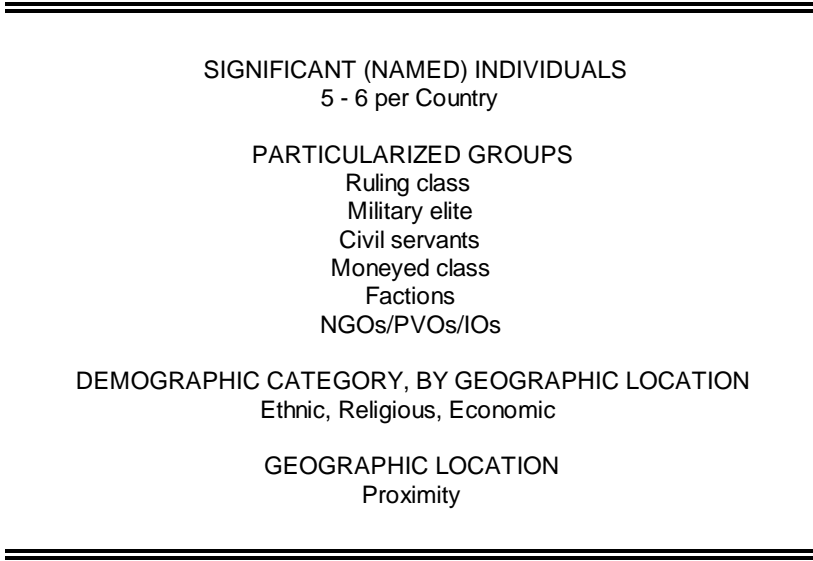

The second level of resolution of the model is concerned with the diffuse psycho-social attributes of the populaces (or sub-cultures) of the countries. Geographical and time related effects will be important, as well as innate characteristics. This level of resolution is important because some overtures are aimed at the populace and will show no effect unless there is a populace to be affected. The principal actors react not only to direct approaches, but also to responses by the populace to various factors.

Table 21 lists several potentially important Table 21. Potential Attributes of Interest factors or attributes. Scalar field factors of interest might include support for democracy, support for autocracy, criminal activity, fear, capitalist activity, sloth, addiction, spying, or terrorism. Which are important and how they are interrelated will be difficult questions to resolve; however, estimates can be made and corrected as the data indicate.

In many situations, the effects produced by the second level of resolution of the model

\section{Table 21. Potential Attributes of Interest}

$$
\begin{gathered}
\text { Fear } \\
\text { Suppression (of various activities) } \\
\text { Ownership, Work ethic } \\
\text { Democratic leanings } \\
\text { Economic competition, Espionage, Pirating } \\
\text { Religious conflict } \\
\text { Crime - general, Narcotics } \\
\text { Drug costs } \\
\text { Health levels } \\
\text { Political corruption } \\
\text { Spectrum of pro-country X sympathy } \\
\text { Spectrum of fervor for causes, percentage favoring } \\
\text { Spectrum of morale } \\
\text { Refugee flow rates } \\
\text { Terrorism level }
\end{gathered}
$$

should be distinctly second-order effects, and not very important. However, the dissolution of the Soviet Union very strongly involved more than just the actions of the original principals. Nation building operations will depend heavily on affecting the populace. It is not clear when this level of resolution can be omitted and prudence thus argues for its inclusion in OOTW scenarios. One would first create a model of the region of interest and develop the first level of resolution objects, based upon best guesses of personalities and psychologies of the key individuals. Then the second level of resolution would be developed, based on general psychology and specific cultural influences. 
An example of a humanitarian assistance operation will serve to illustrate the data and modeling complexity needed for these types of attributes. The details are omitted for brevity. The military will be transporting relief supplies and providing general support, including security for the operation to feed various population groups. The poverty load distribution, defined as the number of poor people divided by the number of wealthy people, is a measure of potential trouble. First, a topographic model is needed because elevations, slopes and spatial relationships affect such things as travel and desirability of locations for living and agriculture. Here, the desirable land consists of a valley and ridge province situated between a mountain range and a parallel plateau. The topography can also be used to connect resources to locations for industry and the general economy.

After the topographic model has been created, overlays of natural and man-made features, such as rivers, roads, towns, and cities are required. The features here are constrained by the higher elevations, with the major city situated at the confluence of two rivers. While the display of these overlays is useful, providing information to the analyst, the overlays should be logically connected to the internal models of human processes for maximum utility. For example, travel should be slower or impossible where there are no roads.

The people in the area represent the most significant item of interest and require extensive data and modeling. They are not distributed uniformly, which affects activities and interacts with movements of both military units and displaced persons. Towns and cities are associated with population clusters (higher densities), while density variations in the countryside are associated (in this example) with the more desirable valleys.

However, the people who make up the population are also not identical. Ethnic or other divisions exist and are not distributed identically with the general population. Six ethnic groups are represented in this example, each with its own geographic centroid. The K-ethnic group is located in the North and its members have historically been miners and rough laborers. The V-ethnic group is located in the Northeast and has a tradition of banking, loan-sharking, and plantation owning. The $\mathrm{N}$-ethnic group is located in the East and its members are a somewhat reclusive people, given to small farms and hunting. The S-ethnic group is located in the Southeast and involved in industries. The G-ethnic group is located in the South and also is involved in industries; however, its members are generally suspicious of the S-ethnic group. The T-ethnic group comprises roughly 50\% of the total population and is located centrally and in the West.

Their individual distributions indicate that their relative concentrations will vary. Two concentration measures may be significant with regard to inter-ethnic tensions, the majority population (in some areas no group exceeds $50 \%$ and no group is listed as the majority) and the smallest minority population. There is so much diversity in the area surrounding the major city that no one group comprises a majority, except in the western suburbs. The patterns of majority coverage generally fit the locational descriptions of the ethnic groups. The fringe areas of an ethnic group's penetration into a region represent the places where the group is present (hence eligible to be a minority) and least dense (hence likely to be the smallest minority). In this example, the major city is subdivided because these fringes overlap in the city. In a real example, elements of each group would be drawn there beyond normal fringe calculations because of the city's economic benefits.

The distribution of the poverty population is not random. There are more poor people in cities and towns because there are more people there. But often there is a differential increase, in part because 
the support systems are superior in cities and towns. Similarly, the number (not illustrated) and the percentage of wealthy people is higher in cities than in the countryside. The overall percentage is $6 \%$, but varies from $3.8 \%$ to $10.4 \%$.

In this example, there are other factors at work. Here the V-ethnic group is differentially wealthier. This accounts for the higher percentage of wealthy people in the Northeast. Areas with K-ethnic majorities are poorer than average and the people in the plateau (Northwest) region are poorer because the coal mines there are played out. These two factors account for the higher percentage of poverty along the plateau and in the Northwest. (The overall poverty average is $21 \%$, ranging from $13.1 \%$ to $27.3 \%$.)

Once all of these factors are represented, the poverty load distribution can be calculated (Fig. 22). The average load is 3.5 poor people per wealthy person; however, this attribute reveals a very high regional load in the less accessible northwest region (up to 6.6). The implication is that there may not be enough wealth locally to feed and clothe the needy. In addition, the low poverty load in the northeast region (as low as 1.5) and the fact that the difference is associated with K-ethnic and V-ethnic groups may drive tensions between the groups.

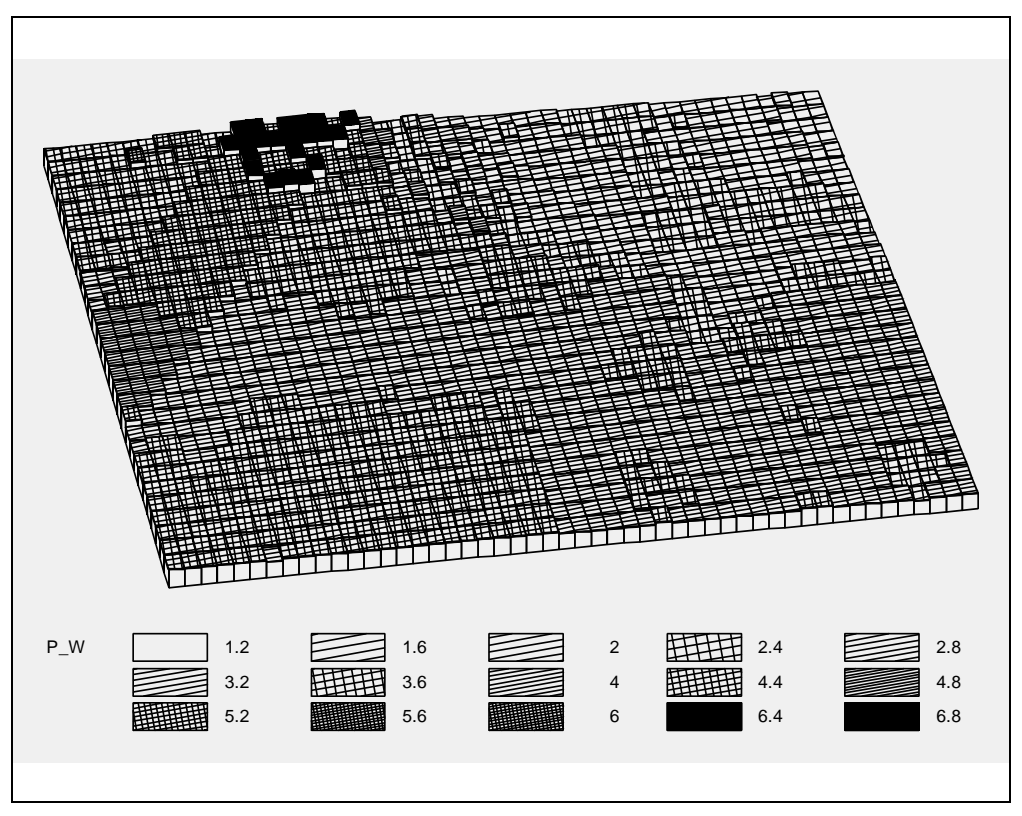

Fig. 22. Poverty load (on the wealthy).

Calculation of this poverty load attribute would be part of the IPB. The location of the hungriest people might be evident from reports on the ground in an actual operation; however, in a contingency planning situation there would be no reports. Even in an actual operation, the reports might be incomplete and the calculation would serve to indicate areas needing investigation. Estimates of where security might be most at risk would be required in any case. In this example, the areas in the Northwest would be likely to experience high levels of need and transport in the area in the North between the area of highest need and the area of least need might experience the greatest threats to security.

This illustration covers only one attribute. Others may also be significant. In this case, no problem was associated with the major city: the high level of poverty there is balanced by a high level of wealth. However, in some oligarchies, such divergences are endemic and are very definitely associated with problems. In that situation, a different poverty load calculation, dividing the number of poor by the number of middle class may be useful. In this example, the overall average is 0.29 ; however, the range is from 0.17 to 0.43 . The major city is located in an area with no ethnic group holding a 
majority and minority groups varying with neighborhood. However, determining the significance of these facts requires more information.

\subsubsection{Representing Relevant Influences}

The previous example is completely static, that is, no events and the changes that result are modeled. Modeling the impacts of single events is shown in Fig. 23. The line of E's marching down the figure represents events that have potential impacts. Each event has time of occurrence and location information, as well as information about its nature. In this figure, Event $4\left(\mathrm{E}_{4}\right)$ is the current event. The two heavy, solid lines originating at $\mathrm{E}_{4}$ indicate that it impacts both levels of resolution, enumerated objects and demographic categories. The specifically enumerated objects are represented in the figure by three people $\left(\mathrm{P}_{1}, \mathrm{P}_{2}\right.$ and $\mathrm{P}_{3}$, in circles) and three particularized groups $\left(\mathrm{G}_{1}, \mathrm{G}_{2}\right.$ and $\mathrm{G}_{3}$, in ellipses). The

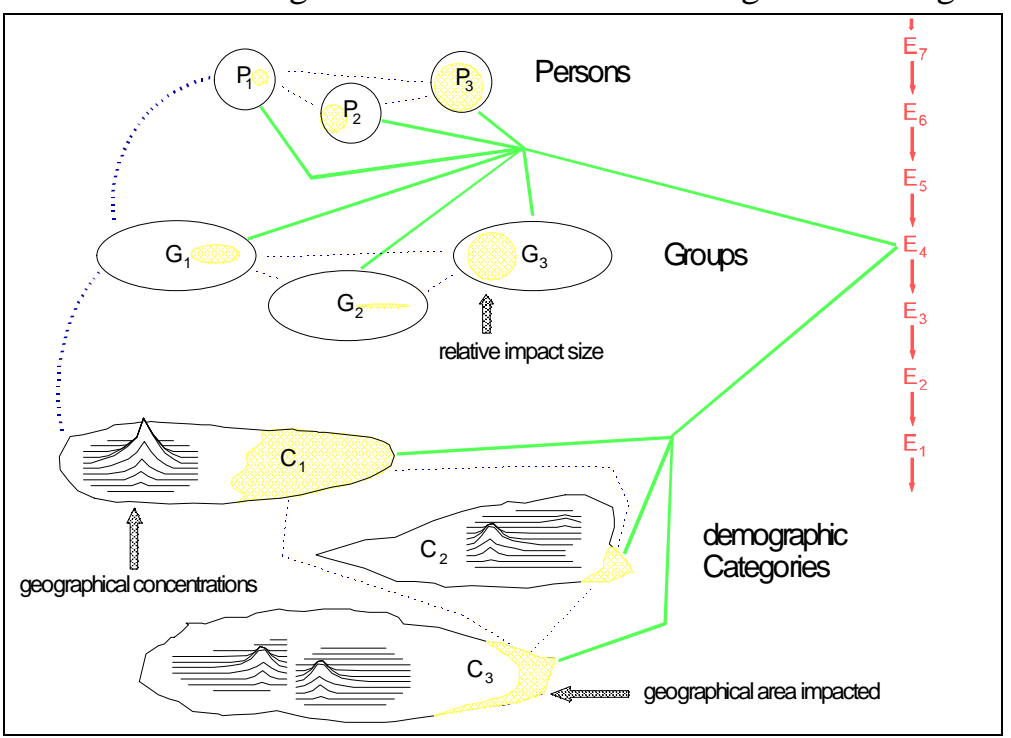

Fig. 23. Event Interactions

diffuse populaces are represented by three demographic categories $\left(C_{1}, C_{2}\right.$ and $C_{3}$, each with a territorial coverage representation, including population density).

The demographic categories are indicated as occupying distinct geographical areas (the overlap must be imagined in this figure), with population density variations within the areas (indicated by the threedimensional sketches). The impact of $\mathrm{E}_{4}$ varies in size (shaded regions) in the enumerated objects and in geographical effect in the demographic categories. For simplicity, the variation in impact on different psycho-social factors is omitted in this figure. Also omitted from the figure are the effects on the external actors, such as NGOs, U.S. or Combined forces, neighboring countries, other interested countries, and the U.N. Interactions among objects are indicated with dotted lines. These interactions propagate over time and include reactions to past events.

The foregoing specification represents the operational environment and permits passive or semi-static analyses. The NationLab and SIAM models are examples of semi-static models. They are structured as complex influence diagrams. Different policies (including sets of actions) or differing assumptions about the state of the environment can be tested for relatively immediate impacts in this type model. For some uses, this type model is adequate and the simplicity inherent in the design aids in achieving transparency. 


\subsubsection{Representing Relevant Actions}

However, some questions require dynamic analysis. Objects must move and perform actions; information channels, such as radio, television, leaflet-dropping, and word-of-mouth campaigns must be explicitly represented; and recursive relationships with positive and negative feedback, requiring the explicit representation of time, must be included. Analyses that address such questions require the structure provided by discrete event simulation. SENSE, CarePlan, GCAM, SimCity, DEXES, and Spectrum provide examples in this category. The situation shown in Fig. 23 becomes more complex. Not only do the various objects react to events (and react to others' reactions), but they also post events $\left(\mathrm{E}_{\mathrm{i}}\right)$ to the queue and move, whether cohesively, semi-cohesively (splitting and re-combining), or diffusively (e.g., refugee movements, religious/political conversions, and spread/contraction of epidemics). Situations in which things must get worse before they can get better require this type of modeling.

\subsection{OPERATIONAL ISSUES}

Because the relationship among factors is poorly understoodand because the impactsof events are inherently variable impact modeling for analysis must not produce single point solutions. Impact modeling for analysis must be designed and used to produce distributions of possible outcomes. The distributions allow for calculation of relative frequency of similar results, e.g., 45 times of 1000 ( $4.5 \%$ of the time) the result is riots. These frequencies must then be interpreted in light of the current state of the art. That is $4.5 \%$ means between $0 \%$ and $50 \%$ for early models or $4.5 \%$ means between $1 \%$ and $10 \%$ for mature models. In addition, because knowledge of the interactions of social, political, economic, and military factors is not an exact science, trial and error will be required. Multiple competing models do not represent wasteful duplication, but necessary replication to explore possible approaches and to identify the successful ones.

Past policies would be gamed in the system to test for first order effects and to calibrate the model. Questions of interest will include: What is the immediate impact of $X$ ? What is the long term impact of X? Where are the likely "hot spots?" The variable X could be actions such as treaties, golf with prime minister, or military exercises. The results should be assessed cumulatively, because everything counts. At the national level and at the force provider level, the questions will address the adequacy of systems, doctrines and forces to produce desirable outcomes. At the CINC level, the questions will more likely be designed to support the CINC's consultation with an Ambassador. Only if there is an appropriate and current database for the AOR of a prospective operation will it be possible for COA analysis to be performed in a timely manner.

Because an impact analysis model is mechanical in nature, it can be consistent in always considering the effects of all known factors. It can be consistently time-binding by always considering the persistent impact of previous actions, as well as currently contemplated options. It can be consistently globally oriented by including the effects of other conscious players (such as other governments with their own agendas) and less conscious players (such as international corporations). It can consistently consider asymmetric warfare aspects in OOTWs, e.g., one or more factions may consider that they are conducting a war, despite the our view of the operation as other than war. An impact analysis model can do these things, but only if its operators use it that way. 
The data requirement for impact analysis represents an additional major difficulty. However, as described in the section on VIC/VAC, the data requirements for OOTW analysis have already been realized as being a major difficulty. In order for an impact model to provide a more thorough exploration of possible impacts, a more thorough data collection effort is required.

Ideally, an impact model should be able to provide some idea of the effects that might result from actions, some appreciation of their likelihood, and some understanding of the reasons for the possible effects. Good decision makers think through these steps before taking action by building mental impact models. The best (or sometimes the luckiest) decision makers have good mental impact models. Building a computerized impact model permits the consistent consideration of a wide range of factors and allows for improvement as lessons are learned and transmission of what is learned to new decision makers.

\subsection{IMPACT MODELING: TRAINING VERSUS ANALYSIS}

The primary purpose of a training model (whether for combat or OOTW) is stimulation, while adjudication of results is a secondary purpose. In the biggest user of computer models for training, the command post exercise (CPX), the training audience never sees the computer. The model outputs are filtered by human controllers or through real-world C4I devices. The computer model is needed as a bookkeeper for the myriad activities being modeled. The model has to adjudicate results internally to produce the sequels that are the stimulants for the training audience; however, those results are not by themselves used to judge the training audience. This is not to say that the fidelity of the model is unimportant: poor models or data that result in unbelievable results can cause participants to break out of a training mode and fight the model and more subtle errors may cause negative training (at worst, inducing participants to learn something that is false).

On the other hand, the primary purpose of analytical models is the adjudication of results. The exact value of the results may not be significant in all cases; however, the relative values when compared to the values under alternative situations must be correct (within the tolerance of the particular use). All analysis depends on determining that one thing is better than another, or not. Even analysis "for insight" depends on a belief that the unfolding of the situation as exposed by the model has a fair chance of being correct.

The current models used to simulate OOTWs for training may not have the required fidelity for analysis or they may not have engendered sufficient confidence in their fidelity for prospective users to trust them. However, they do represent attempts to model elements that are required for analytic OOTW models. Attempts to improve existing models or improve the status of impact modeling for training are highly relevant to attempts to improve impact models for analysis. A recent publication [Loughran, et al., 1999] provides an excellent description of the state of training modeling for OOTWs, including good descriptions of many of the models being used. It also implies that work will be committed to improving the state of OOTW training models. 


\subsection{IMPACT MODELING MNS}

Sections 7 has discussed the uses for impact modeling and means of achieving it; however, the official MNS is missing. During the discussion of the precise requirements for JWARS, it was decided that JWARS would not address the bulk of OOTW modeling needs [Hartley and Packard, 1998a]. These unmet needs have been included in Section 7.1, which describes needs for national analysis, force provider analysis, and geographic CINC analysis. Sections 7.2 and 7.3 describe conditions for success: transparency and validity. Section 7.4 describes specifications for impact modeling, with precise application of the specifications dependent on a more concrete and authoritative characterization of needs. Section 7.5 provides a partial description of the operational environment for impact modeling. Section 7.6 identifies the training community as a potential source of support for the process.

Each of the elements covered in Section 7 provide initial elements of an MNS. Most of the remaining elements could be obtained from a workshop organized around an OOTW Impact Analysis MNS theme. This workshop would also produce initial buy-in of prospective users for the MNS and other appropriate requirements documents produced from the workshop results. 


\section{RECOMMENDATIONS}

The understanding of OOTWs and its analytical support requirements has matured to the point where action can be taken in three areas. While the nature of the action and the length of time before complete results can be expected depends on the area, in each case the action should begin immediately.

\subsection{DEVELOPING A FORCE DESIGN TOOL}

Force design for OOTWs is not a technically difficult process. Like force design for combat operations, it is a process of matching the capabilities of forces against the specified and implied tasks of the operation, considering the constraints of logistics, transport and force availabilities. However, there is a critical difference that restricts the usefulness of combat force design tools for OOTWs: the combat tools are built to infer non-combat capability requirements from combat capability requirements and cannot reverse the direction of the inference, as is required for OOTWs.

Recently, OOTWs have played a larger role in force assessment, system effectiveness and tradeoff analysis, and concept and doctrine development and analysis. In the first QDR, each of the Services created its own OOTW force design tool. Unfortunately, the tools address different parts of the problem and do not coordinate the use of competing capabilities. These tools satisfied the immediate requirements of the QDR, but do not provide a long-term cost-effective solution.

We recommend that a project be initiated to connect MRM, CAPS, JEB, and MIDAS/JFAST as the basis for a force design tool. The resulting combination should be expanded along the lines indicated in Section 5. Actual users must be involved in the process. A users group should be formed to guide the development. The group should be composed of two classes of members, based on expressed immediacy of need: voting members (Joint Staff, OSD, and Service representatives) and advisory members (interested CINC representatives). Concrete results should be expected within a year.

\subsection{EXPERIMENTING WITH THE VIC/VAC CONCEPT}

The second recommendation derives from the need to create OOTW force designs. Crisis action planning for OOTWs suffers from a scarcity of relevant mission and situation information, which is needed to define the function of the force to be designed. Collaborative analysis is required to acquire the information.

We recommend that the VIC experimentation be continued and expanded to include the VAC concept, as described in Section 6. Participation should be broadened to include non-DoD parties. Partial results are already being experienced. As the completeness of the system is increased, benefits will increase. Full capability will probably require years, in part because new capabilities will be defined as experience is gained. A user group should be formed to guide the development composed of CINC 
representatives, Joint Staff representatives and others involved in VIC/VAC creation and use. We recommend initiating a task to create appropriate requirements documents, supervised by this user group.

\subsection{RESEARCH AND DEVELOPMENT OF IMPACT ANALYSIS MODELS}

The third recommendation also derives from the need to create OOTW force designs. Once a plausible force has been designed, impact analysis is needed to evaluate alternative force designs. More detailed impact analysis of alternative courses of action requires the simulation of complex economic, political, cultural, and military activities.

We recommend a study of impact analysis, COA analysis, and engagement plan analysis requirements, methodologies and models. This study would be similar to the study on force design tools reported here. Current and earlier work has identified the significance of impact analysis for OOTWs. Clearly, it should also be useful for Information Warfare, Civil Affairs, Special Operations, and Psychological Operations analysis. There are several models and modeling environments that are potentially useful for OOTW impact analysis, including CarePlan, DEXES, GCAM, JCATS, NationLab, Sense, the SIAM, SimCity ${ }^{\mathrm{TM}}$, and Spectrum; however, there is no current system for comparing and contrasting these or any other candidates. The study would develop the system of meta-models (described in Section 7), gather information, hold workshops, and synthesize the results. The study would also produce input to appropriate requirements documents. The study should require about a year. Because of the difficulty of the subject matter, it is expected that a project to create an impact model will, of necessity, be open-ended, with modifications being made as more is learned. The logical sponsors are J-8, OSD Program Analysis and Evaluation (PA\&E), and the Office of the Assistant Secretary of Defense Special Operations/Low Intensity Conflict (OASD SO/LIC), with supervision by either the Joint Modeling and Simulation Executive Panel (JMSEP) or the Joint Analytic Model Improvement Program (JAMIP) manager, augmented by Service representatives. 


\section{BIBLIOGRAPHY}

1. Christopher, G. L., R. Dickson, and J. Pritchard. Defining and Measuring Success in the New Strategic Environment, Proceedings of a Workshop Organized by Technical Panel JSA-TP-3 of the Technical Cooperation Program (TTCP). Department of National Defence, Ottawa, Canada, 1999.

2. GCCS COP Working Group. GCCS COP / CTP Requirements, 28 October 1998. Joint Chiefs of Staff and Defense Information Systems Agency, Washington, DC, 1998.

3. Harmon, S. Y. and S. M. Youngblood. Validation of Human Behavior Representations, 1999.

4. Hartley, Dean S., III. Modeling Psycho-Social Attributes in Conflict, Extended, Proceedings of the 1995 Winter Simulation Conference, pp 1244-1249, ed. C. Alexopoulos, K. Kang, W. R. Lilegdon, and D. Goldsman. Arlington, VA, 1995.

5. Hartley, Dean S., III. Operations Other Than War: Requirements for Analysis Tools Research Report, K/DSRD-2098. Lockheed Martin Energy Systems, Inc., Oak Ridge, TN, 1996.

6. Hartley, Dean S., III and Stephen L. Packard. OOTW Tool Requirements in Relation to JWARS, Y/DSRD-3076. Lockheed Martin Energy Systems, Inc., Oak Ridge, TN, 1998a.

7. Hartley, Dean S., III and Stephen L. Packard. OOTW Cost Tools, Y/DSRD-3099. Lockheed Martin Energy Systems, Inc., Oak Ridge, TN, 1998b.

8. Hartley, Dean S., III and Richard E. Bell. OOTW Force Design Workshop Proceedings, Y/DSRD-3124. Lockheed Martin Energy Systems, Inc., Oak Ridge, TN, 1999.

9. Loughran, Julia J., et al. Applying Commercial Gaming and Collaboration Technologies to JTF Staff Training. ThoughtLink Inc, Vienna, VA, 1999.

10. Staniec, Cyrus. MORS Workshop on OOTW Analysis and Modeling Techniques (OOTWAMT). Military Operations Research Society, Alexandria, VA, 1998. 
Y/DSRD-3117

\section{INTERNAL DISTRIBUTION}

1. Dr. David S. Alberts, The Center for Advanced Concepts and Technology, National Defense University, Ft. Lesley J. McNair, Washington, DC 20319-6000

2. Ms. Rachele Alvirez, HQ, USSOUTHCOM, Attn: SCJ5-PAS (Ms. Alvirez), 3511 NW 92nd Ave, Miami, FL 33172-1217

3. Dr. Ken Anderson, Research Leader, Theatre Operations, B-2-15 Russell Offices, Canberra 2600, ACT, Australia

4. Dr. Bob Atwell, Institute for Defense Analyses, 1801 N. Beauregard St, Alexandria, Va 22311-1772

5. Dr. Michael Bailey, Marine Corps Combat Development Command (MCCDC), 3300 Russell Road, Quantico, VA 22134-5130

6. Mr. Kevin A. Baugh, OASD (SO/LIC) Forces and Resources, The Pentagon, Room 1A674A, Washington, DC 20301-2500

7. LT COL Barry Bazemore, USACOM, Joint Warfighting Center, JW527, 116 Lakeview Parkway, Suite 100, Suffolk, VA 23445-2697

8. Dr. Paul J. Berenson, Scientific Advisor to the Commanding General, U.S. Army Training and Doctrine Command, Fort Monroe, VA 23651-5000

9. Dr. Alfred Brandstein, US Marine Corps Combat Developments Cmd (MCCDC), 3300 Russell Road, Quantico, VA 22134-5130

10. Mr. William Brundage, OSD (PA\&E) RAMD Support (GRCI), Crystal Gateway II, Suite 300, 1225 Jefferson Davis Highway, Arlington, VA 22202

11. Ms. Angela Butt, c/o Mr. William Brundage, OSD (PA\&E) RAMD Support (GRCI), Crystal Gateway II, Suite 300, 1225 Jefferson Davis Highway, Arlington, VA 22202

12. Dr. Peter Campbell, Argonne National Lab, 9700 Cass Ave, Bldg 900, MS 14, Argonne, IL 60439

13. Mr. Larry Cantwell, US Army TRADOC Analysis Center, USA TRADOC Analysis Center, 255 Sedgewick Ave, Ft Leavenworth, KS 66027

14. COL Ed Cardenes, HQ USCENTCOM, ATTN: CCCA, Bldg 540, 7115 South Boundary Blvd, MacDill AFB, FL 33621-5101

15. Mr. Jerry Chandler, FORSCOM, DCSOPS, 1777 Hardee Ave, SW, Ft Mc Pherson, GA 30330-1062

16. Mr. Eric Coulter, Office of the Secretary of Defense, Program Analysis and Evaluation (PA\&E), 1800 Defense, The Pentagon, Washington, DC 20301-1800

17. Mr. Patrick Curley, c/o Mr. William Brundage, OSD (PA\&E) RAMD Support (GRCI), Crystal Gateway II, Suite 300, 1225 Jefferson Davis Highway, Arlington, VA 22202

18. Dr. Dave Davis, The Institute of Public Policy, GMU, 4400 University Dr (MS3C6), Fairfax, VA 22030-4444

19. Mr. Charles Driggs, Joint Warfighting Center, 380 Fenwick Rd, Bldg 96, Ft Monroe, VA 23651

20. Capt Doug Dudgeon, MCCDC, Studies and Analysis Division, 3300 Russell Rd, Quantico, VA 22134-5130

21. Mr. William Dunn, Army M\&S Office, The Pentagon, Room 1D544, ATTN: DAMO-ZS, Washington, DC 20310 
22. Mr. Jim East, Center for Naval Analyses (USCG), 4401 Ford Ave, Alexandria, VA 22302-8268

23. LT COL Norm Edwards, Joint Staff/J-8/SAMD, Pentagon, Rm 1D929, Washington, DC 20318-8000

24. CDR Robert A. Farmer, USCG Office of Strategic Analysis, US Coast Guard, Headquarters, 2100 Second St SW, Washington, DC 20593-0010

25. Mr. Evan Farris, SPA (SeaState/GCMP), Systems Planning and Analysis, Inc, 2000 N. Beauregard St, Suite 400, Alexandria, VA 22311-1712

26. Ms Chris Fossett, GAO, Office of Policy, Room 6800, 441 G St, NW, Washington, DC 20548

27. Mr. Dean Free, Chief of Naval Operations (N812D3), 2000 Navy Pentagon, Washington, DC 20350-2000

28. LCDR Art Galpin, HQ, USSOCOM (Code: SORR-SCS), 7701 Tampa Point Blvd, MacDill AFB FL 33621-5323

29. LCDR Aasgeir Gangsaas, Joint Staff/J-8/WAD, Pentagon, Rm 1D929, Washington, DC 20318-8000

30. Dr. Steve Gordon, AFAMS/TD, 12350 Research Pkwy, Orlando, FL 32876-3276

31. Lt Col Zachary Green, HQ, USSOUTHCOM, Attn: SCJ5-PAS (Lt Col Green), 3511 NW 92nd Ave, Miami, FL 33172-1217

32. Mr. Matthew Grund, Center for Naval Analyses (USCG), 4401 Ford Ave, Alexandria, VA 22302-8268

33. Mr. Bob Halayko, The Joint Staff/J-8/SAGD, Rm 1D929, The Pentagon, Washington, DC 20318-8000

34. Dr. Bob Hannan, HQ, USSOUTHCOM, Attn: SCJ5-PAS (Dr. Hannan), 3511 NW 92nd Ave, Miami, FL 33172-1217

35. Maj Ray Harris, AFSAA/SAAM, 1570 Air Force, Pentagon, Washington, DC 20330-1570

36. LTC Mike Harwood, US Army Peacekeeping Institute, Box 529, US Army War College, Carlisle Barracks, PA 17013

37. Mr. Dave Haut, Center of Excellence in Disaster Management \& Humanitarian Assistance, 1 Jarrett White Road (MCPA-DM), Tripler AMC, HI 96859-5000

38. Dr. Robert L. Helmbold, 2625 East Southern Ave, C-185, Tempe, AZ 85282-7653

39. Dr. Jackie Henningsen, USAF/AXOC, Room 4C1059, 1480 Air Force Pentagon, Washington, DC 20330-1480

40. Mr. Bob Holcomb, Institute for Defense Analyses, 1801 N. Beauregard St, Alexandria, Va 22311-1772

41. LtCol Tim Hope, HQ, USSOCOM (Code: SORR-SCS), 7701 Tampa Point Blvd, MacDill AFB FL 33621-5323

42. Dr. Lynda Jaques, HQ USPACOM, Chief, Research \& Analysis (J081), Box 64028, Camp H. M. Smith, HI 96861

43. Dr. Dale Kem, Logistics Management Institute, 2000 Corporate Ridge, McLean, VA 22102-7805

44. Mr. Andy Korkoutis, HQ, USEUCOM, Office of Analysis and Simulation, Stuttgart, Germany

45. Ms. Renee Lajoie, DFI, 11 DuPont Circle, 9th Floor, Washington, DC 20036

46. Mr. Martin Lidy, Institute for Defense Analyses, 1801 N. Beauregard St, Alexandria, Va 22311-1772

47. COL Earl Madison, Joint Staff/J-8/SAMD, Pentagon, Rm 1D929, Washington, DC 20318-8000 
48. Mr. Frank Mahncke, Joint Warfare Analysis Center/J8C, 18385 Frontage Rd, Dahlgren, VA 22448-5500

49. Mr. Ray Malatino, Naval Air Warfare Center Training Systems Division, 12350 Research Pkwy, Orlando, FL 32826-3224

50. Mr. Mike McCurdy, HQ USCINCPAC, Attn: J561, Box 64015, Camp H. M. Smith, HI 96861-4015

51. Dr. Thomas J. McGrann, Lawrence Livermore National Lab, PO Box 808, Livermore, CA 94511

52. COL James R. Methered, HQ, USEUCOM, Office of Analysis and Simulation, Stuttgart, Germany

53. CAPT Bill Molloy, Joint Warfighting Center, 380 Fenwick Rd, Bldg 96, Ft Monroe, VA 23651

54. Mr. Andrew Nichols, c/o Mr. William Brundage, OSD (PA\&E) RAMD Support (GRCI), Crystal Gateway II, Suite 300, 1225 Jefferson Davis Highway, Arlington, VA 22202

55. $\quad$ Ambassador Robert Oakley, NDU, Ft. Leslie J. McNair, Washington, DC 203196000

56. Mr. Rusty O'Brien, AB Technology, 1600 N. Beauregard St, Suite 300, Alexandria, VA 22311-1720

57. Lt Col Herman Orgeron, US Army Center for Army Analysis, 6001 Goethals Rd, Suite 102, Ft Belvoir, Va 22060-5230

58. Mr. Bob Osterhoudt, SAIC, MS 1-13-1, 1710 Goodridge Dr, McLean, VA 22102

59. Mr. Donald G. Owen, Joint C4I Battle Center, 116 Lakeview Parkway, Suite 150, Suffolk, VA 23435-2697

60. Mr. Arthur Paarmann, The Joint Staff/J-8/SAMD, Rm 1D929, The Pentagon, Washington, DC 20318-8000

61. Mr. Sam Packer, Institute for Defense Analyses, 1801 N. Beauregard St, Alexandria, Va 22311-1772

62. Maj Roger Perret, AFSAA/SAAM, 1570 Air Force, Pentagon, Washington, DC 20330-1570

63. Mr. Malone Pleasant, c/o Mr. William Brundage, OSD (PA\&E) RAMD Support (GRCI), Crystal Gateway II, Suite 300, 1225 Jefferson Davis Highway, Arlington, VA 22202

64. Mr. Mike Poumade, c/o Mr. William Brundage, OSD (PA\&E) RAMD Support (GRCI), Crystal Gateway II, Suite 300, 1225 Jefferson Davis Highway, Arlington, VA 22202

65. COL John Priddy, OSD S\&R, 2900 Defense, The Pentagon, Washington, DC 203012900

66. Dr. Peter Purdue, C/O Superintendent, Code O8 (Dr. Purdue), U.S. Naval Postgraduate School, Monterey, CA 93943-5419

67. Mr. Gary Robinson, OASD (SO/LIC) PK/HA, The Pentagon, Room 1A674A, Washington, DC 20301-2500

68. Mr. Bill Roege, c/o Mr. William Brundage, OSD (PA\&E) RAMD Support (GRCI), Crystal Gateway II, Suite 300, 1225 Jefferson Davis Highway, Arlington, VA 22202

69. Mr. Vince Roske, Deputy Director for Wargaming, Simulation, \& Analysis, Joint Staff, J-8, The Pentagon, Room 1D940, Washington, DC 20308

70. CDR Bruce Ross, USCG Roles and Missions, 1111 Jefferson Davis Highway, Suite 502, West Tower, Arlington, VA 22002

71. Col Gabriel Rouquie, Logicon, 2100 Washington Blvd, Arlington, VA 22204-5706 
72. LCDR John Ruck, OPNAV N816D6 Assessment Division, Navy Pentagon, Washington, DC 22370

73. Dr. Gordon Schacher, US Naval Postgraduate School, IJWA/Physics, 833 Dyer Rd, Rm 102, Monterey, CA 93943

74. LtCol Scott Shaw, MCCDC, Studies and Analysis Division, 3300 Russell Rd, Quantico, VA 22134-5130

75. Mr. Dan Shedlowski, Center for Army Analysis, ATTN: Mr. Shedlowski, 6001 Goethals Road, Fort Belvoir, VA

76. Mr. Steve Siegal, Center for Army Analysis, 6001 Goethals Road, Fort Belvoir, VA

77. Dr. Adam Siegel, CNA, 4401 Ford Avenue, Alexandria, VA 22302-1498

78. Ms. Elaine Simmons, OSD - PA\&E/ Joint Data Support (JDS), c/o Mr. Joe Rovansek, OSD - PA\&E, 1225 Jeff Davis Hwy, Suite 300, Arlington, VA 22202

79. COL Bruce Simpson, HQ USCENTCOM, ATTN: CCCA, Bldg 540, 7115 South Boundary Blvd, MacDill AFB, FL 33621-5101

80. COL Pat Slattery, US Army War College, Center for Strategic Leadership, ATTN: COL Slattery, Carlisle Barracks, PA 17013-5050

81. LT COL Dan Snyder, Joint Warfighting Center, 380 Fenwick Rd, Bldg 96, Ft Monroe, VA 23651

82. Dr. Mike Sovereign, 150 Shady Lane, Monterey, CA 93940

83. Ms. Martha Staehle, HQ US Army Forces Command, AFOP-MS (ATTN: Ms. Martha Staehle), 1777 Hardee Ave, SW, Ft McPherson, GA 30330

84. CAPT Bruce Stubbs, USCG Operations Planning, US Coast Guard, Headquarters, 2100 Second St SW, Washington, DC 20593

85. Dr. Warren Switzer, MSOSA, DMSO, AB Technologies, 1901, N. Beauregard, Suite 400, Alexandria, VA 22311

86. Mr. Franco Tao, Falcon Model (SAIC), 1570 Air Force, Pentagon, Washington, DC 20330-1570

87. Mr. Clayton Thomas, Headquarters, US Air Force, Assistant Chief of Staff for Studies and Analyses, ATTN: AS/SAS, The Pentagon, Room 1E386, Washington, DC 20330-1570

88. Mr. Milton Tulkoff, OSD/PA\&E RAMD, Room 2C270, 1800 Defense Pentagon, Washington, DC 20301-1800

89. Dr. Dave Waters, USA CLW (FA\&CT Model), 1745 Jefferson Davis Highway, Crystal Square 4, Suite 300, Arlington, VA 22202

90. Ms. Linda L. Weber, MITRE, 7941 Blandy Road, Suite 400, Norfolk, VA 235512498

91. Mr. Scott Welch, Evidence Based Research, 1595 Spring Hill Rd, Suite 250, Vienna, VA 22182-2228

92. Ms. Christy Zeuner, HQ USPACOM, Chief, Research \& Analysis (J081), Box 64028, Camp H. M. Smith, HI 96861

93. Dr. D. S. Hartley III

94. Mr. Rich Bell

95. Mr. S. L. Packard

96. Ms. S. E. Jacobsen

97. Office of the Assistant Manager for Energy Research and Development, Department of Energy, Oak Ridge Operations, P.O. Box 2001, Oak Ridge, TN 37831-8550

98. DSRD Resource Center, 1099COM, RM S07, MS7615

99. $\quad$ Y-12 Central File, Bldg 9711-5, MS 8169

100. $\quad$ Y-12 Plant Records (3), Bldg 9711-5, MS 8169

101. OSTI (2) 